\title{
PREVALENCE AND CHARACTERIZATION OF PLASMID-MEDIATED QUINOLONE RESISTANCE IN VARIOUS AQUATIC SOURCES
}

by

\author{
Farhan Yusuf \\ B.Sc. (Honours), Biology \\ Ryerson University, 2017
}

\begin{abstract}
A thesis presented to Ryerson University
in partial fulfillment of the requirements for the degree of

Master of Science in the program of

Molecular Science
\end{abstract}

Toronto, Ontario, Canada, 2019

(C) Farhan Yusuf, 2019 


\section{AUTHOR'S DECLARATION FOR ELECTRONIC SUBMISSION OF A THESIS}

I hereby declare that I am the sole author of this thesis. This is a true copy of the thesis, including any required final revisions, as accepted by my examiners.

I authorize Ryerson University to lend this thesis to other institutions or individuals for the purpose of scholarly research.

I further authorize Ryerson University to reproduce this thesis by photocopying or by other means, in total or in part, at the request of other institutions or individuals for the purpose of scholarly research. I understand that my thesis may be made electronically available to the public. 


\title{
PREVALENCE AND CHARACTERIZATION OF PLASMID-MEDIATED QUINOLONE RESISTANCE IN VARIOUS AQUATIC SOURCES
}

\author{
Farhan Yusuf \\ Master of Science, Molecular Science, Ryerson University, 2019
}

\begin{abstract}
Bacterial isolates found in aquatic ecosystems often carry antibiotic resistance genes (ARGs). These ARGs are often found on plasmids and transposons, which allows them to be proliferate throughout bacterial communities via horizontal gene transfer (HGT) causing dissemination of multidrug resistance. The increase in antibiotic resistance has raised concerns about the ability to continue to use these drugs to fight infectious diseases. Novel synthetic antibiotics like ciprofloxacin that are not naturally found in the environment were developed to prevent resistances. However, ciprofloxacin resistance has occurred through chromosomal gene mutations of type 2 topoisomerases or by the acquisition of plasmid-mediated quinolone resistances (PMQR). A particular PMQR, qnr genes, encoding for pentapeptide repeat proteins that confer low levels of quinolone resistance and protect DNA gyrase and topoisomerase IV from antibacterial activity. These qnr genes have been identified globally in both clinical and environmental isolates.
\end{abstract}

The aim of this study was to determine the prevalence of ciprofloxacin-resistant bacteria in aquatic environments in the Greater Toronto Area and the potential dissemination of ciprofloxacin resistance. With the selective pressure of ciprofloxacin, we hypothesize that ciprofloxacin-resistant bacteria $\left(\mathrm{Cip}^{\mathrm{R}}\right)$ in the environment may carry PMQR mechanisms while the sensitive population (Cip ${ }^{S}$ ) would not carry PMQR genes. Isolates were tested for resistance to an additional 12 different antibiotics and identified using Sanger sequencing PCR products of the 16S rRNA gene. To determine which genes are responsible for ciprofloxacin resistance, multiplex PCR of associated qnr genes, qnrA, qnrB, and qnrS, was carried out on 202 environmental isolates. Our data demonstrate a similar prevalence of qnr genes was found in $\mathrm{Cip}^{\mathrm{R}}(19 \%)$ and $\mathrm{Cip}^{\mathrm{S}}$ (14\%) populations suggesting that the presence of these genes was not necessarily correlated with the phenotypic resistance to the antibiotic. Furthermore, ciprofloxacinresistant bacteria were found in all locations at similar frequencies suggesting that resistance genes are widespread and could possibly arise through HGT events. Overall, determining the underlying cause and prevalence of ciprofloxacin resistance could help re-establish the effectiveness of these antimicrobial compounds. 


\section{Acknowledgements}

First and foremost, I would like to express my sincerest gratitude and appreciation to my supervisor, Dr. Kimberley Gilbride, for not only providing countless opportunities to succeed over the past 6 years but by providing an amazing work environment to foster my research skills. Thank you for inspiring my undergraduate and graduate career with the excitement and passion for learning and research. I am truly grateful for the advice, motivation, trust and confidence in supporting all my endeavours. From the countless hours in the lab to sharing a campfire story at the cottage I truly will not forget the incredible journey I have taken with the Gilbride Lab.

A special thanks to my supervisory committee, Dr. Martina Hausner and Dr. Sarah Sabatinos, for their invaluable feedback and continuous guidance throughout my graduate research. I would also like to thank Dr. Marthinus Kroukamp in being part of the examination committee for the oral defence and to many professors and staff who have made the Ryerson experience a pleasant one. Thank you all sincerely for the support.

To my lab mates outside and inside the Gilbride lab, thank you for making this journey memorable and getting behind the highs and very lows of research. Shout outs go to Simon Zhao, Kruti Shukla, Tarn Parmar, Adam Khan, Saher Ahmed, Danica Dy, Royce Ing and countless others that I have had the opportunity to mentor and share this academic journey. Special thanks go to Amir Tehrani, from being my first mentor in undergrad to thinking of our next steps in the conquest of understanding antibiotic resistance, I would not change a single moment with you, good buddy. It has been a privilege working alongside you and I hope our destinations come into fruition. It has been a pleasure to meet and work with every one of you throughout the years.

Finally, I would like to thank my family, mi Vongola Famiglia and Amy T., for the constant love, patience and sacrifice throughout all the endeavours I have put you through. Thank you for believing in me and never giving up during all the tough times. I cannot wait to start the next steps of life and share it with you all.

Everything is everywhere, but the environment selects

- Lourens Baas Becking, 1934 


\section{Table of Contents}

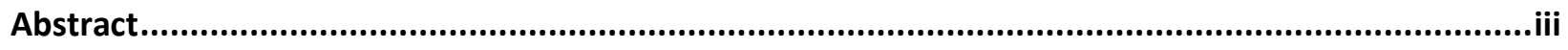

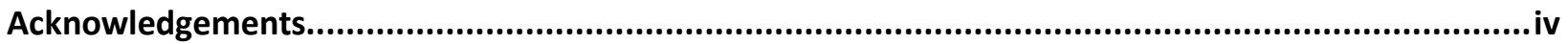

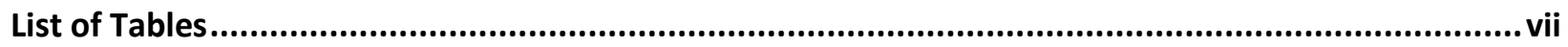

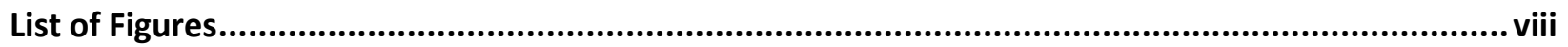

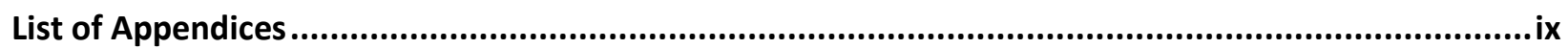

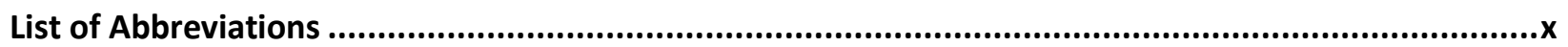

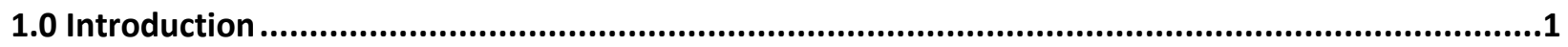

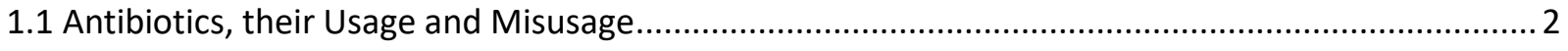

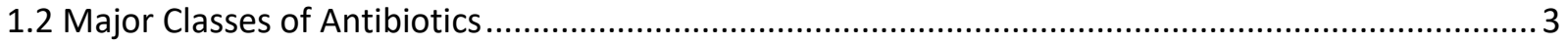

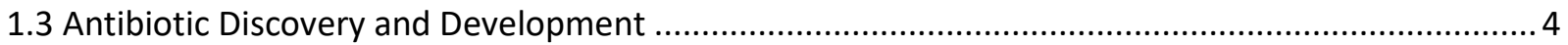

1.4 The History of Quinolones and Fluoroquinolones ..................................................................... 7

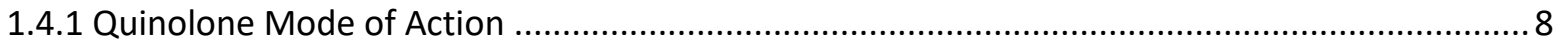

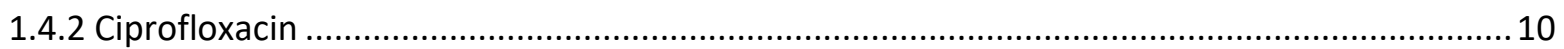

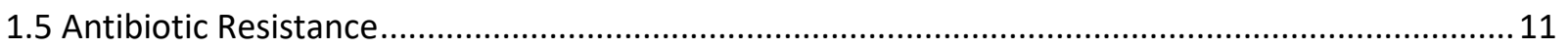

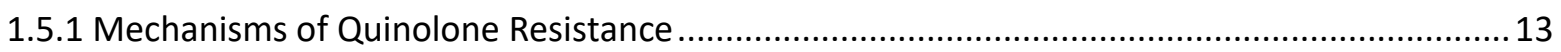

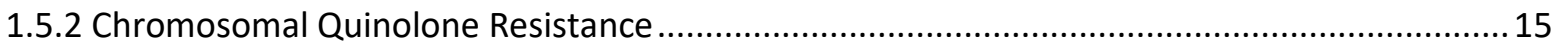

1.5.3 Plasmid-mediated Quinolone Resistance ......................................................................... 17

1.6 Environmental Reservoir of Antibiotic Resistances .....................................................................20

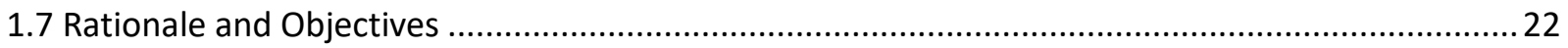

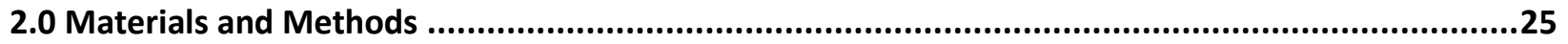

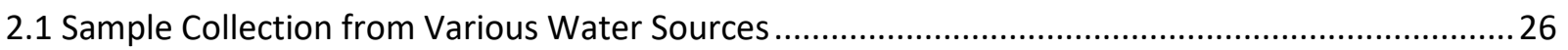

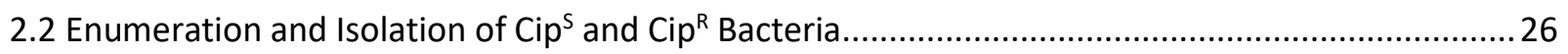

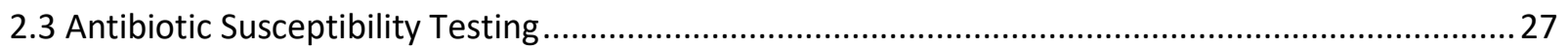

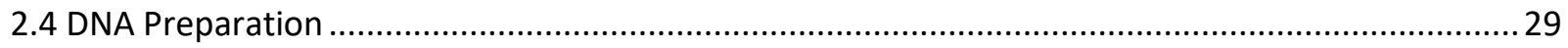

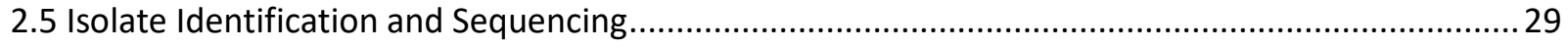

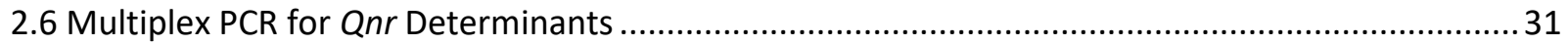

2.7 Minimum Inhibitory Concentrations of Nalidixic Acid and Ciprofloxacin......................................32

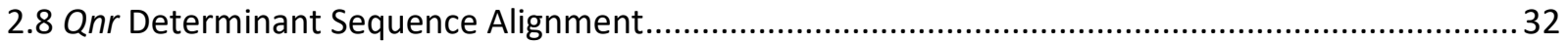

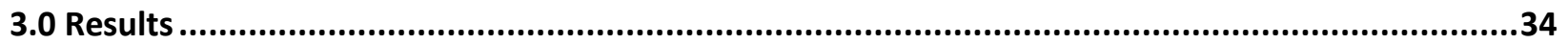

3.1 Detection of Ciprofloxacin-Resistant Bacteria in all Sampled Aquatic Sources..............................35

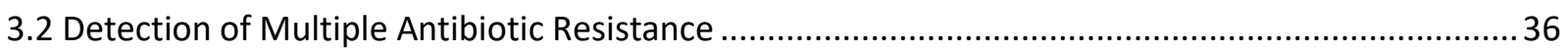


3.2.1 Weka Analysis of Antibiotic Resistance

3.3 Taxonomic Composition of $\mathrm{Cip}^{\mathrm{S}}$ and $\mathrm{Cip}^{\mathrm{R}}$ Isolates from all Aquatic Sources .................................39

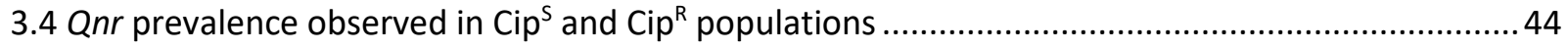

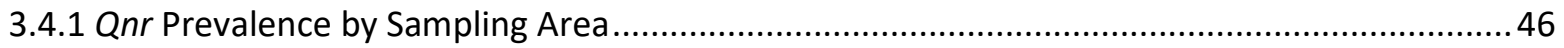

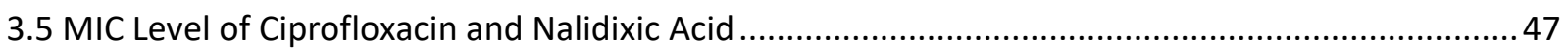

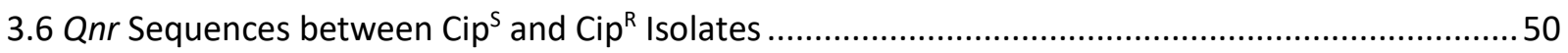

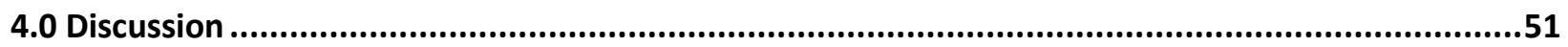

4.1 Prevalence of Ciprofloxacin-Resistant Bacteria ........................................................................ 52

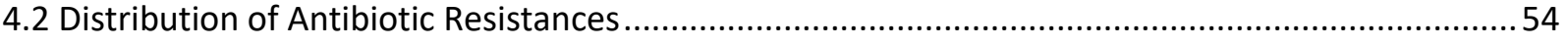

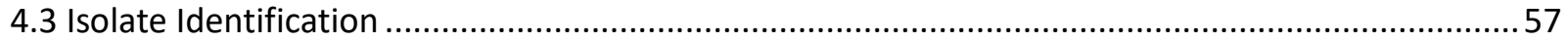

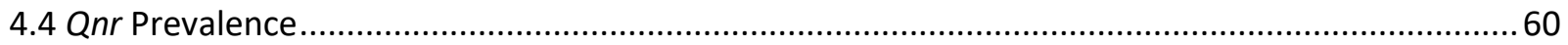

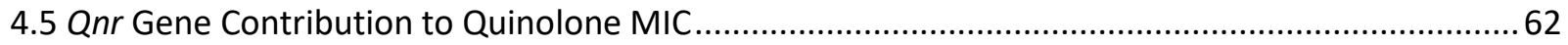

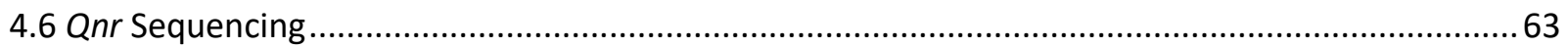

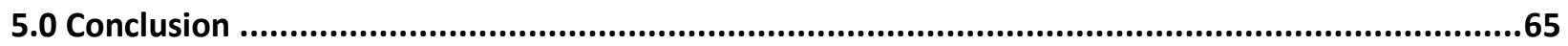

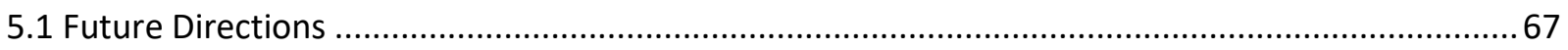

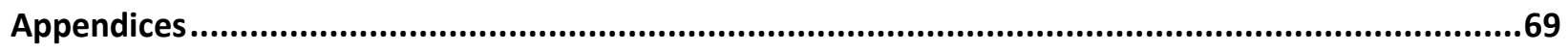

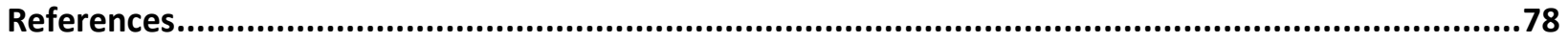




\section{List of Tables}

Table 1: List of PCR primers used for bacterial identification and qnr screening

Table 2: Percentage of culturable ciprofloxacin resistance in various aquatic sources.....

Table 3: Antibiotic resistance profiles of $\mathrm{Cip}^{\mathrm{S}}$ and $\mathrm{Cip}^{\mathrm{R}}$ populations among various aquatic sources .........37

Table 4: Cumulative antibiotic resistance distribution of $\mathrm{Cip}^{\mathrm{S}}$ and $\mathrm{Cip}^{\mathrm{R}}$ isolates tested against 12

antibiotics.

Table 5: Isolate identification and distribution of each phylum, class and genera among all aquatic

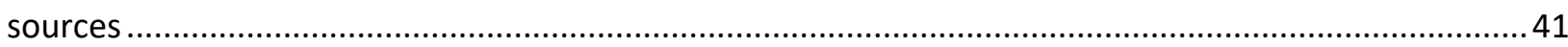

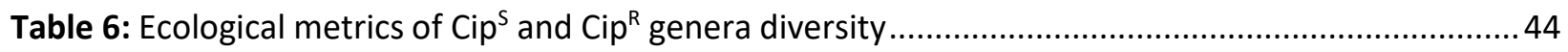

Table 7: Nalidixic acid MIC distribution in Cip ${ }^{R}$ isolates with or without $q n r$ genes................................49

Table 8: Ciprofloxacin MIC distribution in Cip ${ }^{\mathrm{R}}$ isolates with or without $q n r$ genes.................................49 


\section{List of Figures}

Figure 1: Antibiotic classes and potential targets within a bacterial cell ............................................ 4

Figure 2: Antibiotic Development of several antibiotic classes .................................................... 6

Figure 3: Structural comparison of first-generation and second-generation quinolones with subsequent

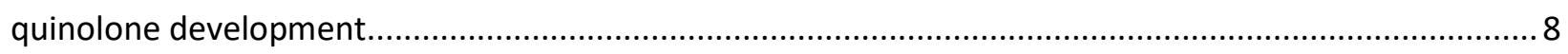

Figure 4: Detailed mechanism of action of quinolone class antibiotics with the effects of DNA topology

Figure 5: Schematic of different antibiotic resistance mechanisms employed by bacteria...................... 12

Figure 6: A timeline of antibiotic discovery with associative appearance of resistance ..........................14

Figure 7: Overview of antibiotic resistance dissemination across different environments .....................2 21

Figure 8: Bacterial counts of culturable ciprofloxacin-resistant and total heterotrophic bacterial

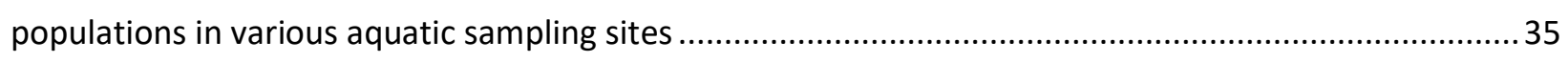

Figure 9: Shared genera among both $\mathrm{Cip}^{S}$ and $\mathrm{Cip}^{\mathrm{R}}$ populations in all sampled aquatic sources ............. 43

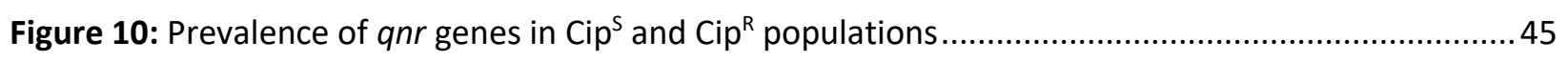

Figure 11: Qnr gene distribution and abundance of qnr-positive isolates ........................................46

Figure 12: Prevalence of $q n r$ genes in all sampled aquatic sources .................................................. 47

Figure 13: Degree of resistance to nalidixic acid and ciprofloxacin in $\mathrm{Cip}^{\mathrm{R}}$ isolates ..............................48 


\section{List of Appendices}

Appendix 1: Structure-activity relationship of quinolone substituents .............................................. 70

Appendix 2: Map of sampling locations within the Greater Toronto Area ........................................... 71

Appendix 3: Weka parameters and outputs of antibiotic resistance relationships in all isolates .............72

Appendix 4: Weka parameters and outputs of antibiotic resistance relationships in $\mathrm{Cip}^{\mathrm{S}}$ isolates...........73

Appendix 5: Weka parameters and outputs of antibiotic resistance relationships in $\mathrm{Cip}^{\mathrm{R}}$ isolates .........74

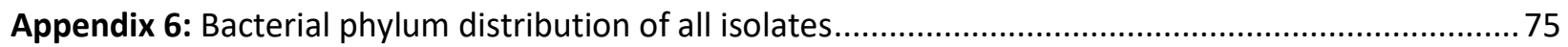

Appendix 7: Isolate distribution by Gram-staining identification ..................................................... 75

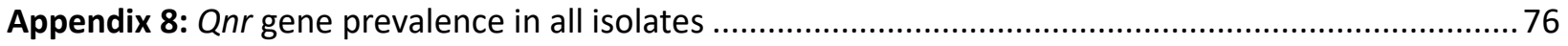




\section{List of Abbreviations}

\begin{tabular}{|c|c|}
\hline ARB & Antibiotic Resistant Bacteria \\
\hline ARGs & Antibiotic Resistant Genes \\
\hline ARI & Antibacterial Resistance Index \\
\hline $\mathrm{BL}$ & Buckhorn Lake \\
\hline BLAST & Basic Local Alignment Search Tool \\
\hline BSA & Bovine Serum Albumin \\
\hline CARD & Comprehensive Antibiotic Resistance Database \\
\hline $\mathrm{CDC}$ & Centers for Disease Control and Prevention \\
\hline cDNA & Complementary Deoxyribonucleic Acid \\
\hline CFU & Colony-forming Unit \\
\hline CIPARS & Canadian Integrated Program for Antimicrobial Resistance Surveillance \\
\hline CLSI & Clinical and Laboratory Standards Institute \\
\hline DNA & Deoxyribonucleic Acid \\
\hline dNTPs & Deoxynucleotide Triphosphates \\
\hline EUCAST & European Committee on Antimicrobial Susceptibility Testing \\
\hline FAO & Food and Agriculture Organization \\
\hline FDA & Food and Drug Administration \\
\hline HW & Humber Wastewater Treatment Plant \\
\hline ISCR & Insertion Sequence Common Region \\
\hline LD & Lake Devo \\
\hline LO & Lake Ontario \\
\hline MAR & Multiple Antibiotic Resistance \\
\hline MDR & Multiple Drug Resistant \\
\hline MFS & Major Facilitator Superfamily \\
\hline MIC & Minimum Inhibitory Concentration \\
\hline MPC & Mutant Protective Concentration \\
\hline mRNA & messenger Ribonucleic Acid \\
\hline MRSA & Methicillin-resistant Staphylococcus aureus \\
\hline $\mathrm{NCBI}$ & National Center for Biotechnology Information \\
\hline OIE & World Organization for Animal Health \\
\hline PCR & Polymerase Chain Reaction \\
\hline PMQR & Plasmid-mediated Quinolone Resistance \\
\hline PRP & Pentapeptide Repeat Proteins \\
\hline Qnr & Quinolone Resistance \\
\hline QRDR & Quinolone Resistance Determining Region \\
\hline QSAR & Quantitative Structure-Activity Relationships \\
\hline R2A & Reasoner's 2A agar \\
\hline RND & Resistance-Nodulation-Cell-Division \\
\hline rRNA & ribosomal Ribonucleic Acid \\
\hline RT-qPCR & Quantitative Reverse transcription Polymerase Chain Reaction \\
\hline TD-PCR & Touchdown-Polymerase Chain Reaction \\
\hline TS & Toronto Storm Drain \\
\hline WHO & World Health Organization \\
\hline WWTP & Wastewater Treatment Plant \\
\hline
\end{tabular}


1.0 Introduction 


\subsection{Antibiotics, their Usage and Misusage}

From bringing mankind from the dark ages and extending the average lifespan, antibiotics have been a crucial tool in modern-day medicine. Antibiotics are antimicrobial agents that have chemotherapeutic properties against bacteria. The benefits of antibiotic usage for treating infectious diseases has saved millions of lives over the 90 years since their discovery. Access to these drugs has allowed better development and standards of medical practices such as organ transplants and primary care. ${ }^{1,2}$ The incomparable advances of antibiotic usage in the $20^{\text {th }}$ century has been crucial to practitioners through their selectiveness. In the pre-antibiotic era and most of history, bacterial infections have been the number one cause of death. Common deaths included child births, individuals acquiring pneumonia, septic shock from any type of procedures performed in hospitals to even skin infections from simple cuts that needed amputations. ${ }^{3-5}$ Pre-antibiotic average life expectancy was 47 years in industrialized countries, illustrating the high morbidity and mortality rates worldwide of infectious diseases. ${ }^{3}$ Now, the wide distribution of antibiotics has been implemented in human and veterinary medicine and agricultural practices.

Unnecessary use and overconsumption of antibiotics have led to the ineffectiveness of many antibiotics. Over prescription, underdosing and inappropriate use of antibiotics has ultimately promoted the ineffectiveness of these "wonder drugs" ${ }^{1,6}$ Antibiotics have been used extensively in the animal husbandry as growth promotors and disease prevention. In 2011, the Food and Drug Administration (FDA) estimated 13.6 million kilograms of antibiotics was used in food-producing animals. ${ }^{7}$ Most of the usage was administered in low doses of antibiotics which allowed the animals to grow faster in inhospitable conditions. This created an environment where some bacteria were able to resist the therapeutic effects of antibiotics and become resistant. Likewise, in humans, 3.29 million kilograms of antibiotics were administered, often unnecessarily. ${ }^{7}$ The misusage of antibiotics in recent decades has led to a post-antibiotic era that sets the stage to return to a time where common infections can kill. 
Currently, many legislations and organizations like the World Health Organization (WHO), World Organization for Animal Health (OIE) and United Nations Food and Agriculture Organization (FAO) are shifting focus in restricting antibiotic usage in humans and food-producing animals alike. ${ }^{8,9}$ Antibiotic resistance has become a global concern and precautions implemented now might aid in returning the effectiveness of these compounds.

\subsection{Major Classes of Antibiotics}

Antibiotics can be categorized based on their chemical structure and bacterial target. The effectiveness of these drugs is based on the ability to eliminate bacteria (bactericidal) or inhibit bacterial growth (bacteriostatic). ${ }^{1,10}$ The proficiency to perform either function lends to the chemical moiety of the pharmacophore. The pharmacophore is responsible for eliciting a biological response that is exhibited in a specific organism. ${ }^{1}$ This assortment of multiple pharmacophores allows the grouping of different antibiotics into classes. Figure 1 outlines the different antibiotic classes and the array of targets

they act upon. Having a multitude of bacterial targets allows for effective strategies in treating infectious diseases. The division of narrow-spectrum antibiotics and broad-spectrum antibiotics aid in the accurate treatment of bacterial infections. Narrow-spectrum antibiotics have specific activity upon a certain type of bacteria such as Gram-positive and Gram-negative bacteria. ${ }^{11,12}$ These two distinct features describe a thick or thin peptidoglycan layer in the bacterial cell wall respectively. This allows a more focused approach in antibiotic development and treatment in penetrating the cell wall of specific genera of bacteria. Broad-spectrum antibiotics affect an array of microorganisms across both Gram-positive and Gram-negative alike. The use of broad-spectrum antibiotics is a life-saving treatment option when the causative agent of a disease is unknown. This group of antibiotics also disturbs the innate microbiome within a host eliminating both commensal and pathogenic bacteria equally. 


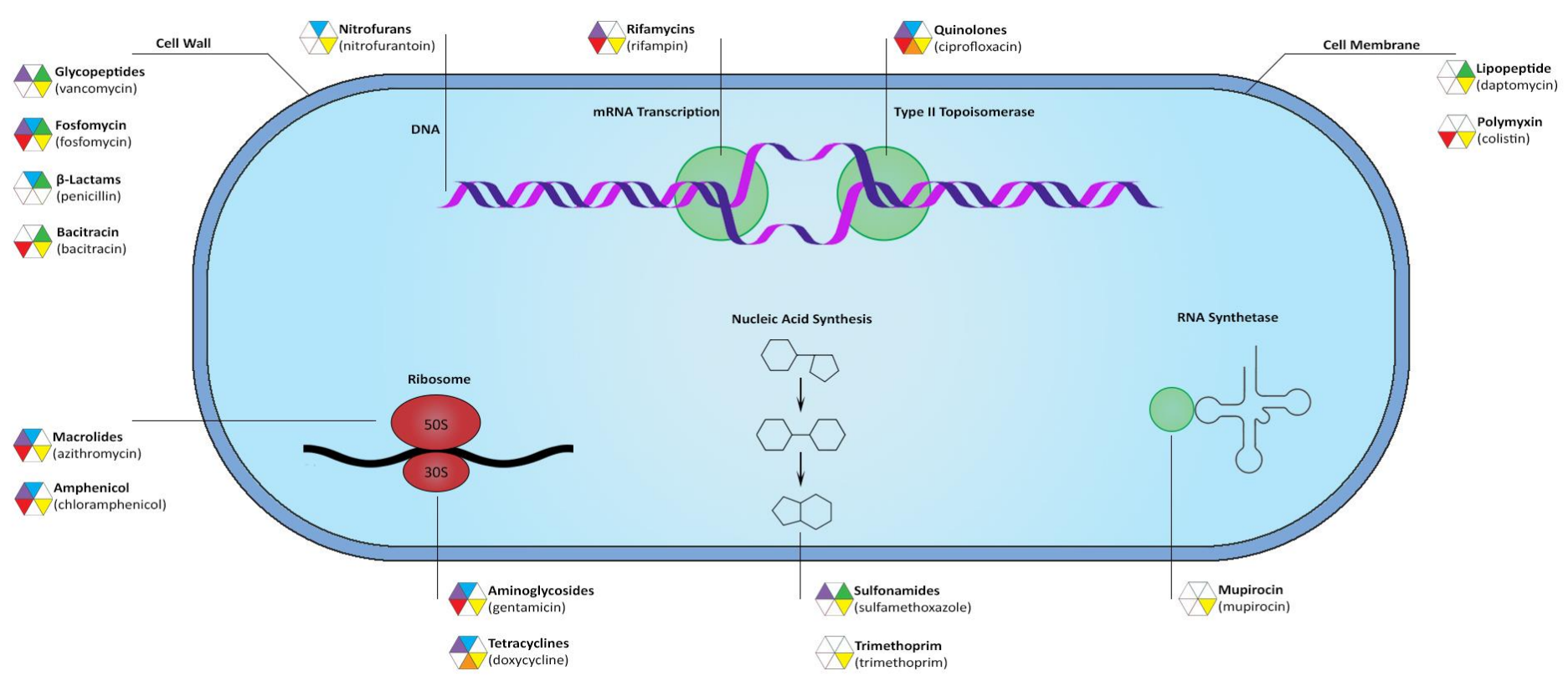

Figure 1: Antibiotic classes and potential targets within a bacterial cell. ${ }^{13}$ Key metabolic pathways are inhibited to reduce bacteria survivability. Multiple drug classes are in bold with example drugs from that class in brackets. Colour-coded legend hexagons indicates the type of resistance mechanisms observed in against the drug class. This is further illustrated in Figure 5. (Adapted from Boolchandani et al., 2019 and credited to Hooman Sarvi)

The mode of action of an antibiotic targets key metabolic pathways of a bacteria cell exerting multiple downstream effects which comprise the invading pathogen. ${ }^{2,14}$ Protein and nucleic acid synthesis inhibition primarily exhibit bacteriostatic effects preventing further proliferation in a host. Antibiotics that target DNA replication and cell synthesis create opportunities for apoptosis or cell death. This bactericidal effect can be caused by disrupting the integrity of the bacterial cell wall in leaching cellular contents or ions into the extra-cellular matrix. ${ }^{14,15}$ Collectively, the effect is the stopping of critical functions which allows the host's immune system to eradicate the pathogen.

\subsection{Antibiotic Discovery and Development}

The discovery of antibiotics, and subsequent advancements, has led to the increased efficacy of novel generations of antibiotics. Initial origins of antibiotics have come from nature with the discovery of penicillin by Alexander Fleming in $1928 .{ }^{16}$ The source of this antibiotic came from the fungus Penicillium notatum revealing its ability to thwart growth from staphylococci bacteria. ${ }^{17}$ This realization that microorganisms were able to produce these natural compounds with great clinical efficacy pushed 
the golden era of antibiotic discovery with several pharmaceutical companies searching the environment for more antibiotic producing organisms. ${ }^{10}$

Select microbes produce antibiotics as secondary metabolites not essential for primary metabolism. ${ }^{18}$ They use low antibiotic concentrations in their natural roles to induce biochemical pathways or in signalling, regulation and quorum sensing. ${ }^{19,20}$ Ecologically, antibiotics provided an environmental niche for the antibiotic-producing organism by warding off competitors with the presence of these metabolites creating a zone of inhibition where only the antibiotic-producing microorganisms can thrive in. ${ }^{21}$ Therefore it holds true that the natural environment is a good reservoir for antibiotic discovery. The Waksman platform developed by Selman Waksman and Boyd Woodruff provided a systematic soil screening method in which antibacterial activity could be observed on agar plates visualized by inhibition zones of several isolated soil microbes. ${ }^{17,22}$ Positive bacterial candidates were then subjected against several pathogenic bacteria for antagonistic behaviours observing effective antibacterial agents being produced. For decades, antibiotic classes including tetracyclines, aminoglycosides, glycopeptides, macrolides and penicillins were discovered and sourced from the bacterial phylum Actinobacteria, expanding clinically relevant compounds used today..$^{10,17,18,22}$

Further development of current antibiotics proved to be an effective strategy in producing novel antibiotics from natural scaffolds. Using the pharmacophore as a scaffold allowed different chemical substituents to be added on for better activity and affinity with reduced side effects and toxicity. These improvements brought about the different generations of antibiotics within the same class. Figure 2 displays multiple classes of antibiotics with subsequent modifications. Analyses like QSAR (quantitative structure-activity relationships) performed in research and development help predict the potential bioactivity of new compounds for evaluating improved pharmacokinetics and pharmacodynamics. ${ }^{23,24}$ Multiple generations of an antibiotic class indicate better effectiveness than predecessors with expanded spectrum against various pathogens. With more chemical alterations to a parent compound 
lets subsequent generations to be more synthetic in nature with hopeful evasion of antibiotic resistance and bacterial resilience. ${ }^{25,26}$

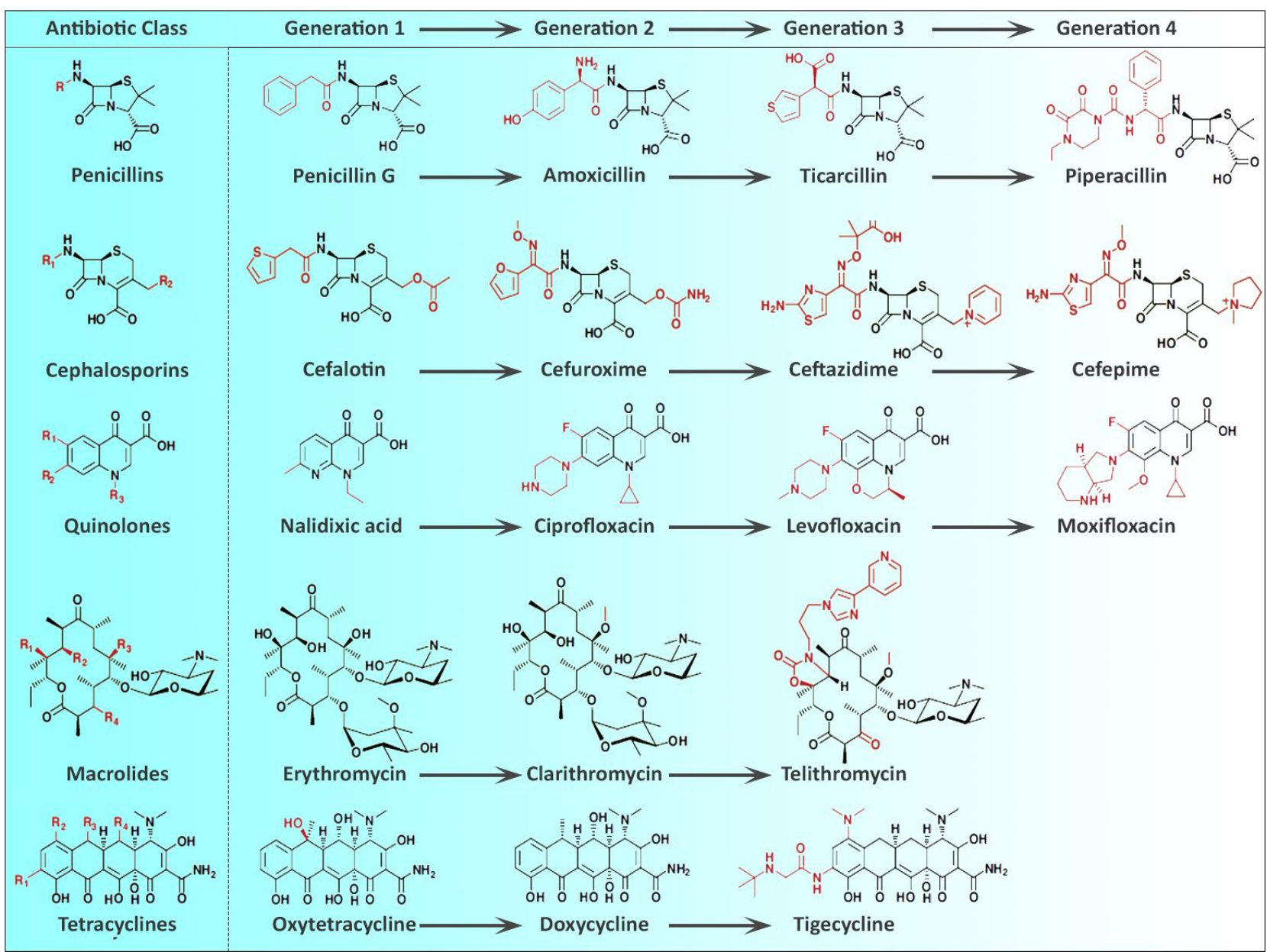

Figure 2: Antibiotic Development of several antibiotic classes. ${ }^{27}$ Subsequent experimentation on first generation attributed to new antibiotics. In black shows the scaffolds used in development with chemical modifications in red. All scaffolds shown here from natural derivatives expect for nalidixic acid from synthetic nature. (Adapted from Fischbach and Walsh, 2009 and credited to Hooman Sarvi)

Antibiotic development has shown limited innovations in recent years. As antibiotic resistance accelerates, fewer novel antibiotics have been approved and developed with pharmaceutical research focusing more on chronic illnesses like asthma, cardiovascular and diabetes. ${ }^{28}$ Drug development is an expensive endeavour where the pre-approval cost estimate can be up to $\$ 2.6$ billion of investments. ${ }^{29}$ Antibiotic development, in particular, have very little profitable return and heavy regulatory conditions upon release as the net present value of a new antibiotic is about $\$ 50$ million compared to $\$ 1$ billion for a drug that treats a neuromuscular disease. ${ }^{17,28}$ In addition, the biological limit and life span of a novel 
antibiotic could be short due to the speed of resistance that is observed in the clinical setting decreasing any economic pay-off or incentives for industries to pursue any drug development research. Between 1985 to 1999, 33 new antibiotics were approved. In 2000 to 2014 this number shrank to $13 .{ }^{28}$ With the exhaustion of multiple natural scaffolds, the synthetic route of development has been also pursued in mining for new antibiotics.

\subsection{The History of Quinolones and Fluoroquinolones}

The introduction of the quinolone class of antibiotics has been an essential tool in the clinical setting with the intent of theoretically limiting the selection of resistant traits and continued treatment

of infectious disease. ${ }^{30,31}$ Quinolones and fluoroquinolones are a fully synthetic class of antibiotics. They have had great success in their broad-spectrum activity, good bioavailability and clinical relevance with low toxicity and side-effects making them an attractive option ${ }^{31,32}$. The initial discovery of this antibiotic came from an accidental discovery through chemical synthesis of the anti-malarial drug chloroquine by George Lesher in early 1960 s. $^{20,24,32,33}$ Further testing resulted in a first-generation quinolone, nalidixic acid, a naphthyridine core drug. ${ }^{34}$ Its moderate narrow-spectrum activity towards Enterobacteriaceae pathogens lead to its primary use on uncomplicated urinary tract infections. Nalidixic acid presented with some limitations in the pharmacokinetics of $90 \%$ plasma protein binding and short serum half-life of 90 minutes. ${ }^{35}$ Subsequent modifications of first-generation quinolones greatly improved the breadth of efficacy to include broad-spectrum antibacterial activity against pneumococci, anaerobes, streptococci, Enterobacteriaceae and atypical pathogens like Pseudomonas aeruginosa (P. aeruginosa), all which are current serious threats outlined by the Centers for Disease Control and Prevention (CDC). ${ }^{36}$ One of the key innovations has been the addition of the fluorine group at position $\mathrm{C} 6$ and quinolone core modifications to create the class fluoroquinolone. ${ }^{35,37-39}$ Figure 3 displays the development of quinolone generations and chemical structure difference between nalidixic acid and ciprofloxacin, a second-generation quinolone and fluoroquinolone. The development of third and fourth-generation 
fluoroquinolones further improved the potency and efficacy of this class of antimicrobials against Grampositive and anaerobic bacteria. ${ }^{34,37}$

a)<smiles>O=C(O)c1cn(C2CC2)c2cc(N3CCNCC3)c(F)cc2c1=O</smiles>

Ciprofloxacin

b)<smiles>CCn1cc(C(=O)O)c(=O)c2ccc(C)nc21</smiles>

Nalidixic acid c)

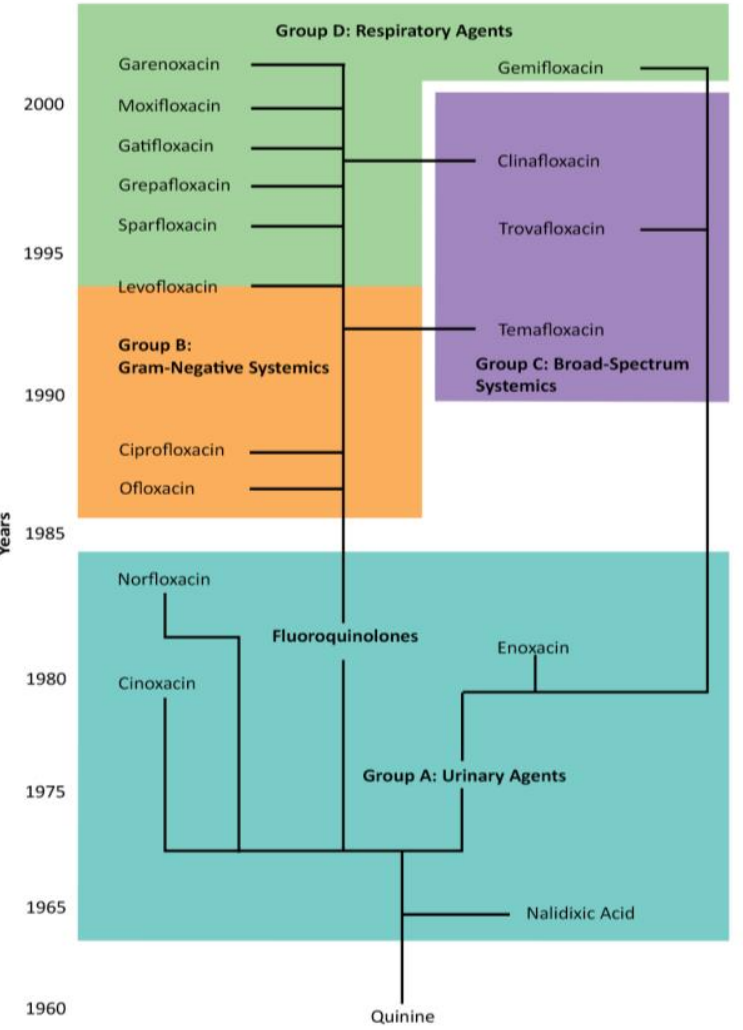

Quinolones

Naphthyridones

Figure 3: Structural comparison of first-generation and second-generation quinolones with subsequent quinolone development. $^{32,37}$ Switching from the naphthyridine core to quinolone core provided better antibacterial efficacy and drug binding from nalidixic acid (a) to fluoroquinolone, ciprofloxacin (b). The development timeline of quinolones (c) illustrates the different quinolone generations with primary advantages over predecessors. (Adapted from Fàbrega et al. 2008 and Andersson and MacGowan, 2003 and credited to Hooman Sarvi)

\subsubsection{Quinolone Mode of Action}

The mode of action of quinolones is the inhibition of enzymes necessary for DNA replication, mRNA transcription and cell division producing an overall bactericidal effect. Quinolones have the natural ability to transverse the lipid bilayer of Gram-negative bacteria due to their relative hydrophobic properties, a task uncommon in many other drugs (Appendix 1). ${ }^{1,40,41}$ Type 2 topoisomerases, specifically DNA gyrase (topoisomerase II) and topoisomerase IV, are the intracellular targets for quinolones. Quinolones show high selectivity for the prokaryotic versions of these enzymes due to absence of 
binding domains in eukaryotic topoisomerases. ${ }^{31}$ The key difference between type 1 and 2 topoisomerases is the ability to create single or double-stranded cuts to DNA respectively. The main function of type 2 topoisomerases is by altering DNA topology and conformation. ${ }^{2}$ DNA in all types of cells are tightly condensed to fit inside the cell and are twisted and turned by the process termed supercoiling. The direction of the twist is stated as positive or negative supercoiling depending if the twist is clockwise or counter-clockwise respectively. ${ }^{39}$ During the initiation of DNA replication, bacterial chromosome undergoes several conformations in opening the replication fork creating torsional stress and positive supercoils. The circular chromosome is forced to cross over on itself and is alleviated by DNA gyrase to introduce negative supercoils through ATP-dependant mechanisms. This is done by binding to the DNA ahead of the replication fork creating a DNA-enzyme complex and creating doublestranded cuts into the DNA to not impede DNA replication. ${ }^{42}$ These enzymes perform similar functions in relaxing positive supercoils and both being heterodimer proteins, DNA gyrase only has the ability to introduce negative supercoils to DNA. Topoisomerase IV on the other hand accomplishes decatenation, a process of which daughter chromosomes can be unlinked and segregated for cell division (Figure 4). ${ }^{1,39}$ Regulating DNA topology and supercoiling is necessary for controlling gene expression, cell survival and pathogenicity resulting in phenotypic changes in bacterial cells. ${ }^{43,44}$

Quinolones interact with type 2 topoisomerases by creating a DNA-quinolone-enzyme complex resulting in DNA fragmentation. All quinolones possess a C4 carbonyl group and C3 carboxylic acid group that are essential for binding to DNA gyrase and topoisomerase IV. ${ }^{37}$ When DNA is bound to these enzymes, a transient state is formed after DNA cleavage and before DNA religation which permits cut DNA to pass through thereby relieving positive supercoils. ${ }^{32}$ Quinolones bind to the enzyme at this transient state stabilizing the gyrase cleavage complex preventing religation of DNA. ${ }^{45,46}$ Multiple events of DNA fragmentation induces SOS responses within the cell halting replication. This increases expression of multiple genes encoding for DNA repair, error-prone polymerases creating and related 
proteins promoting deleterious mutations. ${ }^{47-49}$ This has given quinolones the term topoisomerase poisons. ${ }^{46,50}$ Ultimately these lethal DNA breaks lead to bactericidal consequences of fluoroquinolone usage.

b)

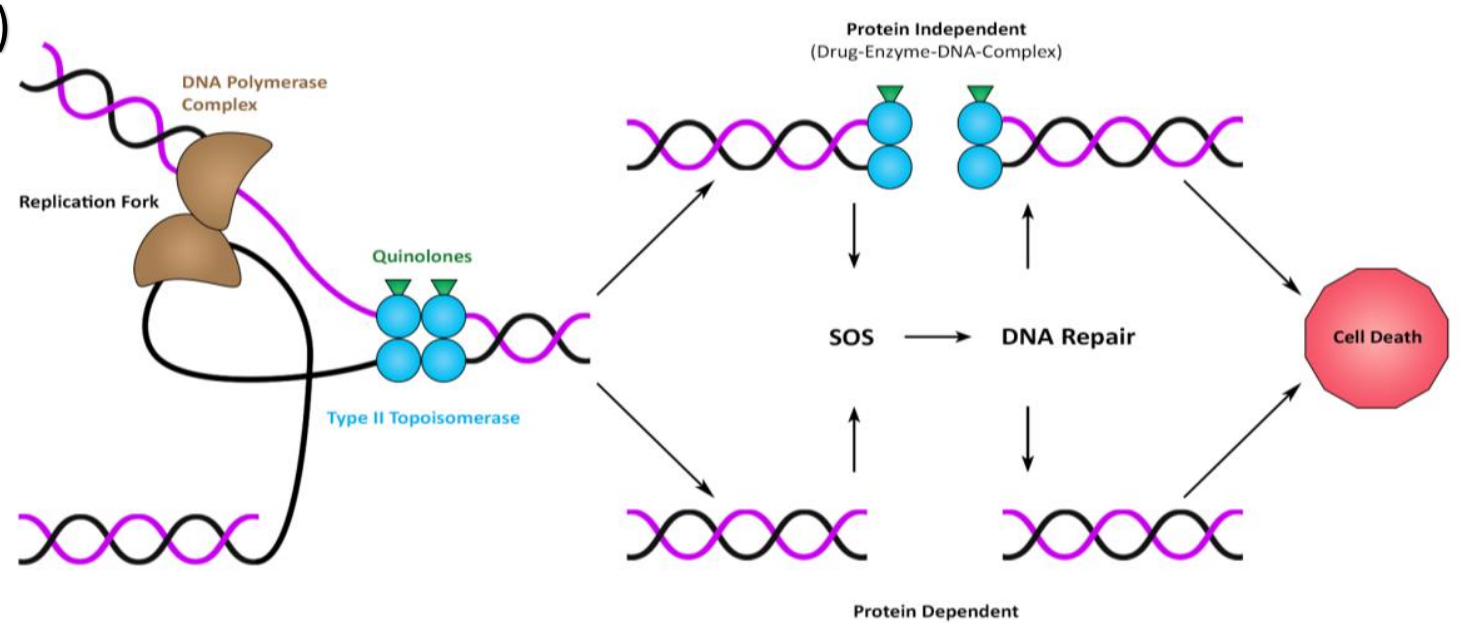

Figure 4: Detailed mechanism of action of quinolone class antibiotics with the effects of DNA topology. ${ }^{14,39}$ During DNA replication and cell division, type 2 topoisomerases, DNA gyrase and topoisomerase IV, regulate DNA conformation to relieve positive supercoiling (a). In the presence of quinolone binding to these enzymes (red spheres) results in double-stranded DNA breaks leading to bacterial apoptosis (b). (Adapted from Redgrave et al. 2014 and Kohanski et al. 2010, and credited to Hooman Sarvi)

a)

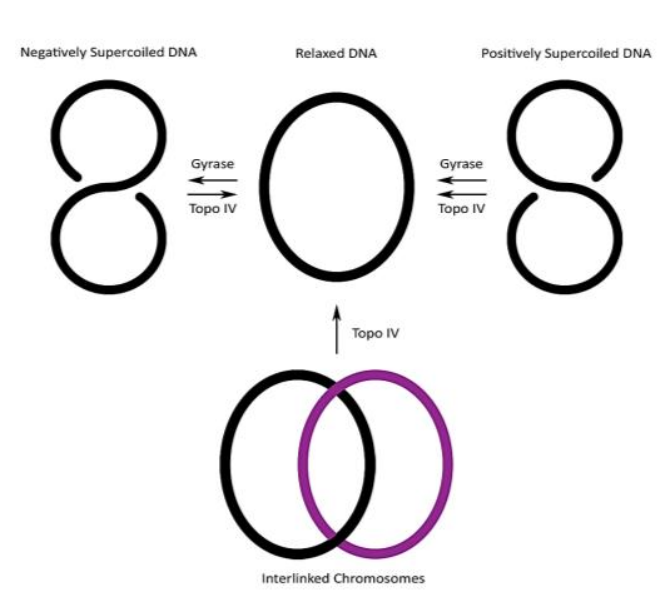

\subsubsection{Ciprofloxacin}

Ciprofloxacin, a second-generation fluoroquinolone holds tremendous efficacy for empirical therapy and is still widely used today. Discovered in 1987, ciprofloxacin became the first quinolone to be used intravenously overcoming past quinolones having incomplete absorption and significant adverse side effects. ${ }^{35}$ Improvements to the quinolone core was done by the addition of a $\mathrm{N}$-cyclopropyl group at position C1, a fluorine atom at position $\mathrm{C} 6$ and a piperazine group at position C7 (Figure 3 ). ${ }^{1}$

Ciprofloxacin treats a multitude of Gram-negative bacteria involved in osteomyelitis, an infection of the 
bone, anthrax, complicated and uncomplicated urinary infections and several sexually transmitted infections like gonorrhea and chlamydia. ${ }^{24}$ It also overcomes $P$. aeruginosa, the most common bacteria associated with chronic bronchitis, cystic fibrosis and community-acquired pneumonia, a bacteria that also has intrinsic resistance mechanisms to several naturally-based antibiotics. ${ }^{24,51}$ With exhibited broadspectrum capabilities, limited side effects and low toxicity, ciprofloxacin became an attractive treatment option compared to aminoglycosides and is a WHO essential medicine..$^{35,52}$

Ciprofloxacin and other fluoroquinolones act on the DNA gyrase by binding to the tyrosyl122 amino acid responsible for the catalytic action of the enzyme. ${ }^{53,54}$ The antibiotic is bound with high affinity to the bacterial enzyme by additional interactions bridged by magnesium ions and water molecules. ${ }^{48}$ Trapping the catalytic intermediate prevents the reunification of DNA strands resulting in accumulation of DNA fragments. With 30 years of use, ciprofloxacin is the most prescribed secondgeneration quinolone with continued antibacterial efficacy and potency than precursor quinolones. ${ }^{55}$

\subsection{Antibiotic Resistance}

To overcome the chemotherapeutic effects of antibiotics, bacteria have accumulated mutations and evolved to combat regular antibiotics. The inability to treat infectious diseases effectively in the future could threaten global health. ${ }^{19,56}$ The WHO defines antimicrobial resistance in microorganisms as those that were once susceptible to an antimicrobial drug but are now resilient against them during treatment. ${ }^{57}$ The ability of which bacteria can evade antibiotics has been known for as long as the discovery of antibiotics. Alexander Fleming understood that the misuse of penicillin can quickly yield to penicillin-resistant organisms infecting patients. ${ }^{7}$ Increased anthropogenic stresses and overuse/misuse of antibiotics have led to an epidemic of antibiotic resistant bacteria (ARB) worldwide. ${ }^{58}$ Treatment options for ARBs have dwindled as many bacteria have acquired multiple drug resistance (MDR) such as Acinetobacter baumannii. ${ }^{36,59,60}$ Aggressive methods like higher dosage of antibiotics or the use of 
combination therapy, a cocktail of multiple types of antibiotics, are required to eradicate these pathogens. This, in turn, increases toxicity and possible harm to the host. The impact of antibiotic resistance has resulted in higher morbidity and mortality rates and overall economic toll on several countries. ${ }^{6}$ In the USA alone, the annual cost of antibiotic-resistant infections ranges from $\$ 21$ billion to $\$ 34$ billion with 8 million additional hospital days. ${ }^{61}$ The rising global issue of antibiotic resistance is complicated by the lack of novel antibiotic development and innovations resulting in more severe consequences.
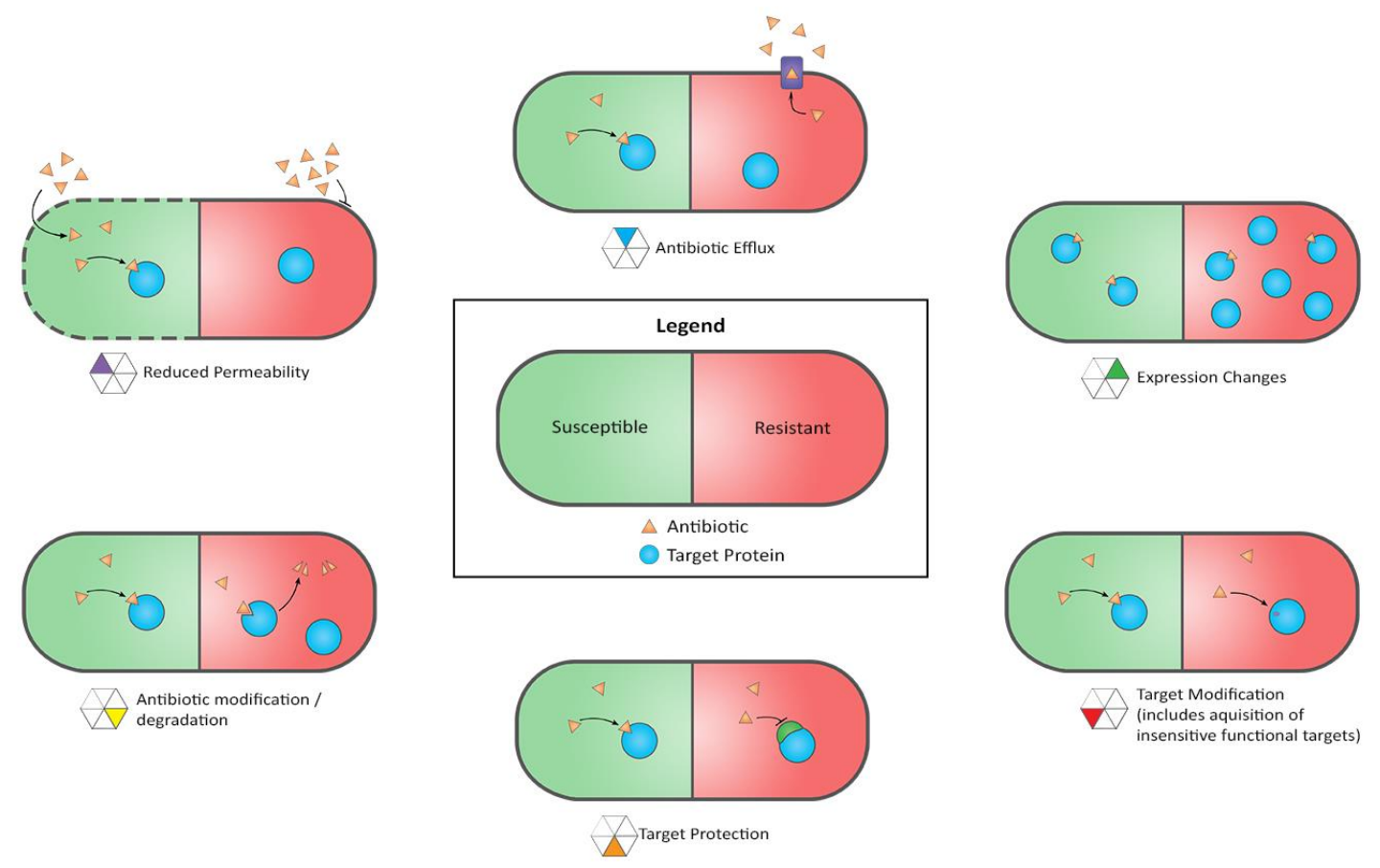

Figure 5: Schematic of different antibiotic resistance mechanisms employed by bacteria. ${ }^{13}$ In the presence of an antibiotic, bacteria can adapt and evolve methods in eliminating or evading antimicrobial properties becoming resistant. Coloured hexagon legends aid to illustrate in Figure 1 of which resistance mechanisms are commonly deployed to escape the antibiotic. (Adapted from Boolchandani et al., 2019 and credited to Hooman Sarvi)

Bacteria have the capabilities to be antibiotic-resistant through intrinsic resistance and the acquisition of antibiotic resistance genes (ARGs). The multiple mechanisms of antibiotic resistance that bacteria develop can be brought about through genetic mutation, natural resistance to the antibiotic of choice and predominantly the spread of resistances through mobile genetic elements (Figure 5). ${ }^{62-64}$ Intrinsic resistances are naturally occurring mechanisms that bacteria innately have such as multidrug 
efflux pumps or reduced membrane permeability observed in Stenotrophomonas maltophilia and

P. aeruginosa. ${ }^{62,65,66}$ Microorganisms can acquire ARGs through horizontal gene transfer disseminating resistant determinants across all environments. ${ }^{1,63,67,68}$ Horizontal gene transfer involves three main mechanisms. ${ }^{69}$ First conjugation which involves the mating of live bacteria through a type IV secretion system. Second bacterial transformation which is the uptake of naked DNA from the surrounding environment. Third is transduction which is the passage of genetic information by use of a bacteriophage, a type of virus. These ARGs can be carried on various mobile genetic elements such as plasmids, transposons, integrons and insertion sequence common region (ISCR) elements that can hold a multitude of antibiotic and metabolism gene cassettes to provide an evolutionary advantage in adapting to an environment. ${ }^{70,71}$ Antibiotic resistance is ubiquitous in the environment and can be found in natural reservoir across sources such as agriculture, wastewater and soil. ${ }^{72}$ Emergence of ARB and ARGs has given rise to superbugs and MDR pathogenic bacteria. It is not difficult for bacteria to become antibiotic-resistant with a selection pressure such as sub-inhibitory concentrations of antibiotics expose bacteria to non-lethal quantities to acquire resistance mechanisms. As a result of increased prevalence of pan-resistant bacteria, resistance to all available antibiotics, can eliminate all viable treatment options. $^{28}$

\subsubsection{Mechanisms of Quinolone Resistance}

With the increasing abundance of ARGs to natural-based antibiotics like penicillins and tetracyclines, the development of semi-synthetic or fully synthetic antibiotics were developed. Several new classes of antibiotics were developed which originally contained both synthetic and natural source backbones, however, they have shortly been followed by antimicrobial resistance mechanism that causes them to lose their effectiveness within a short amount of time (Figure 6). ${ }^{28}$ Drugs of last resort, a group of antibiotics used only when all treatment options have failed, have even shown resistances within a few years of use. 


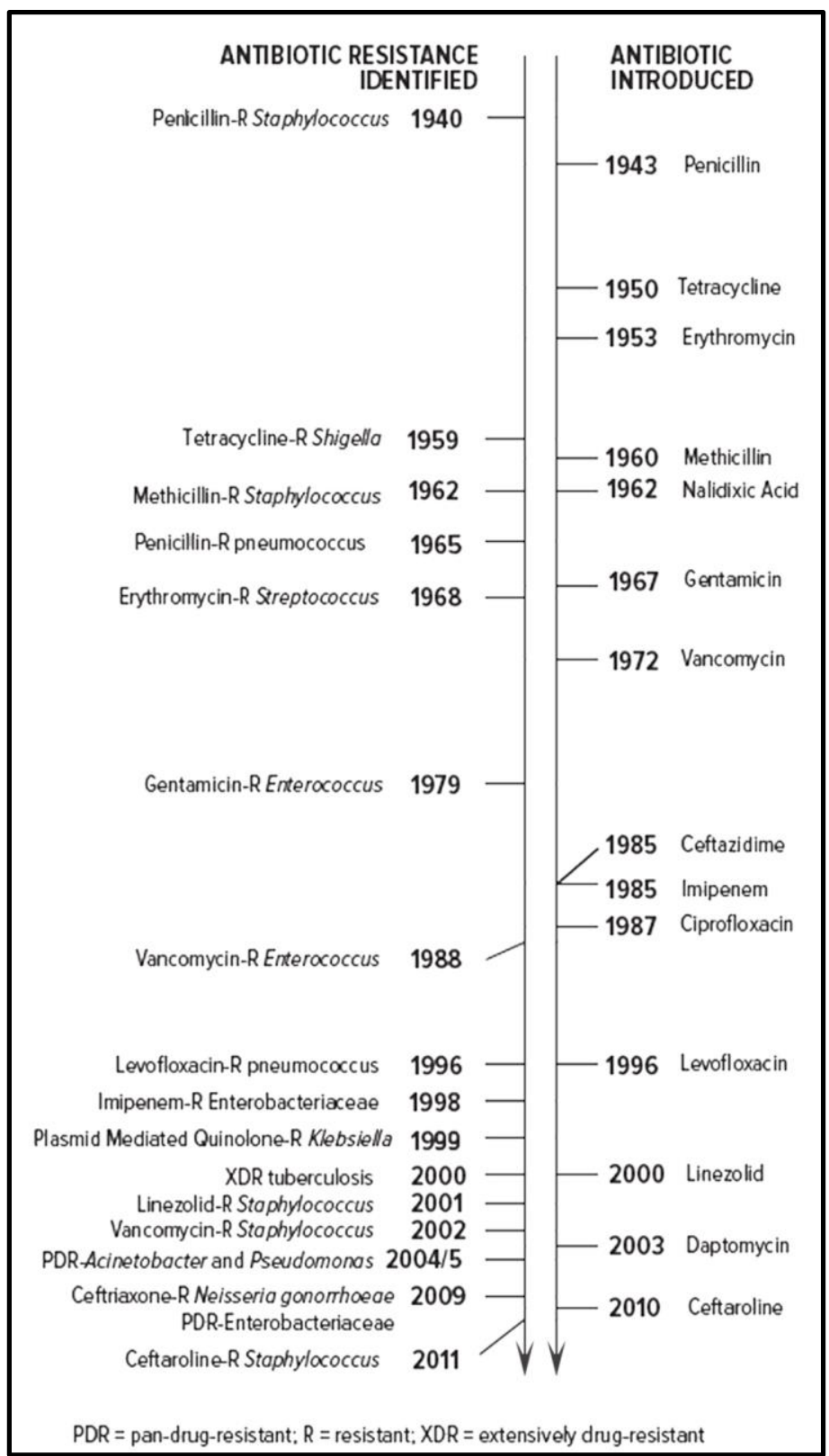

Figure 6: A timeline of antibiotic discovery with associative appearance of resistance. ${ }^{28}$ Recent development of antibiotics such as ceftaroline show a small window between antibiotic usage and first appearance of resistant bacteria. (Adapted from C. Lee Ventola, 2015 and credited to Hooman Sarvi)

Bacteria naturally do not produce quinolones or fluoroquinolones thus limiting the exposure of this class of antibiotics to the clinical setting. However, despite the lack of prior exposure, $10 \%$ of soil microbes demonstrate intrinsic ciprofloxacin resistance. ${ }^{2}$ With greater consumption and increased use of quinolones, bacteria have acquired various quinolone resistance mechanisms. The prevalence of these specific resistance genes has escalated dramatically. ${ }^{73}$ After 10 years of ciprofloxacin market use, 
the first instances of ciprofloxacin resistance in clinical and food isolates came from Campylobacter and several Enterobacteriaceae genera (Salmonella, Escherichia, Klebsiella). ${ }^{35,74}$ In the 1990s, fluoroquinolones usage in the USA increased by $40 \%$ with a doubling rate of ciprofloxacin resistance in Gram-negative bacilli with higher rates reported in other parts of the world. ${ }^{73}$ Since then, the spread of quinolone resistances has evolved independently and worldwide and not from clonal propagation. ${ }^{50}$ Quinolone resistance is described as a sequential process rather than concurrent mechanisms eliciting bacterial resistance. This is attributed to a combination and accumulation of evolved mechanisms stressing the involvement of several genetic factors and complexities to ciprofloxacin resistance. ${ }^{45,75}$

\subsubsection{Chromosomal Quinolone Resistance}

Fluoroquinolone resistance is generally due to sequential point mutations in the DNA gyrase and the topoisomerase IV genes on the bacterial chromosome. The accumulations of point mutations in these genes produce enzymes that incur high levels of ciprofloxacin resistance ranging from 10 to 60 fold change in minimum inhibitory concentration (MIC) depending on the number of mutations. ${ }^{39}$ Generally, Gram-negative bacteria DNA gyrases are more susceptible to quinolone inhibition than topoisomerase IV. In Gram-positive bacteria is vice-versa where topoisomerase IV are more susceptible. ${ }^{73}$ This in turn is where the first-step mutations are often found within quinolone-resistant bacteria. DNA gyrase consists of two dimer subunits, GyrA and GyrB subunits, encoded by gyrA and gyrB respectively. ${ }^{32}$ Topoisomerase IV is also a heterodimer consisting of ParC and ParE subunits encoded by parC and parE respectively. ${ }^{32}$ Both GyrA and ParC are presented to be catalytic subunits for DNA topology facilitation and are where mutations result in more susceptibility to the antibiotics. In GyrA, amino acid substitutions are found within the quinolone resistance determining region (QRDR) located between amino acids alanine 67 and glutamine 106 with amino acid serine 83 and aspartic acid 87 being frequently mutated. ${ }^{50,76}$ In ParC, amino acids serine 80 and glutamic acid 84 are more susceptible to mutations. ${ }^{32} \mathrm{~A}$ single mutation at either position supports a low level of resistance. The QRDR is 
relatively close to the active site of DNA gyrase where the tyrosine 122 covalently interacts with DNA phosphate groups to initialize strand breaking. ${ }^{73}$ These point mutations are responsible for the reduction of fluoroquinolone binding to the enzymes preventing the DNA-drug-enzyme complex to form. ${ }^{32} \mathrm{After}$ a single mutation in $g y r A$, consequential mutations can easily occur in other regions of QRDR or mutations in $g y r B$, parC or parE to further augment the quinolone resistance.

Moreover, quinolone resistance has been observed through the overexpression of chromosomally encoded efflux pumps and decreased membrane permeability. Efflux pump genes encode for proteins that aid in the physical extrusion of antibiotics and foreign compounds out of the cell. ${ }^{62}$ Recognition of these compounds can be specific or non-specific resulting in lower intracellular concentrations of toxic substances, including multiple classes of antibiotics, returning normal metabolic function. Several pathogens are intrinsically equipped with active efflux mechanisms to evade antimicrobials. Multidrug efflux pump AcrAB-TolC and MexAB-OprM has been credited to intrinsic resistance phenotype in quinolone and antibiotic efflux when overly expressed in Escherichia coli (E. coli) and $P$. aeruginosa. ${ }^{77,78}$ To limit quinolone entry, expression of outer membrane porin proteins that form open channels for passive diffusion is reduced. Decreased uptake of antibiotics reduces the intracellular accumulation of quinolones to act upon their intracellular targets. Major outer membrane proteins OmpF and OmpC in E. coli have shown synergistic capabilities with efflux mechanisms supplementing overall quinolone resistance. ${ }^{32,62}$

These non-transferable mechanisms working in tandem alter the mutant protective concentration (MPC). The presence of sub-inhibitory concentrations of quinolones can increase the rate of mutation accordingly to obtain advantageous traits. The induction of mutator genes like mutD5 can increase the frequency of mutations observed in a population acquiring quinolone resistance. ${ }^{79-81}$ In addition, quinolone activity activates SOS response in cells which already elevates the mutation rate. ${ }^{49}$ Treating a large inoculum $\left(10^{10}\right.$ cells of bacteria) at the MIC level can still dispose some surviving bacteria 
with inherent mutations. ${ }^{82}$ To identify the lowest concentration needed of which no mutants appear in a large inoculum is called the MPC developed by Drlica and Zhao. ${ }^{83,84}$ This is performed by plating a large inoculum on various concentrations of a quinolone above the MIC and counting surviving bacteria after 72 hours. Therapeutically, having a narrow window between MIC and MPC will be effective in reducing the number of mutants with a quinolone drug administration above the MPC can prevent reoccurring resistant infections. Chromosomal quinolone resistances of any kind have shown a strong correlation with increased mutation rates which in turn increases the MPC level. ${ }^{85,86}$ Widening the window between MIC and MPC creates more opportunities for mutants in the population at various quinolone concentrations past the maximum human serum drug concentration. ${ }^{82}$ If the MPC increases, the likelihood of more chromosomal mutation increases with overall therapeutic failure of quinolones. This presents with the risk of fluoroquinolone usage giving rise to a single mutation can increase successive resistant traits in quinolone-resistant bacteria.

\subsubsection{Plasmid-mediated Quinolone Resistance}

The threat of transferability of quinolone resistances seemed unlikely due to the synthetic nature of the antibiotic in curing plasmids out of the cells and its inherent ability to inhibit DNA replication and cell division. ${ }^{87}$ However, plasmid-mediated quinolone resistances (PMQR) were first reported in 1998 in the USA, and can directly add and disseminate a repertoire of bacterial genes that

aid in evading quinolone antibiotics. ${ }^{88,89}$ PMQR genes exist in three forms: quinolone resistance proteins (Qnr), fluoroquinolone-modifying enzyme (modified aminoglycoside acetyltransferase) and specific quinolone efflux pump and multi-drug efflux pump (QepA and OqxAB respectively). ${ }^{76}$ Plasmids of broad host ranges and conjugative nature carry PMQR genes abundantly which overall confers a low-levels of quinolone resistance with a 4 to 32 fold change in the ciprofloxacin MIC. ${ }^{39}$ Furthermore, PMQR genes affect the MPC level by already reducing susceptibility to quinolones, even if the gene does not confer clinical resistance. These additional mobilizable genes increase the MIC to MPC window promoting the 
occurrence of quinolone-resistant mutants. These non-significant MIC fold changes illustrate a combo effect of PMQR genes assisting in the emergence of higher-level resistance within the chromosome by the proliferation of lower-level resistances in PMQR genes. ${ }^{77}$ Through horizontal gene transfer events, the microbial community in all settings can bear some form of PMQR determinants through rapid dissemination.

Qnr proteins are pentapeptide repeat proteins that protect type 2 topoisomerases from quinolones returning normal catalytic function through competitive inhibition. Pentapeptide repeat proteins (PRP) are elongated protein tandem repeats that share similar sequence motifs in a linear consecutive fashion creating a righthanded quadrilateral $\beta$-helix. ${ }^{53}$ This is exhibited by the general consensus motif sequence represented as $A(D / N) L X X$ in single-letter amino acid notation where $X$ is any amino acid. ${ }^{90}$ The overall structure of PRP is a dimeric protein with two domains of nine repeats on either side separated by a single amino acid, usually a glycine forming a hinge in the protein structure. ${ }^{50}$ These Qnr proteins are encoded by qnr genes which are currently divided into six Qnr families (A, B, C, D, S, and VC) with an overall 101 different qnr genes in the Comprehensive Antibiotic Resistance Database (CARD, https://card.mcmaster.ca/ontology/36558). ${ }^{91,92}$ Among these Qnr families, QnrB holds the most allelic variations with 76 different variants. Recently they have discovered a new family of Qnr, QnrE, which holds one variant (QnrE1)..$^{93}$ These families are defined by the purposed cut-off of 30\% or more differences between nucleotides or derived amino acids. ${ }^{50}$ Variants within a Qnr protein family differ by one or two amino acids which give rise to reduced susceptibility to nalidixic acid or fluoroquinolones. From the primary structure of different Qnr variants it is impossible to predict their activity. Studies show that when qnr homologues are cloned into a plasmid, they did not confer fluoroquinolone resistance unless it was mutated from a cysteine 115 to a tyrosine. ${ }^{94}$ This proposed mutation when performed in QnrA1 or QnrS1 conferred a reduced ability in protecting against quinolones. ${ }^{95}$ Through phylogenetic analysis of Qnr alleles it has been suggested that high 
recombination has aided in their evolution and variation. ${ }^{96}$ The overall structure of Qnr proteins mimics the structure of $\beta$-form DNA hypothesizing that they interact with DNA gyrase directly preventing quinolone inhibition by binding to the QRDR. The detailed mechanisms of action of how Qnr proteins interact with gyrase are not clearly understood but multiple biochemical assays such as supercoiling and DNA gyrase assays have shown the protective nature of Qnr proteins towards DNA gyrase. In a dosedependant manner, approximately $0.32 \mu \mathrm{M}$ of histidine-tagged QnrA reversed the effects of ciprofloxacin inhibition (1.5 $\mu \mathrm{M})$ from $0.93 \mathrm{nM}$ of DNA gyrase.$^{92,97-99}$ To further understand Qnr protein function, analogous PRP that confers fluoroquinolone resistance, McbG and MfpA, has been characterized and used as a model for Qnr mechanisms. McbG and MfpA PRP share $19.6 \%$ and $18.9 \%$ amino acid similarity with Qnr proteins. In the case of McbG, it protects bacterial DNA gyrase from the effects of microcin B17, an excreted small inhibitory protein, that acts as a topoisomerase poison much like quinolones. ${ }^{100}$ To defend the producing microorganism from effects of microcin B17, McBg is translated from the same operon as microcin B17 to interact with DNA gyrase by displacement of the bound DNA. This is similarly observed with the effect of CccDB toxin with MfpA. Both McbG and MfpA homologues display three-dimensional structure and charge distribution similarly to B-form DNA, preventing DNA gyrase activity independent of the presence of DNA, fluoroquinolone or ATP. ${ }^{50}$ This takes form as a protective manner of competitive inhibition between DNA and quinolone to interact with the type 2 topoisomerases giving bacteria time to acquire resistances like gyrase mutations preventing fluoroquinolone efficacy. Qnr proteins could function analogous to these proteins as antitoxins for other underdetermined toxins but were heavily selected under fluoroquinolone presence.

Modified aminoglycoside acetyltransferase is a fluoroquinolone-inactivating enzyme which directly acetylates ciprofloxacin and norfloxacin. Encoded by the aac $\left(6^{\prime}\right)-\mathrm{Ib}-\mathrm{cr}$ gene, $\mathrm{AAC}\left(6^{\prime}\right)-\mathrm{Ib}-\mathrm{cr}$ enzyme is predominantly responsible for transferable resistance to aminoglycoside antibiotics such as kanamycin, tobramycin and amikacin. ${ }^{101}$ The cr variant which stands for ciprofloxacin resistance is a 
mutant variant of this enzyme having dual purposes of inactivating select aminoglycosides and quinolones. The mechanism of action of $A A C\left(6^{\prime}\right)-\mathrm{Ib}-\mathrm{cr}$ is by acetylating the piperazinyl group at the $7^{\text {th }}$ position of quinolones that this functional group. ${ }^{102,103}$ The enzyme interacts with the quinolone rings through $\pi$-stacking interactions for better drug inactivating. ${ }^{50}$ Substrate competitive inhibition assays of this enzyme indicate functional overlap between both antibiotic classes and are due to two mutations from the wild-type enzyme, Trp102Arg and Asp179Tyr. ${ }^{32,50}$ The catalytic efficiency of AAC(6')-Ib-cr on fluoroquinolone acetylation was about 50 times lower compared to aminoglycosides but is effective enough to give bacteria cells ciprofloxacin resistance. ${ }^{103}$

Mobilizable efflux pumps QepA and OqxAB have recently been discovered in giving rise to multi-drug resistances including quinolones. QepA shares similarity with the MFS (major facilitator superfamily) efflux pump transporters. QepA significantly increases resistance to hydrophilic quinolones like nalidixic acid, ciprofloxacin, norfloxacin and enrofloxacin with 2 to 64 fold increase in MIC. ${ }^{104}$ Currently there is only two variants of QepA, QepA1 and QepA2, that differ by two amino acid substitutions. ${ }^{50}$ OqxAB efflux is a multidrug efflux pump that belongs to the RND (resistance-nodulationcell-division) efflux system, ubiquitous in Gram-negative bacteria. ${ }^{105}$ This PMQR prevalence is rare but shows multi-drug resistance including quinolones and chloramphenicol.

\subsection{Environmental Reservoir of Antibiotic Resistances}

The prevalence of ARGs in the natural environment poses significant threats to the clinical setting with decreased antibacterial efficacy through rapid dissemination. The more prominent these ARGs, the less alternative treatments available towards MDR bacteria. Multiple sources such as the agricultural soils, wastewater treatment plants (WWTP) and fresh waters have been illustrated as natural reservoirs for ARGs (Figure 7). The widespread of environmental ARB and ARGs have been shown in several studies displaying the ubiquity of these resistant determinants. ${ }^{106-109}$ The misuse of 
antibiotics can be seen in archived soil samples from the 1940s to the present day where the resistance gene abundances have dramatically increased over the years since clinical introduction of antibiotics. ${ }^{110}$

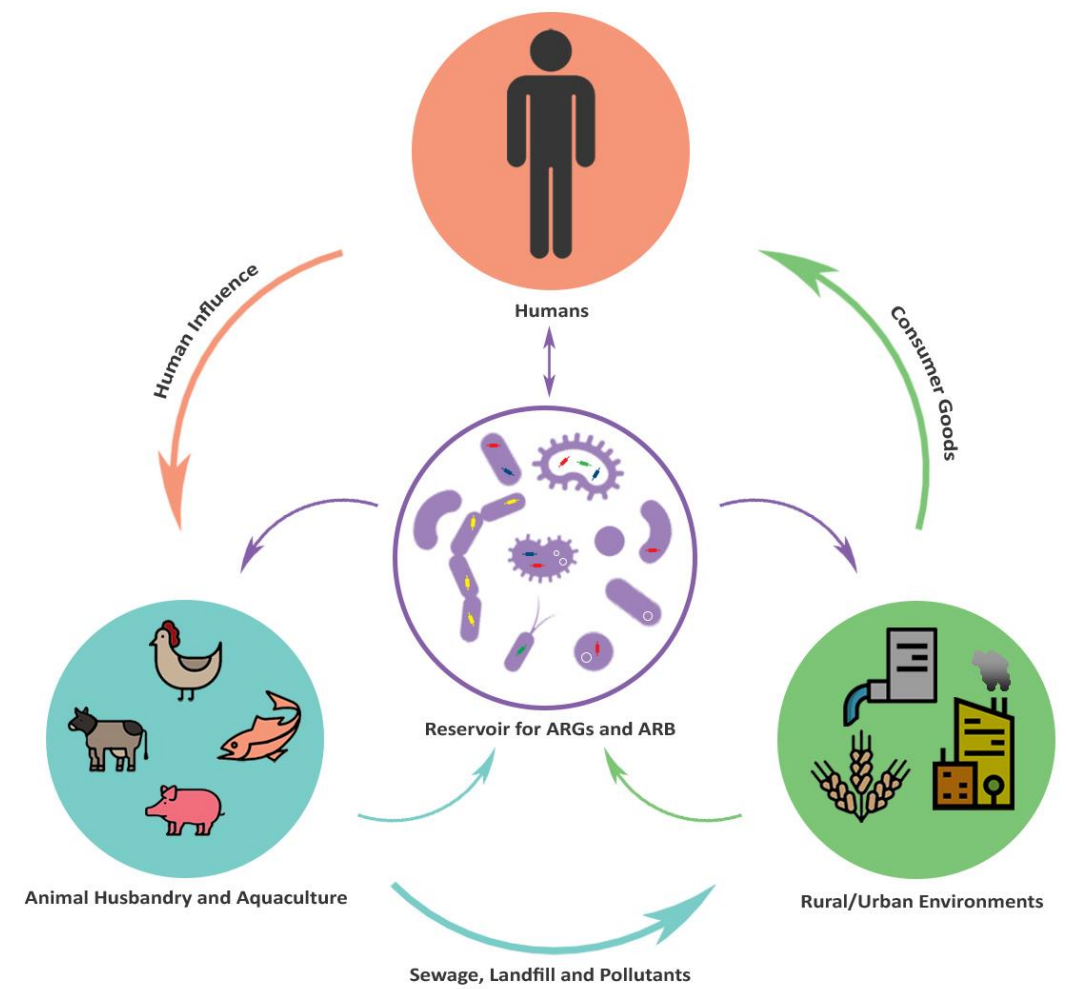

Figure 7: Overview of antibiotic resistance dissemination across different environments. ${ }^{9}$ Coming from multiple sources, the movement of ARBs can influence the natural microbiome contributing to overall ARG prevalence. Several anthropogenic stresses like animal husbandry can readily increase the rate of dissemination. (Credited to Hooman Sarvi)

The existence and origins of ARGs have always been present in the environment but with certain selection, pressures can promote the ideal conditions of genetic maintenance and transfer of ARGs which include 1) high microbial diversity, 2) high nutrient concentrations, 3) sub-inhibitory concentrations of antibiotics. ${ }^{12,28,67}$ These factors can encourage environmental "hotspots" of which microbial communities can acquire multiple ARGs. Phylogenetic evidence and direct epidemiologic surveillance have already shown direct relationships between human pathogens acquiring resistance genes from environmental bacteria. ${ }^{72}$ Community-acquired methicillin-resistant Staphylococcus aureus (MRSA) infections have become more prevalent in recent years than nosocomial infections already leading to a global threat of antibiotic resistance to public health. ${ }^{17,28,36}$ Surveillance and investigation is 
critical in understanding the epidemiology of ARGs but current and previous research show a heavy focus on clinical pathogens. The Canadian Integrated Program for Antimicrobial Resistance Surveillance (CIPARS) monitors antimicrobial resistance in agricultural and food sectors but displays a need for investigation of the natural environment resistome. A call for immediate action from the several institutions and health organizations (IDSA, WHO, CDC, etc.) to the medical community to circumvent the spread of ARGs and optimize the use of antimicrobial medicine in humans and animal health with the development of guidelines towards the burden of antibiotic resistance. ${ }^{15,56,63,111}$ By the year 2050, it is predicted that antibiotic resistance will out-compete the mortality rate of cancer with a staggering 10 million deaths a year that succumb to infections that could easily be treated. ${ }^{6}$

Increased PMQR prevalence in all settings already shows detrimental effects in maintaining the effectiveness of quinolones. Antibiotic resistance genes located on mobile genetic elements in bacteria have the highest risks for human health. The widespread prevalence of qnr genes has been observed in several countries harboured on different conjugative incompatibility group plasmids and integron cassettes linked alongside other ARGs. ${ }^{50,92}$ The host range of qnr genes have extended to Gram-negative Enterobacteriaceae pathogens like $K$. pneumonia and E. coli but originally were found in waterborne species such as Shewanella and Aeromonas. ${ }^{72,112}$ Bacteria disperse through these aquatic ecosystems giving a dissemination route to pass on qnr genes and associated ARGs widely. Exposure to these highly impacted waterfronts or improper water sanitation can lead to multiple qnr reservoirs in various aquatic environments. ${ }^{113,114}$

\subsection{Rationale and Objectives}

With the continued use of ciprofloxacin and other quinolones in clinical practices, the detection and surveillance of emerging PMQR should remain a priority. Clinical importance of an ARG can be determined through three factors: 1 ) the class of antibiotic it renders ineffective, 2) the host and 
pathogenicity of the bacterium and 3) the genetic location of the ARG. ${ }^{115}$ PMQR genes highlight all three of these concerns with the additional threat of originating from aquatic sources. Although these synthetic fluoroquinolone compounds are not naturally found in the environment, bacterial isolates from hospital effluent, wastewater and receiving waters have been found to be resistant. Understanding the evolution and spread of MDR bacteria associated with PMQR determinants can help mitigate any further risk of resistance spreading to different bacterial genera or adapting to new environments. Rapid detection of resistances can allow successful countermeasures in the potential recovery of quinolone class antibiotics. Urban and rural water sources contain a diverse bacterial community and can be used to examine how antibiotic resistances proliferate and disseminate throughout these water systems. The presented work here underlies the importance of the environment as a gene reservoir for ARGs and possible ARG dissemination. In addition, the work demonstrates the prevalence and distribution of $q n r$ genes as indicators of ciprofloxacin resistance. Determining the underlying cause of ciprofloxacin dissemination could help re-establish the effectiveness of these antimicrobial compounds in the clinical setting.

The aim of this research is to investigate the prevalence of ciprofloxacin-resistant bacteria in the natural environment in order to observe potential qnr determinant reservoirs in various aquatic sources. Using culture-based methods, ARB prevalence to specific isolates/genera can be associated with antibiotic resistance determinants wherein metagenomic analyses lack this conclusion ability. Evaluating these $q n$ r determinants through prevalence and characterization can aid in understanding the current impact of PMQR genes as an emerging contaminant. With the selective pressure of ciprofloxacin, we hypothesize that the presence of ciprofloxacin-resistant bacteria in the environment will encounter PMQR genes while the sensitive population to hold no PMQR genes. To test this hypothesis the following objectives were carried out: 
1. To determine the presence of ciprofloxacin-resistant bacteria in various environmental aquatic sources using culture-based techniques.

2. To determine the abundance of antibiotic resistances of all isolates in observing co-resistance patterns and multi-drug resistances with and without ciprofloxacin selection using the antimicrobial disk-diffusion method and Weka software.

3. To identify all environmental isolates using genomic DNA extraction, PCR of the $16 \mathrm{~S}$ rRNA gene and Sanger sequencing to observe genera diversity and richness between ciprofloxacin-resistant and ciprofloxacin-sensitive populations.

4. To detect qnr genes and overall frequency of these genes in all environmental isolates via PCR multiplex screening of PMQR genes $q n r A$, qnrB and qnrS.

5. To examine ciprofloxacin and nalidixic acid MIC levels and nalidixic acid levels in select isolates to quantify increased resistance in the presence of qnr genes

6. To determine possible qnr gene sequence difference in both ciprofloxacin-resistant and ciprofloxacin-sensitive isolates 


\subsection{Materials and Methods}




\subsection{Sample Collection from Various Water Sources}

Five southern Ontario sites were selected for this study in which environmental water samples were collected at various time points for enumeration and culturing purposes. Water samples represented different water usages and influences (Appendix 2). At each location, water samples were taken from both the water column and surface sediment. The water column samples were collected by immersing $1 \mathrm{~L}$ sterile glass bottles $30 \mathrm{~cm}$ below the water surface approximately 1 meter from the shoreline. The surface sediment samples were collected by immersing the bottle above the sediment and disturbing the top layer of depth of $1-2 \mathrm{~cm}$. Samples were collected and transported to the lab for processing on the same day. Each sample was mixed homogeneously before plating on media.

The first location was Buckhorn Lake, which is situated in a recreational area for cottages in the Karwartha Lake region and was sampled in June 2017, July 2017 and October 2017. The second location was a Toronto storm drain beside an urban pedestrian park pathway that fed into the Toronto sewage system. This location was sampled in June 2017 and June 2018. The third location was Lake Ontario at the shore of Woodbine Beach. This sample site is $1 \mathrm{~km}$ away from the final effluent of the adjacent Ashbridges Bay WWTP. Samples were taken in July 2017 and May 2018. The fourth location was from the Humber WWTP which receives 473,000 cubic meters of wastewater per day from mostly residential and industrial sources. ${ }^{116}$ Samples were taken from the secondary treatment process by on-site personnel and sampled on July 2017 and April 2018. The last location, Lake Devo is an artificial cement pond on the Ryerson University campus beside a high foot traffic pathway that undergoes biweekly drainage. Samples were taken in June and July 2018.

\subsection{Enumeration and Isolation of $\mathrm{Cip}^{\mathrm{S}}$ and $\mathrm{Cip}^{\mathrm{R}}$ Bacteria}

At each time point, water samples were plated in triplicates for total culturable heterotrophic bacteria and frequency of ciprofloxacin-resistance bacteria. Preparation of serial dilutions with sterile 
$0.9 \% \mathrm{NaCl}$ was followed by plating several dilutions on Reasoner's 2A agar (R2A) (Sigma-Aldrich, Canada) for countable bacterial counts. This was supplemented with and without ciprofloxacin (Enzo Life Sciences, Canada). Clinical studies observing ciprofloxacin resistance range between concentrations from 4 to $8 \mu \mathrm{g} / \mathrm{mL}$ in reporting MIC levels. For proper selection of ciprofloxacin-resistant microorganisms, isolates were directly screened on $10 \mu \mathrm{g} / \mathrm{mL}$ of ciprofloxacin. ${ }^{117-119}$ Ciprofloxacinsensitive isolates were selected from R2A plates not containing the antibiotic and confirmed by lack of growth on ciprofloxacin containing plates. All plates were incubated at room temperature for up to 48 hours for CFU enumeration.

In total, 202 colonies were isolated and subcultured based on varying morphological characteristics and subjected to antibiotic susceptibility testing. Of this, 105 ciprofloxacin-sensitive isolates $\left(\mathrm{Cip}^{\mathrm{S}}\right)$ and 97 ciprofloxacin-resistant isolates $\left(\mathrm{Cip}^{\mathrm{R}}\right)$ were processed for DNA isolation and identified using $16 \mathrm{~S}$ rRNA PCR. In total, 39 isolates were from Buckhorn Lake (BL), 37 isolates were from Toronto Storm Drain (TS), 45 isolates were from Lake Ontario (LO), 51 isolates were from the Humber WWTP (HW) and 30 isolates were from Lake Devo (LD).

\subsection{Antibiotic Susceptibility Testing}

All isolates were tested for antibiotic susceptibility to up to twelve antibiotics using the standard Kirby-Bauer disk diffusion method provided by BBL ${ }^{\mathrm{TM}}$ Sensi-Disc ${ }^{\mathrm{TM}}$ antimicrobial susceptibility test discs manufacturer except that R2A agar instead of Mueller-Hinton was used. This media is standard for environmental isolates as it is a low nutrient media that mimics the environment. Laboratory strains E. coli (DH5 $\alpha)$ and P. putida (ATCC 12633) were used as control standards for the antibiotic susceptibility of heterotrophic bacteria. The diameter of the zone of inhibition was measured and categorized as sensitive, intermediate or resistant per specific antibiotic as outlined by the manufacturer (Becton, Dickinson and Company, USA). The twelve antibiotics tested were ampicillin (10 $\mu \mathrm{g})$, chloramphenicol 
$(30 \mu \mathrm{g})$, ciprofloxacin $(5 \mu \mathrm{g})$, erythromycin $(15 \mu \mathrm{g})$, gentamicin $(10 \mu \mathrm{g})$, kanamycin $(30 \mu \mathrm{g})$, polymyxin $\mathrm{B}$ (300 U) spectinomycin $(100 \mu \mathrm{g})$, streptomycin $(10 \mu \mathrm{g})$, sulfamethoxazole-trimethoprim (23.75 ug/1.25 ug), tetracycline (30 $\mu \mathrm{g})$ and vancomycin (30 $\mu \mathrm{g})$ (Becton, Dickinson and Company, USA).

The multiple antibiotic resistance (MAR) score was calculated by the percentage of isolates that had least 3 or more antibiotic resistance determinants at each location and population of $\mathrm{Cip}^{\mathrm{S}}$ and Cip $^{\mathrm{R}} \cdot{ }^{106,120,121}$ Antibacterial resistance index (ARI) was used in determining the prevalence of resistance determinants in each location and population. ARI was calculated with the following formula:

$$
\mathrm{ARI}=A / N Y,
$$

where $A$ is total number of resistant determinants recorded in the population, $N$ is the number of isolates in the population, and $Y$ is the total number of antibiotics tested. ${ }^{64,107}$

Antibiotic resistance profiles were analyzed using the Weka software 3.8.3

(https://www.cs.waikato.ac.nz/ml/weka/downloading.html) in determining the probability which resistances are co-present. ${ }^{106,122}$ Isolate resistance values were initially converted to binary as 1 indicated sensitivity to an antibiotic and 0 as resistant. For the total population, eleven antibiotics were labelled as attributes and converted to ARFF file format for data analysis. The Apriori association rule algorithm was performed in Weka in outputting confidence rules of at least $95 \%$ confidence and 0.35 minimum support in looking for associations among attributes. Removal of the ciprofloxacin attribute in observing antibiotic cross-resistance in $\mathrm{Cip}^{S}$ and $\mathrm{Cip}^{R}$ populations was done to minimize outputs given. The premise of this was to observe different antibiotic relationships in the absence or presence of ciprofloxacin in $\mathrm{Cip}^{S}$ and $\mathrm{Cip}^{\mathrm{R}}$ populations respectively. Therefore, all instances with the $\mathrm{Cip}^{\mathrm{R}}$ associations would default to include ciprofloxacin. Three metrics were assessed to determine validity of each antibiotic resistance relationships: support, confidence and lift. ${ }^{123}$ Support is shown by the number of isolates that encompass the relationship in all isolates (i.e. the number of instances in a population). 
Confidence is the proportion of isolates covered within that the relationship that agree with the righthand agreement (i.e. output after the initial relationship). Lastly, lift is the ratio of confidence to the total frequency of the right-hand agreement. For example, if an isolate is resistant to kanamycin and streptomycin, then it is resistant to gentamicin. Out of 199 isolates, 95 isolates were resistant to both kanamycin and streptomycin and of those 94 isolates were resistant to gentamicin. From here this provides a support of 0.47 (94/199) and confidence of 0.99 (94/95). Regardless of this relationship, gentamicin resistance is observed in 161 out of 199 isolates. For this outlined relationship the lift is calculated to be $1.22(0.99 /(161 / 199))$. A lift value greater than 1 indicates that the relationship is not due to simple chance. The larger the support, confidence and lift, the more significant the relationship. Weka run information can seen in the appendix.

\subsection{DNA Preparation}

All pure cultures were extracted for whole genomic DNA using the Power Soil ${ }^{\circledR}$ DNA Isolation Kit (MoBio Laboratories Inc., Canada). Manufacturer's protocol was followed with certain steps modified to elute better DNA yield. This included the time variation in the bead beading lysis step from 7 to 15 minutes from the standard 10 minutes depending on the culture. Additionally, the final elution step included a 5 min incubation period to increase DNA yield. DNA quality and concentration were verified through gel electrophoresis and nanodrop A280/260 measurement respectively. DNA was stored at $20^{\circ} \mathrm{C}$ until needed.

\subsection{Isolate Identification and Sequencing}

Of the 202 isolates, 184 isolates $\left(104 \mathrm{Cip}^{\mathrm{S}}, 80 \mathrm{Cip}^{\mathrm{R}}\right)$ were identified using the $16 \mathrm{~S}$ rRNA gene amplified via PCR. Highly conserved V3 and V4 variable regions of the 16S rRNA gene were targeted using primers U341-F and U758-R synthesized by the Peter Gilgan Centre for Research and Learning (Toronto, Canada) and described in Table 1.24,125 
Table 1: List of PCR primers used for bacterial identification and qnr screening

\begin{tabular}{|c|c|c|c|c|}
\hline Primer $^{a}$ & Gene & Sequence $\left(5^{\prime}-3^{\prime}\right)$ & $\begin{array}{l}\text { Amplicon Size } \\
\text { (bp) }\end{array}$ & Reference \\
\hline $\mathrm{U} 341-\mathrm{F}$ & \multirow{2}{*}{ 16S rRNA } & CCTACGGGAGGCAGCAG & \multirow{2}{*}{500} & (Muyzer et al., 1993)124 \\
\hline $\mathrm{U} 758-\mathrm{R}$ & & CTACCAGGGTATCTAATCC & & $\left(\right.$ Lee et al., 1993) ${ }^{125}$ \\
\hline QnrA-F & \multirow{2}{*}{ qnrA1 to qnrA6 } & AGAGGATTTCTCACGCCAGG & \multirow{2}{*}{580} & \multirow{6}{*}{ (Cattoir et al., 2007) ${ }^{126}$} \\
\hline QnrA-R & & TGCCAGGCACAGATCTTGAC & & \\
\hline QnrB-F & \multirow{2}{*}{$q n r B 1$ to $q n r B 6$} & GGMATHGAAATTCGCCACTG $^{b}$ & \multirow{2}{*}{264} & \\
\hline QnrB-R & & TTTGCYGYYCGCCAGTCGAA & & \\
\hline QnrS-F & \multirow{2}{*}{ qnrS1 to $q n r S 2$} & GCAAGTTCATTGAACAGGGT & \multirow{2}{*}{428} & \\
\hline QnrS-R & & TCTAAACCGTCGAGTTCGGCG & & \\
\hline
\end{tabular}

aF denotates sense primer; $R$ denotates antisense primer

${ }^{\mathrm{b}} \mathrm{M}=\mathrm{A}$ or $\mathrm{C} ; \mathrm{H}=\mathrm{A}$ or $\mathrm{C}$ or $\mathrm{T} ; \mathrm{Y}=\mathrm{C}$ or $\mathrm{T}$

Each PCR reaction contained final concentrations of $10 \mathrm{X}$ Taq Thermpol ${ }^{\circledR}$ buffer $(10 \mathrm{mM}$ Tris- $\mathrm{HCl}$ pH 9.0, 50 mM KCl, 1.5 mM MgCl ) (New England Biolabs, Canada), $200 \mu \mathrm{M}$ dNTPs (Bio Basic, Canada), $0.5 \mu \mathrm{M}$ of forward and reverse primers, $3.44 \mu \mathrm{g}$ BSA (Roche, Canada), 1.25 units Taq DNA polymerase (New England Biolabs, Canada) with 50 ng of template DNA. Reactions were positioned using T100 ${ }^{\mathrm{TM}}$ thermal cycler (Bio-Rad Laboratories, Canada). A Touchdown-PCR (TD-PCR) protocol was executed at the following settings: an initial denaturation temperature of $96^{\circ} \mathrm{C}$ for 5 min continuing with the primary cycle. The primary cycle includes a denaturation of $94^{\circ} \mathrm{C}$ for $1 \mathrm{~min}$, an annealing temperature of $65^{\circ} \mathrm{C}$ for $1 \mathrm{~min}$ with a decrease of $1^{\circ} \mathrm{C}$ per cycle for 10 cycles with an elongation of $3 \mathrm{~min}$ at $72^{\circ} \mathrm{C}$. This is followed by the second cycle of $94^{\circ} \mathrm{C}$ for $1 \mathrm{~min}, 55^{\circ} \mathrm{C}$ for $1 \mathrm{~min}$ and $72^{\circ} \mathrm{C}$ for $1 \mathrm{~min}$. The secondary cycle was repeated for a total of 20 cycles which completed the protocol. PCR products were analyzed by gel electrophoresis in a $1 \%$ agarose gel containing SYBR Safe DNA stain at $100 \mathrm{~V}$ for 25-30 min alongside a 100 bp ladder (Froggabio, Canada). PCR products were sent for Sanger sequencing to ACGT (Toronto, Canada) using both the forward and reverse primer. The obtained nucleotide sequences were analysed via Sequence Scanner v2.0 (Applied Biosystems, USA). Sequences were then compared to the National Center for Biotechnology Information (NCBI) nucleotide Basic Local Alignment Search Tool (BLAST) database to determine the isolate identity. 
In observing genera abundance and diversity between both $\mathrm{Cip}^{S}$ and $\mathrm{Cip}^{\mathrm{R}}$ populations, the Shannon Diversity Index $(H)$ and genera richness $(S)$ was calculated. ${ }^{127,128}$ The genera richness is calculated by taking the natural logarithm $(I n)$ of the number of genera in a population. The Shannon Diversity Index is calculated by the following formula:

$$
H=-\sum_{i=1}^{s} p_{i} \ln p_{i}
$$

where $p_{i}$ is the proportion of $(n / N)$ of individuals of one genus found $(n)$ by the total number of individuals observed $(N)$, and $s$ is the number of species/genera.

The Sorenson coefficient (SC) was calculated in observing how common genera are among both populations. ${ }^{127}$ It is calculated as followed:

$$
\frac{2 C}{\left(S^{1}+S^{2}\right)}
$$

where $C$ is the number of common genera among all populations, $S^{1}$ is the number genera in population 1 , and $S^{2}$ is the number of genera in population 2 .

\subsection{Multiplex PCR for Qnr Determinants}

All collected isolates (202) were screened for the presence of qnr determinants qnrA-, qnrB-, qnrS-like genes described by Cattoir and collegues. ${ }^{126}$ Multiple allele variants of each gene were screen with the use of degenerative primers with the associated product size described in Table 1. PCR reactions contained final concentrations of 10X Taq Thermpol ${ }^{\circledR}$ buffer $(10 \mathrm{mM}$ Tris-HCl pH 9.0, $50 \mathrm{mM}$ $\mathrm{KCl}, 1.5 \mathrm{mM} \mathrm{MgCl}$ ) (New England Biolabs, Canada), $200 \mu \mathrm{M}$ dNTPs (Bio Basic, Canada), 20 pmol of each of the six primers, 2.5 units Taq DNA polymerase (New England Biolabs, Canada) with 50 ng of template DNA. PCR reactions were performed using the following sequence: initial denaturation temperature at $95^{\circ} \mathrm{C}$ with $35 \mathrm{cycles}$ of $1 \mathrm{~min}$ at $95^{\circ} \mathrm{C}, 54^{\circ} \mathrm{C}$ for $1 \mathrm{~min}$ and $72^{\circ} \mathrm{C}$ for $1 \mathrm{~min}$. Final elongation for $10 \mathrm{~min}$ at 
$72^{\circ} \mathrm{C}$ completed the protocol. PCR products were visualized by electrophoresis in a $2 \%$ agarose gel at 100V for 45-60 min. Select Qnr positive isolates were subjected to gel extractions and were sent off for Sanger sequencing. Qnr gene abundance was analyzed using Chi-square analysis to determine if there was any significant difference in the absence or presence of qnr genes.

\subsection{Minimum Inhibitory Concentrations of Nalidixic Acid and Ciprofloxacin}

Levels of quinolone resistance of the $\mathrm{Cip}^{\mathrm{R}}$ bacterial isolates were determined by minimum inhibitory concentration (MIC) susceptibility testing. Both qnr-positive and qnr-negative Cip ${ }^{\mathrm{R}}$ isolates were tested. R2A plates were supplemented with either nalidixic acid or ciprofloxacin using a doubling dilution method ranging in concentrations from 10 to $256 \mu \mathrm{g} / \mathrm{mL}$. The minimum concentration of 10 $\mu \mathrm{g} / \mathrm{mL}$ was based on the isolation of Cip ${ }^{\mathrm{R}}$ isolates initially on $10 \mu \mathrm{g} / \mathrm{mL}$ ciprofloxacin plates. ${ }^{129,130} \mathrm{R} 2 \mathrm{~A}$ plates with no antibiotic were used as reference. E. coli DH5 $\alpha$ and P. putida ATCC 12633 were used as reference strains that were known not to exhibit ciprofloxacin resistance. E. coli MM294 was used as a reference strain for nalidixic acid MIC testing due to other controls containing DNA gyrase mutation gyrA96, the gene responsible for its nalidixic acid resistance. ${ }^{131}$

Plates were divided into three different subsets of concentrations for enough bacterial growth across each plate surface. Subsets of plates were: 0,10 and $16 \mu \mathrm{g} / \mathrm{mL} ; 0,32$ and $64 \mu \mathrm{g} / \mathrm{mL}$ and 0,128 and $256 \mu \mathrm{g} / \mathrm{mL}$. A flat-ended toothpick was used to streak a bacterial colony across the different subsets starting from the highest concentration plate. Replicates of seven streaks were performed. All plates were incubated overnight at room temperature. MIC values were recorded as the lowest concentration of quinolone required to inhibit visible growth. ${ }^{129,130}$

\subsection{Qnr Determinant Sequence Alignment}

Positive Qnr determinant sequences for select $\mathrm{Cip}^{\mathrm{S}}$ and $\mathrm{Cip}^{\mathrm{R}}$ isolates were aligned accordingly to discover possible genetic differences between both populations. This was to elucidate possible 
functional properties in sequences that generate higher ciprofloxacin resistance. The use of BLAST alignment with positive $Q n r$ determinants from the NCBI database was used for allelic identity and confidence. 


\subsection{Results}




\subsection{Detection of Ciprofloxacin-Resistant Bacteria in all Sampled Aquatic Sources}

Five diverse aquatic sites were samples and spread plated onto R2A agar with and without ciprofloxacin to determine the total percentage of culturable ciprofloxacin resistant bacteria at each site and to collect both ciprofloxacin resistant and ciprofloxacin sensitive isolates for comparison. Overall, ciprofloxacin resistance was observed in all sampling locations with percentages ranging from 0.12 to $1.62 \%$ of the culturable heterotrophic bacteria except at the Lake Devo site immediately after disinfection (Figure 8 and Table 2). However, after 2 days of use, the Lake Devo site was as heavily contaminated as the other locations. Bacterial counts did not vary significantly between the sediment and water column samples which could be attributed to the different sampling periods.

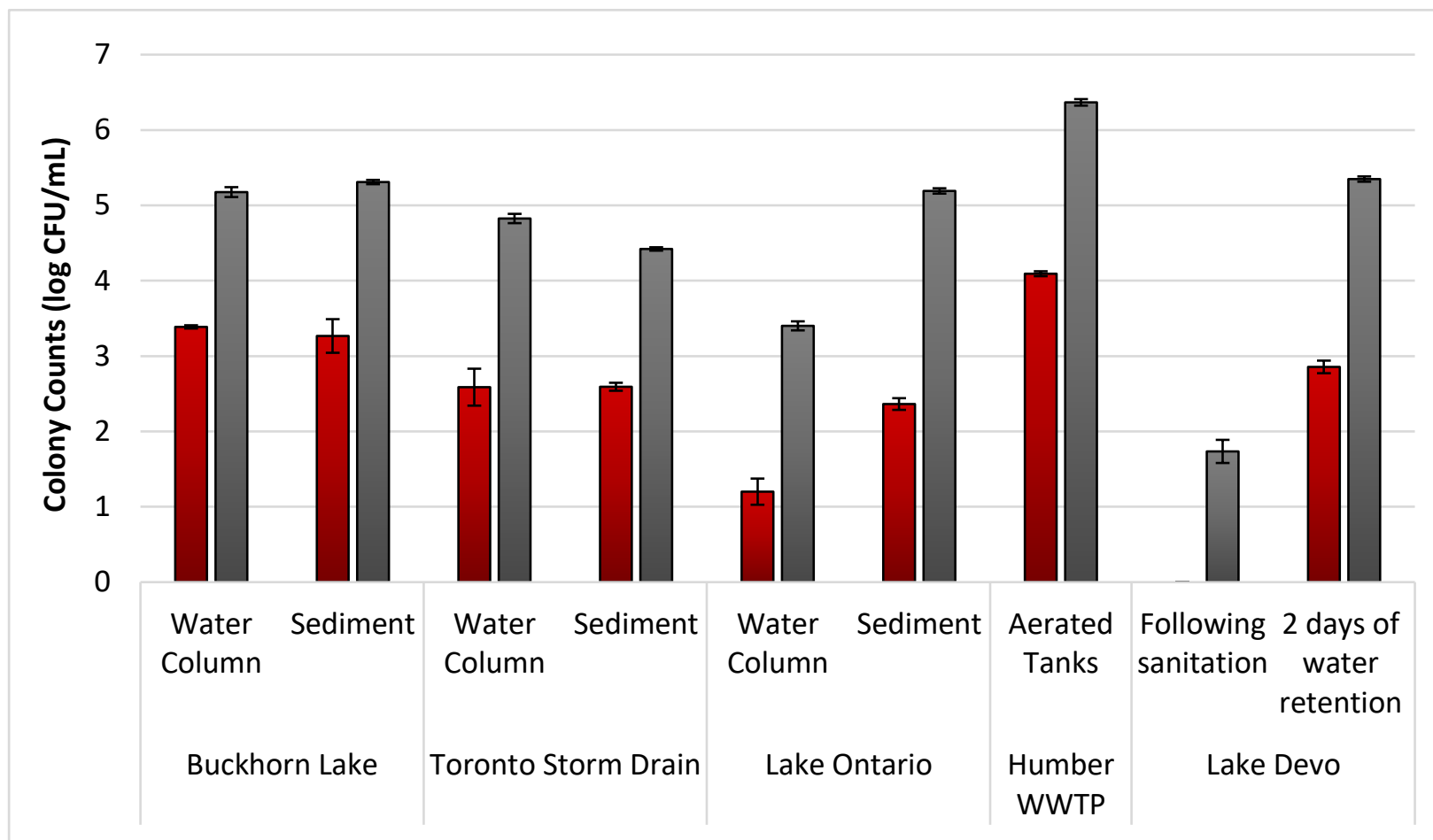

$\square$ Ciprofloxacin-resistant population

$\square$ Total heterotrophic population

Figure 8: Bacterial counts of culturable ciprofloxacin-resistant and total heterotrophic bacterial populations in various aquatic sampling sites 
The Humber WWTP was found to have the highest heterotrophic culturable population count at $2.33 \times 10^{6} \mathrm{CFU} / \mathrm{mL}$, however, did not exhibit the highest ciprofloxacin resistance frequency among all locations at $0.53 \%$. On the other hand, Buckhorn Lake and the Toronto Storm Drain were found to have a higher than expected prevalence of ciprofloxacin-resistant bacteria. Despite having fewer observable human activity/interactions within these areas, they displayed resistance levels above $1 \%$. Observations from this study demonstrate that the environmental ciprofloxacin resistance is comparable between several aquatic locations.

Table 2: Percentage of culturable ciprofloxacin resistance in various aquatic sources

\begin{tabular}{|c|c|c|c|c|}
\hline Sampling site & $\begin{array}{c}\text { Location or Period } \\
\text { Taken }\end{array}$ & $\begin{array}{l}{\text { Average of } \text { Cip }^{\mathrm{R}}}^{\text {population }} \\
\text { (CFU/mL } \pm \mathrm{SD} \text { ) }\end{array}$ & $\begin{array}{c}\text { Average of total } \\
\text { culturable } \\
\text { heterotrophs } \\
\text { (CFU/mL } \pm \text { SD) }\end{array}$ & $\begin{array}{c}\text { Range of } \\
\text { ciprofloxacin } \\
\text { resistance (\%) }\end{array}$ \\
\hline \multirow{2}{*}{ Buckhorn Lake } & Water Column & $2.44 \times 10^{3} \pm 1.2 \times 10^{2}$ & $1.51 \times 10^{5} \pm 2.4 \times 10^{4}$ & $0.39-1.62$ \\
\hline & Sediment & $2.01 \times 10^{3} \pm 9.3 \times 10^{2}$ & $2.04 \times 10^{5} \pm 1.3 \times 10^{4}$ & $0.23-0.98$ \\
\hline \multirow{2}{*}{$\begin{array}{c}\text { Toronto Storm } \\
\text { Drain }\end{array}$} & Water Column & $4.27 \times 10^{2} \pm 2.1 \times 10^{2}$ & $6.73 \times 10^{4} \pm 9.7 \times 10^{3}$ & $0.35-0.63$ \\
\hline & Sediment & $3.93 \times 10^{2} \pm 4.9 \times 10^{1}$ & $2.64 \times 10^{4} \pm 1.4 \times 10^{3}$ & 1.49 \\
\hline \multirow{2}{*}{ Lake Ontario } & Water Column & $1.67 \times 10^{1} \pm 5 \times 10^{0}$ & $2.53 \times 10^{3} \pm 3.5 \times 10^{2}$ & 0.66 \\
\hline & Sediment & $2.33 \times 10^{2} \pm 4.0 \times 10^{1}$ & $1.56 \times 10^{5} \pm 1.3 \times 10^{4}$ & 0.15 \\
\hline Humber WWTP & Aerated Tanks & $1.24 \times 10^{4} \pm 9.5 \times 10^{2}$ & $2.33 \times 10^{6} \pm 2.3 \times 10^{5}$ & $0.12-0.53$ \\
\hline \multirow[b]{2}{*}{ Lake Devo } & Following sanitation & 0 & $5.67 \times 10^{1} \pm 2.0 \times 10^{1}$ & 0 \\
\hline & $\begin{array}{c}2 \text { days of water } \\
\text { retention }\end{array}$ & $7.27 \times 10^{2} \pm 1.4 \times 10^{2}$ & $2.24 \times 10^{5} \pm 1.9 \times 10^{4}$ & 0.32 \\
\hline
\end{tabular}

\subsection{Detection of Multiple Antibiotic Resistance}

One hundred and ninety-nine isolates comprised of both $\mathrm{Cip}^{S}$ isolates (101) and Cip ${ }^{R}$ isolates (98) from all sampling locations were tested for their resistance to an additional 12 antibiotics. The antibiotic resistance profiles of all isolates from each location are displayed in Table 3. The isolates that had initially been selected on $10 \mu \mathrm{g} / \mathrm{mL}$ of ciprofloxacin and therefore constituted the basis of the Cip ${ }^{\mathrm{R}}$ population (100\% ciprofloxacin resistance) demonstrated a higher diversity and abundance of resistance to many of the 12 antibiotics. This can be illustrated in $\mathrm{Cip}^{\mathrm{R}}$ isolates of the Toronto Storm drain site that displayed a $50 \%$ resistance to tetracycline and spectinomycin in contrast to the $0 \%$ resistance of Cip ${ }^{\mathrm{S}}$ 
isolates to the same 2 antibiotics. However, conversely, Cip ${ }^{5}$ isolates in Lake Devo showed a $46 \%$

resistance to kanamycin in comparison to the $\mathrm{Cip}^{\mathrm{R}}$ isolates which only displayed a $7 \%$ resistance. Overall,

the most common resistances observed in all locations regardless of population were ampicillin and

gentamicin. The grand total of all antibiotic resistance profiles shows the ubiquity of ARGs among

different aquatic sources.

Table 3: Antibiotic resistance profiles of $\mathrm{Cip}^{\mathrm{S}}$ and $\mathrm{Cip}^{\mathrm{R}}$ populations among various aquatic sources

\begin{tabular}{|c|c|c|c|c|c|c|c|c|c|c|c|c|c|c|}
\hline \multirow{2}{*}{ Location $^{\mathrm{a}}$} & \multirow{2}{*}{ Resistance } & \multirow{2}{*}{$\begin{array}{l}\text { Sample } \\
\text { Size }\end{array}$} & \multicolumn{12}{|c|}{ Antibiotics resistance $(\%)^{b}$} \\
\hline & & & AMP & TET & CHL & CIP & GEN & KAN & STR & SXT & ERY & VAN & SPT & $\mathrm{PMB}^{\mathrm{c}}$ \\
\hline \multirow{2}{*}{ BL } & $\mathrm{Cip}^{\mathrm{S}}$ & $n=20$ & 60 & 6 & 35 & 0 & 25 & 0 & 15 & 50 & 35 & 35 & 5 & 25 \\
\hline & $\operatorname{Cip}^{R}$ & $n=20$ & 90 & 30 & 75 & 100 & 40 & 25 & 30 & 80 & 70 & 40 & 25 & 55 \\
\hline \multirow{2}{*}{ TS } & $\mathrm{Cip}^{\mathrm{S}}$ & $\mathrm{n}=17$ & 35 & 0 & 6 & 0 & 65 & 47 & 41 & 18 & 38 & 50 & 0 & 63 \\
\hline & $\mathrm{Cip}^{\mathrm{R}}$ & $n=18$ & 89 & 50 & 56 & 100 & 100 & 89 & 83 & 50 & 56 & 83 & 50 & 100 \\
\hline \multirow{2}{*}{ LO } & $\mathrm{Cip}^{\mathrm{S}}$ & $n=26$ & 31 & 0 & 4 & 0 & 69 & 19 & 12 & 15 & 12 & 16 & 4 & 64 \\
\hline & $\mathrm{Cip}^{\mathrm{R}}$ & $n=19$ & 58 & 5 & 21 & 100 & 89 & 32 & 47 & 26 & 21 & 32 & 16 & 95 \\
\hline \multirow{2}{*}{ HW } & $\mathrm{Cip}^{\mathrm{s}}$ & $\mathrm{n}=25$ & 40 & 10 & 12 & 0 & 64 & 32 & 16 & 20 & 44 & 20 & 12 & 60 \\
\hline & $\mathrm{Cip}^{\mathrm{R}}$ & $n=26$ & 69 & 58 & 54 & 100 & 77 & 77 & 69 & 69 & 85 & 85 & 54 & 100 \\
\hline \multirow{2}{*}{ LD } & $\mathrm{Cip}^{\mathrm{S}}$ & $n=13$ & 31 & 8 & 8 & 0 & 69 & 46 & 8 & 8 & 31 & 31 & 23 & 54 \\
\hline & $\mathrm{Cip}^{\mathrm{R}}$ & $n=15$ & 33 & 7 & 13 & 100 & 67 & 7 & 53 & 47 & 20 & 20 & 13 & 100 \\
\hline \multirow{2}{*}{ Total } & $\mathrm{Cip}^{\mathrm{s}}$ & $n=101$ & 40 & 4 & 13 & 0 & 58 & 27 & 18 & 23 & 31 & 28 & 8 & 54 \\
\hline & $\mathrm{Cip}^{R}$ & $n=98$ & 69 & 33 & 46 & 100 & 74 & 49 & 57 & 56 & 54 & 55 & 34 & 90 \\
\hline \multicolumn{2}{|c|}{ Grand Total } & $\mathrm{n}=199$ & 54 & 19 & 29 & 51 & 66 & 38 & 37 & 39 & 43 & 42 & 21 & 72 \\
\hline
\end{tabular}

a BL = Buckhorn Lake, TS = Toronto Storm Drain, LO = Lake Ontario, HW = Humber WWTP, LD = Lake Devo

${ }^{\mathrm{b}} \mathrm{AMP}=$ ampicillin, $\mathrm{TET}=$ tetracycline, $\mathrm{CHL}=$ chloramphenicol, $\mathrm{CIP}=$ ciprofloxacin, $\mathrm{GEN}=$ gentamicin, $\mathrm{KAN}=$ kanamycin, $\mathrm{STR}=$ streptomycin, SXT = sulfamethoxazole-trimethoprim, ERY = erythromycin, VAN = vancomycin, $\mathrm{SPT}=$ spectinomycin, $\mathrm{PMB}=$ polymyxin B

${ }^{\mathrm{C}}$ Additional testing for polymyxin $\mathrm{B}$ resistance need to be done for confirmation

To compare multiple antibiotic resistance between populations and sites, MAR and ARI scores

were calculated for each sampled location (Table 4). In this study, all aquatic sources showed MAR

scores of $40 \%$ or higher. Comparing the distribution of MAR scores, $\mathrm{Cip}^{\mathrm{s}}$ isolates were less likely to have

3 or more resistances (40 to $69 \%$ ) in contrast to $\mathrm{Cip}^{\mathrm{R}}$ isolates with scores above $95 \%$. In all locations,

$100 \%$ of $\mathrm{Cip}^{\mathrm{R}}$ isolates exhibited at least 2 antibiotic resistances. The increased prevalence of resistance

determinants in $\mathrm{Cip}^{\mathrm{R}}$ populations could be due to the initial antibiotic selection of ciprofloxacin

suggesting co-selection of other resistances. Isolates from all locations were resistant to 11 of the 
antibiotics tested while $10 \%$ of Buckhorn Lake isolates, $39 \%$ of Toronto Storm Drain isolates and $46 \%$ of Humber WWTP isolates showed resistance to all 12 antibiotics tested. On the other hand, none of the $\mathrm{Cip}^{\mathrm{S}}$ isolates displayed resistance to more than 8 antibiotics. In addition, $12-20 \%$ of the isolates from the Cip ${ }^{S}$ populations at all locations were found to be susceptible to all tested antibiotics.

ARI scores between $\mathrm{Cip}^{S}$ and $\mathrm{Cip}^{\mathrm{R}}$ populations also differed greatly with $\mathrm{Cip}^{\mathrm{R}}$ isolates demonstrating up to 2.3 times higher values than the $\mathrm{Cip}^{\mathrm{S}}$ isolates (Table 4). Higher ARI scores align with higher MAR scores confirming that $\mathrm{Cip}^{\mathrm{R}}$ isolates were likely to contain additional resistant determinants. The Humber WWTP and Toronto Storm Drain displayed the highest ARI scores of 0.75 and 0.74 respectively. Interestingly, Lake Devo showed a higher abundance of resistant determinants than Lake Ontario. Highly resistant phenotypes among isolates suggests a higher risk of ineffectiveness of multiple antibiotic therapy.

Table 4: Cumulative antibiotic resistance distribution of $\mathrm{Cip}^{\mathrm{S}}$ and $\mathrm{Cip}^{\mathrm{R}}$ isolates tested against 12 antibiotics

\begin{tabular}{|c|c|c|c|c|c|c|c|c|c|c|c|c|c|c|}
\hline \multirow{2}{*}{ Source } & \multirow{2}{*}{ ARI index } & \multicolumn{13}{|c|}{ Isolates found resistant to multiple different antibiotics (\%) } \\
\hline & & 0 & 1 & 2 & 3 (MAR Score) & 4 & 5 & 6 & 7 & 8 & 9 & 10 & 11 & 12 \\
\hline BL - Cips & 0.24 & 20 & 80 & 55 & 40 & 40 & 35 & 20 & 15 & 5 & 0 & 0 & 0 & 0 \\
\hline BL - Cip ${ }^{R}$ & 0.55 & 0 & 100 & 100 & 95 & 90 & 80 & 70 & 35 & 30 & 25 & 15 & 10 & 10 \\
\hline TS - Cips & 0.31 & 18 & 82 & 76 & 65 & 65 & 47 & 35 & 6 & 0 & 0 & 0 & 0 & 0 \\
\hline TS - Cip ${ }^{R}$ & 0.75 & 0 & 100 & 100 & 100 & 94 & 89 & 89 & 89 & 56 & 50 & 50 & 50 & 39 \\
\hline LO - Cip & 0.22 & 12 & 88 & 73 & 54 & 27 & 12 & 4 & 4 & 0 & 0 & 0 & 0 & 0 \\
\hline LO - Cip ${ }^{R}$ & 0.45 & 0 & 100 & 100 & 100 & 63 & 58 & 47 & 37 & 16 & 11 & 5 & 5 & 0 \\
\hline HW - Cip & 0.28 & 12 & 88 & 68 & 60 & 56 & 32 & 16 & 8 & 4 & 0 & 0 & 0 & 0 \\
\hline$H W-C^{R}{ }^{R}$ & 0.74 & 0 & 100 & 100 & 100 & 96 & 96 & 81 & 73 & 58 & 50 & 46 & 46 & 46 \\
\hline LD - Cip ${ }^{\mathrm{s}}$ & 0.27 & 15 & 85 & 77 & 69 & 46 & 31 & 15 & 0 & 0 & 0 & 0 & 0 & 0 \\
\hline LD - Cip ${ }^{R}$ & 0.40 & 0 & 100 & 100 & 93 & 80 & 40 & 20 & 13 & 13 & 7 & 7 & 7 & 0 \\
\hline Cip $^{s}$ Total & 0.26 & 15 & 85 & 69 & 56 & 46 & 30 & 17 & 7 & 2 & 0 & 0 & 0 & 0 \\
\hline Cip $^{R}$ Total & 0.60 & 0 & 100 & 100 & 98 & 86 & 76 & 64 & 52 & 37 & 31 & 27 & 26 & 21 \\
\hline
\end{tabular}




\subsubsection{Weka Analysis of Antibiotic Resistance}

To detect any observable associations of different antibiotic resistances co-occurring together, an Apriori algorithm was performed using the Weka software. Antibiotic resistance relationships was outputted to determine the probability of certain antibiotic resistance co-selection being carried together. Comparison of relationships was performed on the total population, the $\mathrm{Cip}^{\mathrm{S}}$ population and the $\mathrm{Cip}^{\mathrm{R}}$ population with the best three associations reported of at least $95 \%$ confidence. Among the 199 isolates tested for antibiotic resistance associations (Appendix 3 ) it was found that: a) if isolates were resistant to kanamycin and streptomycin then they were most likely resistant to gentamicin, b) if isolates were resistant to ciprofloxacin and kanamycin then they were most likely resistant to gentamicin, and c) if isolates were resistant to kanamycin, streptomycin and erythromycin then they were most likely resistant to gentamicin. Of the $101 \mathrm{Cip}^{\mathrm{s}}$ isolates tested for associations (Appendix 4), similar patterns was found that if they were: a) resistant to kanamycin then they were most likely resistant to gentamicin, b) if they were resistant to kanamycin and streptomycin then they were most likely resistant to gentamicin and, c) if they were resistant to kanamycin and erythromycin then they were most likely resistant to gentamicin. Lastly among the $98 \mathrm{Cip}^{R}$ isolates tested for associations there were numerous instances for 2 or more resistances coinciding together (Appendix 5). They were: a) if isolates were resistant to ciprofloxacin, chloramphenicol and sulfamethoxazole-trimethoprim then they were most likely resistant to ampicillin, b) if isolates were resistant to ciprofloxacin, ampicillin and streptomycin then they were most likely resistant to gentamicin and c) if isolates were resistant to ciprofloxacin, ampicillin and sulfamethoxazole-trimethoprim then they were most likely resistant to erythromycin.

\subsection{Taxonomic Composition of Cip ${ }^{S}$ and Cip ${ }^{R}$ Isolates from all Aquatic Sources}

Analysis of the 16S rRNA gene sequence from bacterial DNA extractions aided in identifying 184 culturable isolates, among which 104 isolates were $\mathrm{Cip}^{\mathrm{S}}$ and 80 isolates were Cip ${ }^{\mathrm{R}}$. Table 5 displays the 
genus identity distribution of all sampling locations. From the identified isolates, over $50 \%$ of isolates were from the phylum Proteobacteria (94 isolates) including the most abundant genera, Brevundimonas, Aeromonas and Pseudomonas. Five other bacterial phyla were identified with Bacteroidetes (52 isolates), Firmicutes (19 isolates), Actinobacteria (16 isolates), Deinococcus-Thermus (2 isolates) and lastly Verrucomicrobia (1 isolate) (Appendix 6). Within the phylum Proteobacteria, $\mathrm{Cip}^{\mathrm{s}}$ isolates (40) were most identified within the bacterial class gamma-proteobacteria being the most numerous while the $\mathrm{Cip}^{\mathrm{R}}$ isolates (27) were mostly of the alpha-proteobacteria class. The most abundant Cip ${ }^{R}$ isolates belong to the genus Brevundimonas (18.8\%) and Sphingobacterium (11.3\%), are pathogenic and opportunistic bacteria respectively. The most abundant $\mathrm{Cip}^{\mathrm{S}}$ isolates belong to the genus Flavobacterium (12.5\%) and Aeromonas (10.6\%) both of which have can be found naturally in aquatic sources. Interestingly not one genus was observed in every sampling location. Abundantly as well, $52.7 \%$ of all isolates considered to be potential human pathogens belonged to Proteobacteria. Overall, $80.3 \%$ of isolates were classified as Gram-negative whereas $19.7 \%$ of isolates were Gram-positive (Appendix 7). 
Table 5: Isolate identification and distribution of each phylum, class and genera among all aquatic sources

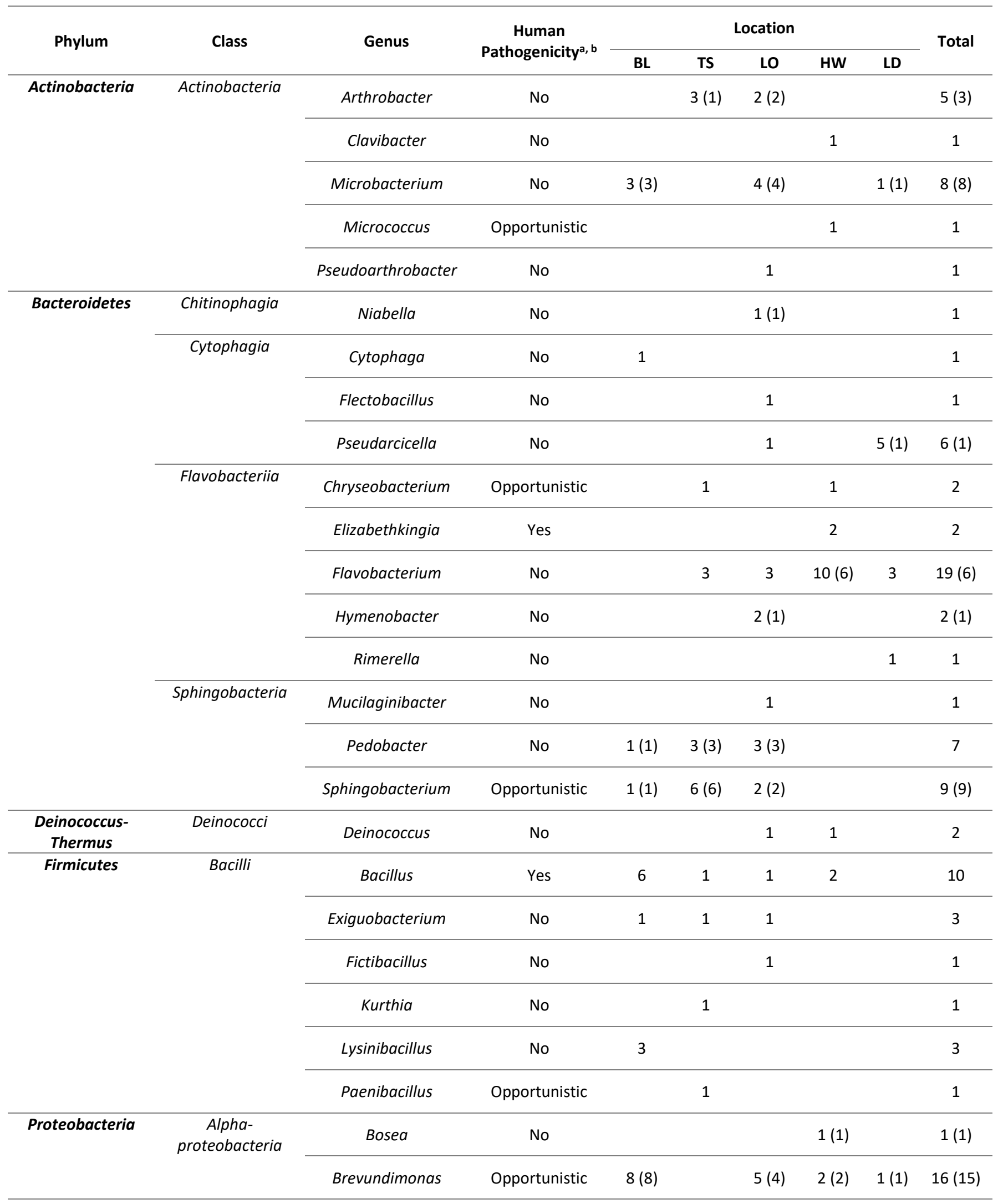




\begin{tabular}{|c|c|c|c|c|c|c|c|c|c|}
\hline & & Caulobacter & No & & & $1(1)$ & & $4(4)$ & $5(5)$ \\
\hline & & Novosphingobium & Yes & & & & & $6(6)$ & $6(6)$ \\
\hline & & Paracoccus & Opportunistic & & & & 1 & & 1 \\
\hline & & Rhodobacter & No & & & 1 & & & 1 \\
\hline & & Delftia & No & & 1 & & & & 1 \\
\hline & & Leptothrix & No & & & 1 & & & 1 \\
\hline & & Massilia & No & & & 1 & & 2 & 3 \\
\hline & & Roseateles & No & & & & & 3 & 3 \\
\hline & $\begin{array}{c}\text { Gamma- } \\
\text { proteobacteria }\end{array}$ & Acinetobacter & Yes & & 1 & & $3(1)$ & & $4(1)$ \\
\hline & & Aeromonas & Yes & & 1 & 3 & $9(2)$ & $1(1)$ & $14(3)$ \\
\hline & & Cedecea & No & & 1 & & & & 1 \\
\hline & & Citrobacter & Opportunistic & & & & 1 & & 1 \\
\hline & & Escherichia & Yes & & 1 & & $5(5)$ & & $6(5)$ \\
\hline & & Raoultella & No & & 1 & & & & 1 \\
\hline & & Serratia & Opportunistic & & & 1 & 1 & 2 & 4 \\
\hline & & Shewanella & No & & 1 & & & & 1 \\
\hline & & Stenotrophomonas & Opportunistic & $3(3)$ & $1(1)$ & & & & $4(4)$ \\
\hline & & Yersinia & Yes & 1 & & 1 & & & 2 \\
\hline Verrucomicrobia & Verrucomicrobiae & Verrucomicrobium & No & & & & $1(1)$ & & $1(1)$ \\
\hline \multicolumn{4}{|c|}{ Total } & $\begin{array}{c}36 \\
(17)\end{array}$ & $\begin{array}{c}29 \\
(11)\end{array}$ & $\begin{array}{c}45 \\
(18)\end{array}$ & $\begin{array}{c}45 \\
(20)\end{array}$ & $\begin{array}{c}29 \\
(14)\end{array}$ & $\begin{array}{l}184 \\
(80)\end{array}$ \\
\hline
\end{tabular}

Note: Values in brackets indicate the number of isolates that were ciprofloxacin resistant

a Human pathogenicity is defined as the ability to cause disease in humans (Yes), this column may still contain animal and plant pathogens

b Opportunistic pathogens are designated by some genera that cause human infections if the host is comprised 
In total, 51 different genera were identified, 9 of which are found in both $\mathrm{Cip}^{\mathrm{S}}$ and $\mathrm{Cip}^{\mathrm{R}}$ populations (Figure 9). These 9 genera pre-dominantly were Gram-negative except for Arthrobacter. Among these shared genera, 5 out 9 were potential pathogens including Acinetobacter, Escherichia and Klebsiella being part of the ESKAPE nosocomial pathogen group. The potential threat and dissemination of resistance determinants increases between the passage of common bacteria suggested by high Cip $^{R}$ Brevundimonas bacterial counts. Uniquely, 31 different genera were only observed in the Cip ${ }^{\text {s }}$ population whereas 11 genera were only found in the $\mathrm{Cip}^{R}$ population. This displays a difference in genera diversity and richness between the two populations which is calculated in Table 6 . The Cip population demonstrated a significantly higher genera diversity and genera richness through the Shannon diversity index. Comparison of similarities between bacterial communities, the Sorenson coefficient of 0.3 illustrates that both $\mathrm{Cip}^{S}$ and $\mathrm{Cip}^{\mathrm{R}}$ populations are relatively distinct with very little genera overlap.

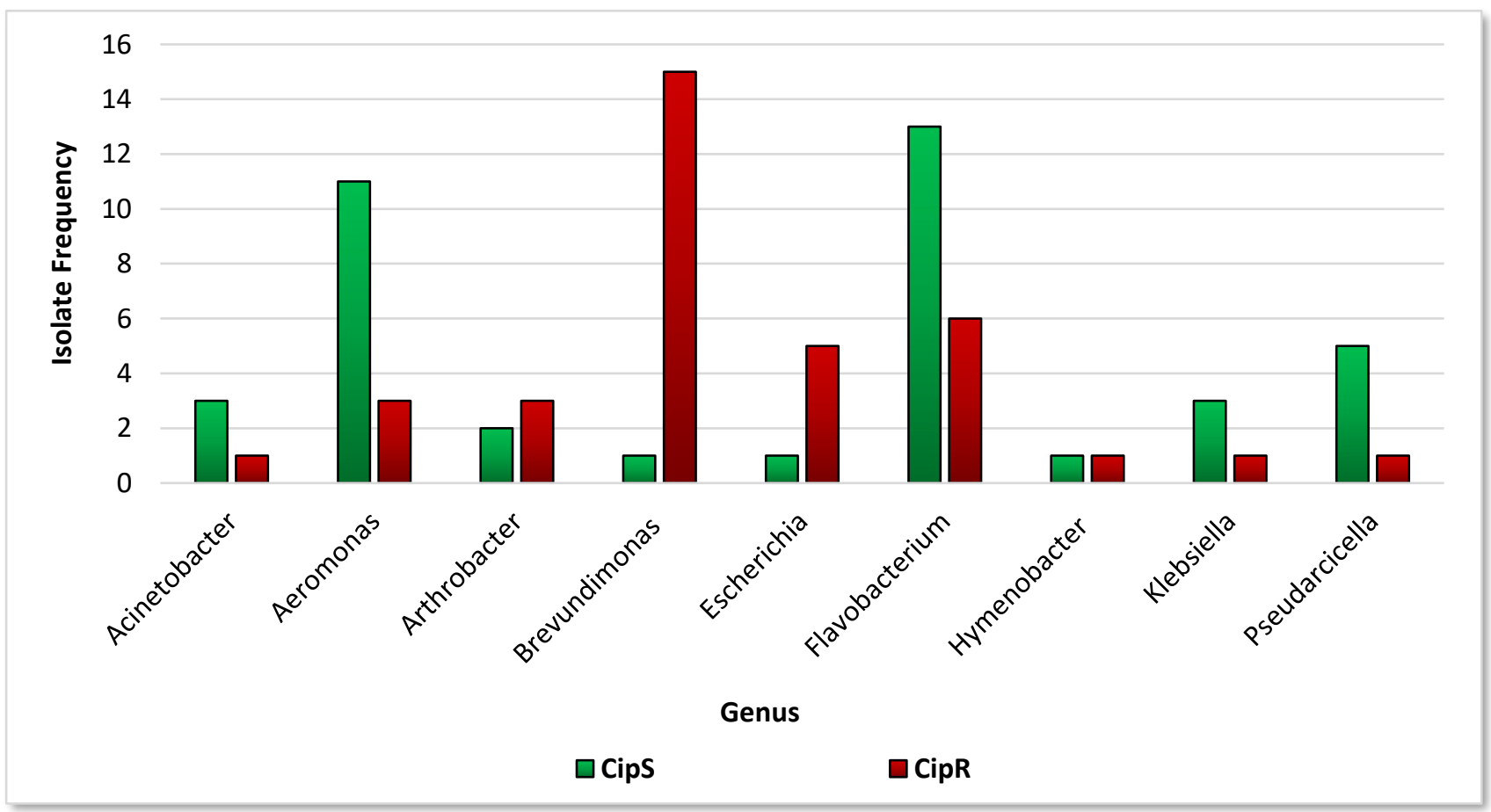

Figure 9: Shared genera among both $\mathrm{Cip}^{\mathrm{S}}$ and $\mathrm{Cip}^{\mathrm{R}}$ populations in all sampled aquatic sources 
Table 6: Ecological metrics of $\mathrm{Cip}^{S}$ and $\mathrm{Cip}^{\mathrm{R}}$ genera diversity

\begin{tabular}{|c|c|c|}
\hline & Cip $^{\text {S }}$ & Cip $^{\mathbf{R}}$ \\
\hline Isolate total (N) & 104 & 80 \\
\hline \# of genera & 40 & 20 \\
\hline Shannon Diversity index (H) & 3.26 & 2.63 \\
\hline Genera richness (S) & 3.69 & 3.00 \\
\hline Sorenson Co-efficient (SC) & \multicolumn{2}{|c|}{} \\
\hline
\end{tabular}

\subsection{Qnr prevalence observed in Cip ${ }^{S}$ and $C_{i p}^{R}$ populations}

The ciprofloxacin-resistant determinants in the $\mathrm{Cip}^{\mathrm{R}}$ population were screened for the prevalence of the PMQR gene qnr through a multiplex PCR. Qnr variants $q n r A$, $q n r B$ and $q n r S$ were targeted to elucidate possible resistance mechanism to ciprofloxacin and to observe the overall prevalence of these genes. The literature suggests that ciprofloxacin resistance in ciprofloxacin-resistant bacteria is highly correlated with detection of qnr genes. All 202 isolates were screened for the $q n r$ genes and it was found that $33.2 \%$ isolates contained at least one of the genes. Although many were in the $\mathrm{Cip}^{\mathrm{R}}$ isolates, interestingly, many of the $\mathrm{Cip}^{\mathrm{S}}$ isolates also screened positive for one of the qnr genes. Initially, screening of the $\mathrm{Cip}^{\mathrm{s}}$ population was to serve as a negative control as no qnr genes were expected to be detected. Complete screening of all qnr-positive isolates can be viewed in Appendix 8 . Figure 10 displays the $q n r$ prevalence in both $\mathrm{Cip}^{S}$ and $\mathrm{Cip}^{\mathrm{R}}$ populations where isolates contained at least one $q n r$ gene. Comparably, $14.36 \%$ (29 isolates) and $18.81 \%$ (38 isolates) of Cip ${ }^{S} \&$ Cip $^{R}$ populations respectively contained at least one qnr gene. A Chi-square test of independence was performed to see if the $q n r$ presence were correlated with ciprofloxacin resistance. The Chi-square test with 1 degree of freedom produced a critical value of 3.03 with a P-value of 0.08 . The statistic fails to reject the null hypothesis that qnr presence was depended on ciprofloxacin pressure. Therefore, the qnr genes in the $\mathrm{Cip}^{\mathrm{S}}$ isolates suggest that the gene may be present but not active and that these genes can not be used 
as positive markers for ciprofloxacin resistance. Consequently, potential qnr gene reservoirs may be present in both $\mathrm{Cip}^{S}$ and $\mathrm{Cip}^{\mathrm{R}}$ populations and allow for possible dissemination of those genes.

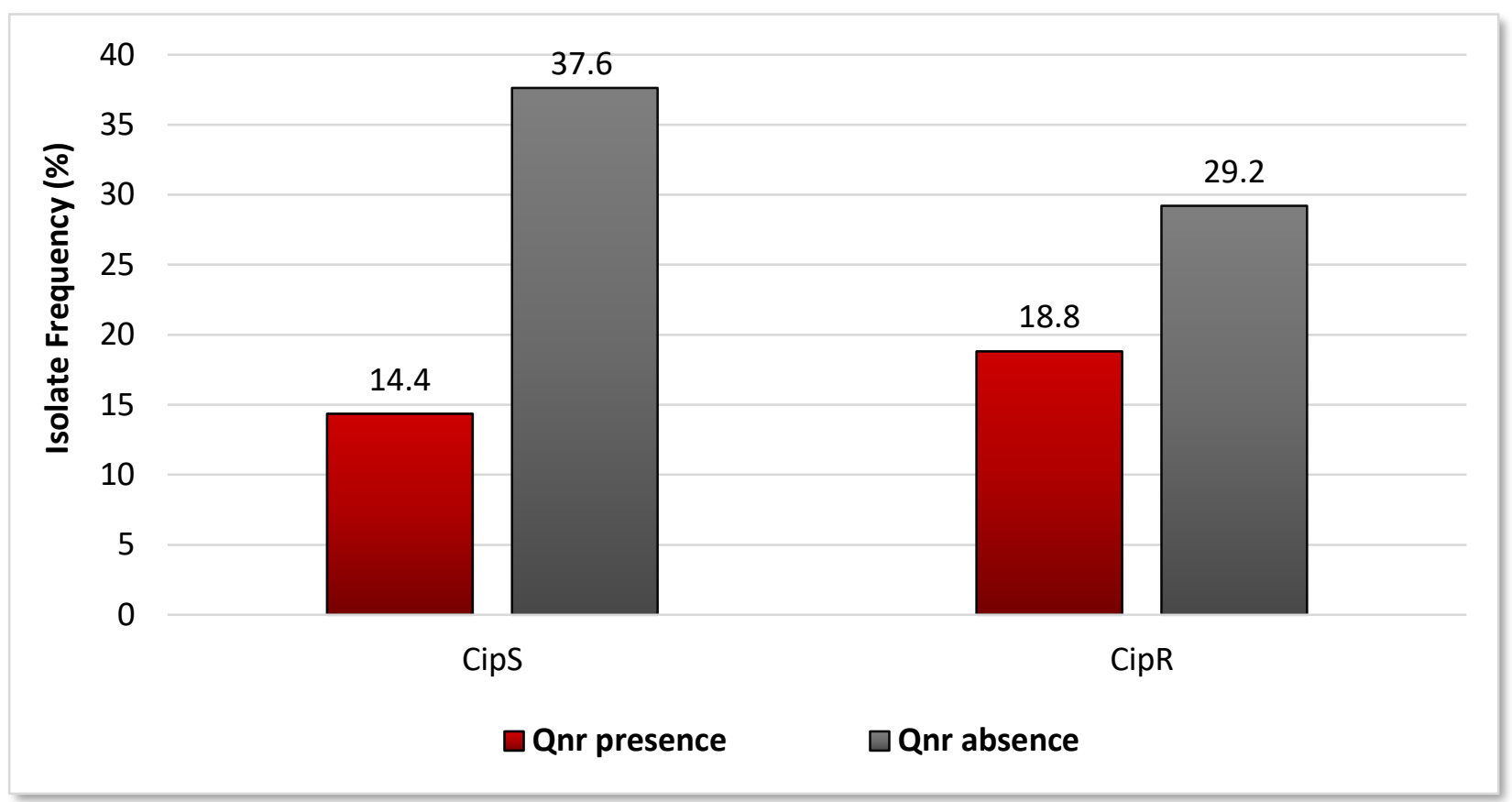

Figure 10: Prevalence of qnr genes in $\mathrm{Cip}^{S}$ and $\mathrm{Cip}^{\mathrm{R}}$ populations

Through gel electrophoresis of all multiplex PCR products, differentiation between specific qnr genes could be observed. Figure 11 illustrates the occurrence and prevalence of the qnr genes in the $\mathrm{Cip}^{\mathrm{S}}$ and $\mathrm{Cip}^{\mathrm{R}}$ populations. Overall, the most prevalent gene observed was qnrS at $19.3 \%$ with qnrA and qnrB at approximately 15\%. Among the 67 qnr-positive isolates, $56.7 \%$ displayed one $q n r$ gene whereas 43.3\% contained at least 2 or more qnr genes. QnrB presence was predominantly observed in the Cip ${ }^{S}$ qnr-positive isolates with Pseudomonas, Aeromonas, Yersinia being the majority with 13 other genera. In the $\mathrm{Cip}^{\mathrm{R}}$ qnr-positive isolates, the qnrS prevalence was largely seen in Brevundimonas, Stenotrophomonas and Aeromonas isolates with subsequent 11 other genera. Only Aeromonas and Klebsiella genera were observed to be qnr-positive and present in both $\mathrm{Cip}^{\mathrm{S}}$ and $\mathrm{Cip}^{\mathrm{R}}$ populations. 


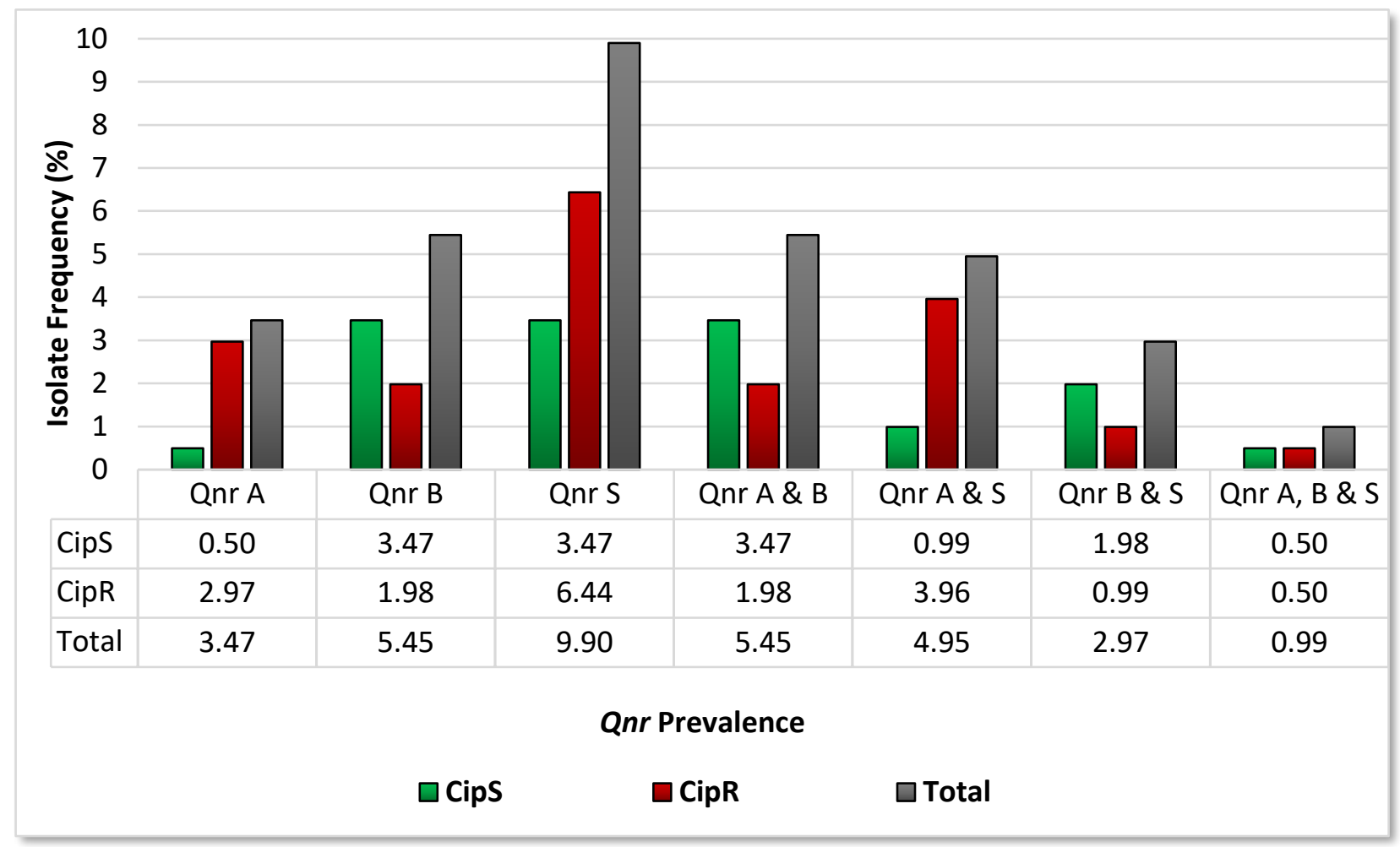

Figure 11: Qnr gene distribution and abundance of qnr-positive isolates

\subsubsection{Qnr Prevalence by Sampling Area}

Total qnr distribution by sampling location can depict potential hotspots of qnr gene reservoirs in aquatic communities. Isolate frequency of qnr presence and absence in all sampled locations can be observed in Figure 12. Buckhorn Lake and Humber WWTP had the highest prevalence of qnr genes at $11.39 \%$ and $8.91 \%$ respectively. Comparing specific $q n r$ gene frequencies in $q n r$-positive isolates, qnrS frequency was observed mostly in Toronto Storm Drain, Humber WWTP and Lake Devo. Buckhorn encompassed higher qnrA genes and Lake Ontario contained an even amount of all three qnr genes. Chisquare statistical analysis was performed to determine if sampling locations had an influence on qnr distribution. The null hypothesis for this premise was to observe whether qnr gene presence or absence was independent of the sampling location. A chi-square critical value of 17.38 with 4 degrees of freedom produced a P-value of 0.0016 , rejecting the null hypothesis. This suggests that there is a relationship between qnr presence and sampling location, but it could not be attributed to a single variable or factor. 
Factors such as human activity, environmental contaminants and/or presence of higher organisms within these aquatic sources may contribute to this differential relationship. Nonetheless, certain aquatic locations may promote $q n r$ gene reservoirs and further attribute to ARG prevalence and dissemination.

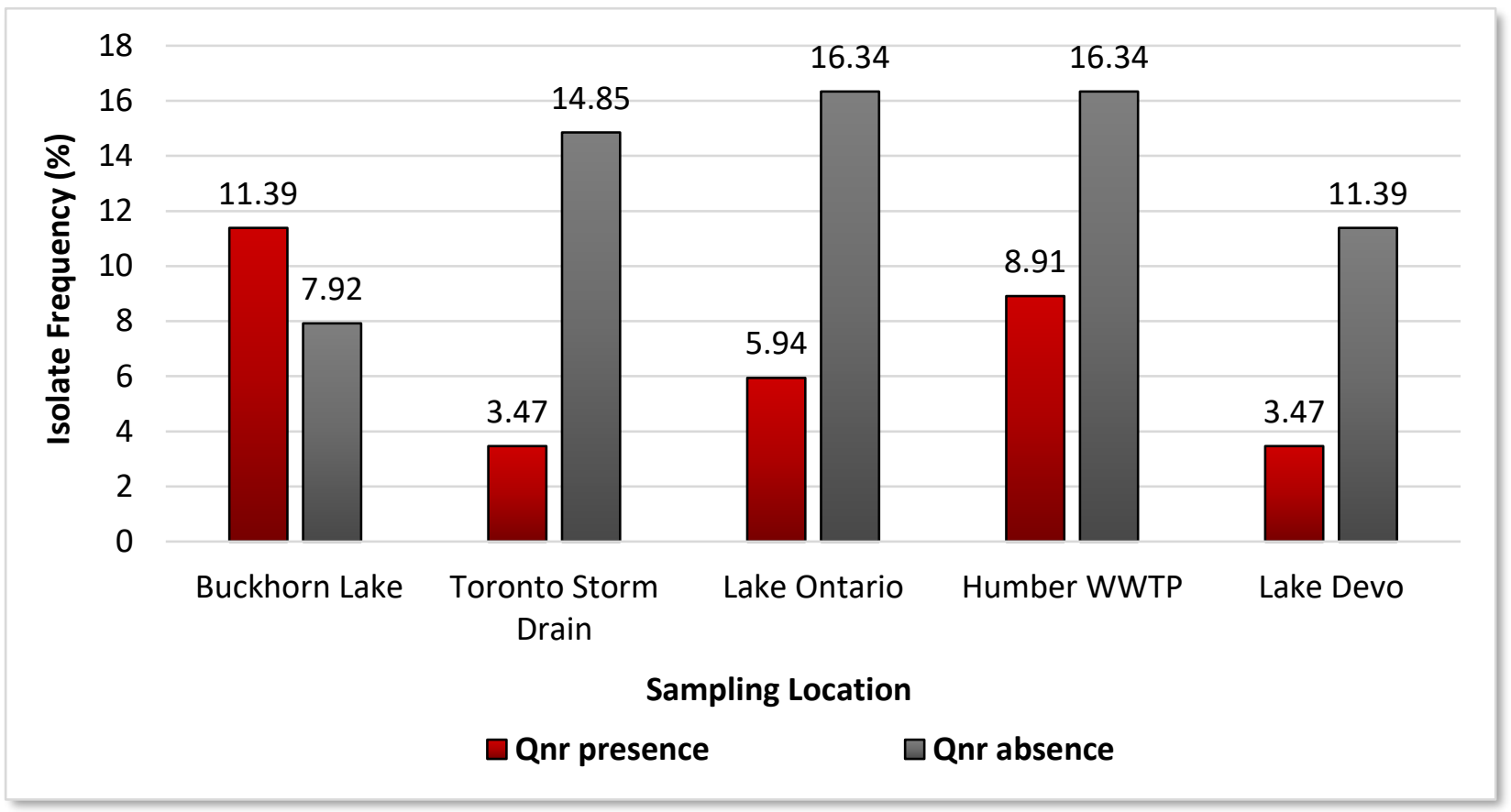

Figure 12: Prevalence of qnr genes in all sampled aquatic sources

\subsection{MIC Level of Ciprofloxacin and Nalidixic Acid}

MIC susceptibility testing to ciprofloxacin was performed to examine the degrees of resistance in comparison to first-generation quinolone, nalidixic acid. 104 isolates were tested, which 90 were $\mathrm{Cip}^{\mathrm{R}}$ and 14 were $\mathrm{Cip}^{\mathrm{S}}$, against varying concentration of both antibiotics. Cip ${ }^{\mathrm{S}}$ isolates were tested primarily on nalidixic acid as preliminary ciprofloxacin streak plating exhibited a MIC value below $10 \mu \mathrm{g} / \mathrm{mL}$. Figure 13 demonstrates the varying resistance levels observed in $\mathrm{Cip}^{\mathrm{R}}$ isolates to nalidixic acid and ciprofloxacin. Ciprofloxacin MIC values below $16 \mu \mathrm{g} / \mathrm{mL}$ were not displayed as all isolates showed resistance at this concentration during initial plating. Samples that grew on all tested concentrations of quinolone antibiotics were categorized as above $256 \mu \mathrm{g} / \mathrm{mL}$. Twenty-seven isolates exhibited resistance 
to both antibiotics at a very high level (>256 $\mu \mathrm{g} / \mathrm{mL}$ ). The isolate MIC distribution of nalidixic acid existed on the extreme ends of resistance $(\geq 128 \mu \mathrm{g} / \mathrm{mL})$ as $86.7 \%$ of tested isolate presented with this phenotype. In comparison, ciprofloxacin MIC values showed a wider phenotype distribution of the extreme resistance at $62.2 \%$ of isolates.

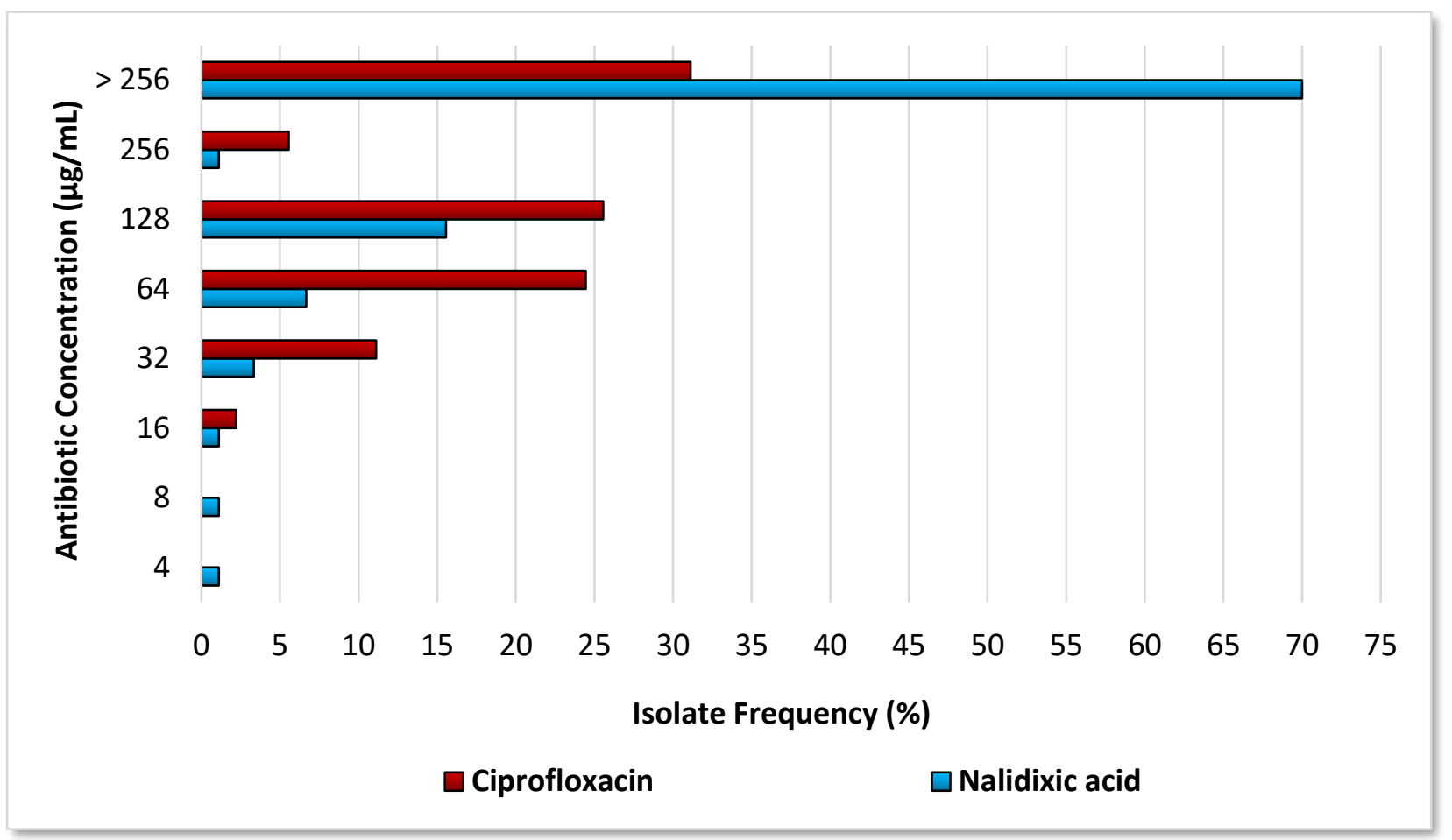

Figure 13: Degree of resistance to nalidixic acid and ciprofloxacin in Cip ${ }^{R}$ isolates

It was noted that the isolates that displayed low resistance to nalidixic acid and ciprofloxacin as opposed to high resistance constituted different in genera diversity. Low levels of resistance to both nalidixic acid and ciprofloxacin $(\leq 32 \mu \mathrm{g} / \mathrm{mL}$ ) were found in cultures of Arthrobacter, Novosphingobium, Aeromonas, Pseudarciciella, Flavobacterium or Pedobacter. Inversely, isolates that displayed high MIC levels of both nalidixic acid and ciprofloxacin $(\geq 256 \mu \mathrm{g} / \mathrm{mL}$ ) included a wide array of bacteria including Sphingobacterium, Pedobacter, Cytophaga, Bacillus, Aeromonas, Verrucomicrobium, Escherichia, Klebsiella, Acinetobacter, Stenotrophomonas and Brevundimonas. Twelve unidentifiable Cip ${ }^{R}$ isolates also demonstrated the same high level of resistance to both antibiotics. In particular, Brevundimonas isolates showed complete resistance to nalidixic acid at $\geq 256 \mu \mathrm{g} / \mathrm{mL}$ with a broad range of ciprofloxacin 
resistance between 32 to $128 \mu \mathrm{g} / \mathrm{mL}$. A majority of Cips isolates presented with no resistance to ciprofloxacin and with MIC levels of 2 to $8 \mu \mathrm{g} / \mathrm{mL}$ of nalidixic acid. Five Cip ${ }^{\mathrm{s}}$ isolates (E3, E16, E18, E30, R7) demonstrated no resistance to ciprofloxacin but had high levels of nalidixic acid above $32 \mu \mathrm{g} / \mathrm{mL}$. Overall, quinolone resistance, especially to ciprofloxacin, appeared to be prevalent at high resistance levels in many bacterial genera.

Table 7: Nalidixic acid MIC distribution in Cip ${ }^{\mathrm{R}}$ isolates with or without qnr genes

\begin{tabular}{cccccc}
\hline \multirow{2}{*}{ Qnr Genes } & \multirow{2}{*}{ Sample Size } & \multicolumn{4}{c}{ Nalidixic acid MIC $(\mu \mathrm{g} / \mathrm{mL})$} \\
\cline { 3 - 5 } & & $\leq 32$ & 64 & 128 & $\geq 256$ \\
\hline Present & $\mathrm{n}=34$ & $8.82 \%$ & $2.94 \%$ & $11.76 \%$ & $76.47 \%$ \\
\hline Absent & $\mathrm{n}=56$ & $5.36 \%$ & $8.93 \%$ & $17.86 \%$ & $67.86 \%$ \\
\hline Total & $\mathrm{n}=90$ & $6.67 \%$ & $6.67 \%$ & $15.56 \%$ & $71.11 \%$ \\
\hline
\end{tabular}

Table 8: Ciprofloxacin MIC distribution in Cip ${ }^{\mathrm{R}}$ isolates with or without qnr genes

\begin{tabular}{|c|c|c|c|c|c|}
\hline \multirow{2}{*}{ Qnr Genes } & \multirow{2}{*}{ Sample Size } & \multicolumn{4}{|c|}{ Ciprofloxacin MIC ( $\mu \mathrm{g} / \mathrm{mL})$} \\
\hline & & $\leq 32$ & 64 & 128 & $\geq 256$ \\
\hline Present & $\mathrm{n}=34$ & $5.88 \%$ & $26.47 \%$ & $29.41 \%$ & $38.24 \%$ \\
\hline Absent & $n=56$ & $17.86 \%$ & $23.21 \%$ & $23.21 \%$ & $35.71 \%$ \\
\hline Total & $\mathrm{n}=90$ & $13.33 \%$ & $24.44 \%$ & $25.56 \%$ & $36.67 \%$ \\
\hline
\end{tabular}

To observe the influence of $q n r$ genes on MIC, qnr-positive and qnr-negative isolates were compared. Cip ${ }^{R}$ isolates that contained at least 1 or more $q n r$ genes ( $q n r$-positive) were categorized to reveal MIC trends to nalidixic acid and ciprofloxacin in Table 7 and 8 respectively. Within this study, the influence of qnr genes did not significantly impact at the tested MIC levels of either antibiotic with similar percentages observed in both qnr presence and absence. Cip ${ }^{R}$ isolates with no qnr genes (qnrnegative) still demonstrated high resistance which can be attributed to other quinolone mechanisms at play. Among isolates that did carry a qnr gene predominantly displayed at least a two-fold change within MIC levels when compared from ciprofloxacin to nalidixic acid. For example, isolate BHWC8 identified as 
Brevundimonas containing qnrA and qnrS showed a 16-fold increase of MIC from nalidixic acid to ciprofloxacin. Two instances of qnr-positive isolates did show a decrease of MIC with qnrA. Overall, Cip ${ }^{R}$ isolates that were qnr-positive and highly resistant to both antibiotics ( $\geq 256 \mu \mathrm{g} / \mathrm{mL}$ ) were more likely to show qnrS and other qnr genes. One unidentifiable bacterium, F12, contained all three qnr genes.

\subsection{Qnr Sequences between $\mathrm{Cip}^{S}$ and $\mathrm{Cip}^{\mathrm{R}}$ Isolates}

The appearance of $q n r$ genes in both $\mathrm{Cip}^{S}$ and $\mathrm{Cip}^{\mathrm{R}}$ isolates during multiplex PCR screening inquired further investigation. In observing genetic differences like mutations between qnr genes could determine the functionality of $q n r$ genes being present in either Cip $^{s}$ isolates. The $q n r$ amplicon from select qnr-positive isolates were sent off for Sanger sequencing to compare the sequences of the Cips and $\mathrm{Cip}^{\mathrm{R}}$ qnr genes. Resultant sequences were queried using the BLAST database to identity the origins and similarity between the $q n r$ genes. The sequence of the $q n r B$ amplicon from Cip ${ }^{\mathrm{R}}$ isolate $\mathrm{F} 6$ (Klebsiella pneumonia) was matched to a Klebsiella pneumonia strain KPN528 (Accession number NZ_CP020854.1). The confidence value between F6 and KPN528 as a qnrB1 variant was found to have a $99.51 \%$ via nucleotide alignment. Similarly, sequencing of $q n r S$ from $\mathrm{Cip}^{\mathrm{R}}$ isolate F5 (Aeromonas salmonicida) corresponded to a qnrS2 variant from Aeromonas veronii (Accession number AFS33292.1). Nucleotide alignment between these bacteria showed $98.36 \%$ confidence. On the other hand, sequencing of either qnrB or qnrS amplicons from $\mathrm{Cip}^{\mathrm{S}}$ isolates (BHW8, BHW10, 111, E13 and E25) did match to any qnr gene sequences in the database. Although the $q n r$ primers generated positive amplicons in several of the Cip ${ }^{\mathrm{s}}$ isolates, complete sequencing of the PCR products revealed little to no homology to the qnr gene in the database. Further investigation of this phenomenon is necessary as it may suggest that qnr-like genes are very diverse, or a possible alternate gene can be detected with the qnr primers generating false positives. 
4.0 Discussion 
The rapid dissemination of ARGs and proliferation of ARB poses a significant challenge to the public health sector. ARGs have always been present in the microbial world with records documenting resistance gene sequences from permafrost cores and isolated caves dating back millions of years. ${ }^{62,132}$ Through metagenomic analysis of ancient DNA samples, levels of resistance determinants in the early antibiotic resistome showed less abundance of ARGs. The accelerated rate of recent dissemination, resistance accumulation and antimicrobial evolution has been suggested to be due to horizontal gene transfer which has been further selected through anthropogenic stresses and misuse of antibiotic consumption. With over 30 years of clinical use, ciprofloxacin resistance and PMQR genes have become widespread which decreases the efficacy of quinolone class antibiotics in the clinical setting. Current investigations of ciprofloxacin resistance focus largely on the clinical prevalence of PMQR genes. ${ }^{126,133}$ However, studies of phylogenetic analysis show that certain ARGs are not sourced from antibioticproducing bacteria and not disseminated towards pathogenic or commensal bacteria. ${ }^{134}$ This suggests that ARG development could be due to the onset of anthropogenic stress from multiple environments. Surveying the environmental prevalence of PMQR genes through culture-based techniques can help link and characterize the connection between ARGs and specific bacteria, which stills remain unclear. In summary, the results of this research project demonstrate the wide prevalence of culturable ciprofloxacin-resistant bacteria in various aquatic sources and the possible environmental reservoirs of qnr genes.

\subsection{Prevalence of Ciprofloxacin-Resistant Bacteria}

In general, ciprofloxacin resistant bacteria were found in every location sampled although the prevalence of the resistance in culturable heterotrophs varied between each sampling source. As suggested by many literature sources, the intensity and variation of anthropogenic compounds received by isolates in WWTPs and other aquatic sources could create ideal conditions to promote the growth and dissemination of ARB. ${ }^{113,135,136}$ With respect to ciprofloxacin concentrations in aquatic sources, 
unmetabolized quinolones have been found at concentrations up to $0.005 \mu \mathrm{g} / \mathrm{mL}^{137,138}$ They can remain active in the environment and therefore can aid in maintaining quinolone resistances in these environments. Past studies that studied the prevalence of ciprofloxacin-resistant bacteria from the environment used agar supplemented with $1-5 \mu \mathrm{g} / \mathrm{mL}$ of ciprofloxacin, a concentration that is close to the CLSI (Clinical and Laboratory Standards Institute) guidelines. ${ }^{139,140}$ However, when examining pure cultures, higher antibiotic concentrations selection can demonstrate the current impact and frequency of resistant bacteria in the natural environment with possible PMQR genes. To observe ciprofloxacin resistance, the selection on agar plates with $10 \mu \mathrm{g} / \mathrm{mL}$ provided completely resistant isolates and better depiction of aquatic microbial communities. ${ }^{141}$

In this study, five locations were sampled for ciprofloxacin resistance. It was predicted that the Humber WWTP samples would contain the highest percentage of ciprofloxacin resistance due to being most anthropogenically impacted among the sampling sites owing to receiving influent from various domestic and commercial wastewater. The results in Table 2 show that all the aquatic sources contained similar levels of resistant bacteria when selected on $10 \mu \mathrm{g} / \mathrm{mL}$ of ciprofloxacin. Marti et al. found a similar percentages of culturable bacteria on R2A medium at $5 \mu \mathrm{g} / \mathrm{mL}$ of ciprofloxacin among both heterotrophic and ciprofloxacin-resistant population in the WWTP. ${ }^{142}$ This confirms with the current study that the prevalence and abundance of ciprofloxacin-resistant bacteria are comparable among various aquatic sources. This suggest that the ciprofloxacin-resistant population can withstand a higher concentration of antibiotics when selected for in the natural environment. Supplementing the current data by measuring antibiotic concentrations can elucidate possible stressors influencing the abundance of ciprofloxacin-resistant bacteria.

Lake Devo is an artificial concrete pond on a university campus experiencing high foot traffic throughout the year. The initial Lake Devo sample after disinfection showed no ciprofloxacin-resistant bacteria as shown in Figure 8. However, after only 2 days of water retention the pond exhibited 
comparable percentages of ciprofloxacin resistance as seen with the other aquatic sources. This rapid acquisition of ciprofloxacin-resistant bacteria into the pond could indicate how common these bacteria are in the urban ecosystem and the potential for any aquatic source to contain such bacteria. Buckhorn Lake and Toronto storm drain also had a higher than expected ciprofloxacin resistance compared to the Humber WWTP at above 1\%. The WWTP gathers and treats influent from multiple sources within the city. This influent contains multiple types of bacteria and contaminants such as antibiotics that increases the likelihood in encountering more ciprofloxacin-resistant bacteria. Percentage of ciprofloxacin resistance within Buckhorn Lake and Toronto storm drain interestingly compare with other studies displaying percentages of $1.7-4.4 \%$ eluding to possible heavy contaminants or other factors in these areas. ${ }^{143}$ Overall, the percentage of ciprofloxacin resistance in heterotrophs was found to be the same in the sediment and the water column. Significant conclusions elucidating the various levels of ciprofloxacin-resistant bacteria in the sampled water sources cannot be confirmed. Multiple external factors such as total human activity and contaminant levels within each area might explain the potential reservoirs for ciprofloxacin-resistant bacteria and associated genes. This can provide advantages to resistant bacteria in proliferating under low concentrations of quinolones. Variation in ciprofloxacinresistant heterotrophs in all sites could be due to seasonal differences of the microbial populations and discharges/contaminants towards these waters that can have immediate effects on the microbial ecosystems and ARG pool.

\subsection{Distribution of Antibiotic Resistances}

The diversity and abundance of other antibiotic resistances carried by all isolates in this study illustrate the ubiquity of ARGs in the aquatic environments (Table 3). Furthermore, it was found that a higher prevalence of resistance determinants was present in the isolates that had already been selected for ciprofloxacin resistance. These results support the observation that many resistance determinates often cluster together on mobile genetic elements and they can be transferred simultaneously. Studies 
have shown that antibiotic selection pressure from a single antibiotic can increase the likelihood of additional resistant determinants to be carried with other resistances via plasmids and transposons. ${ }^{106,107,144,145}$ This formation of gene reservoirs sets the track for bacteria to accumulate and transfer resistances into potential pathogens.

Isolate profiles of antibiotic resistance in Table 3 and 4 show the variation of resistances between $\mathrm{Cip}^{\mathrm{S}}$ and $\mathrm{Cip}^{\mathrm{R}}$ isolates. In general, more $\mathrm{Cip}^{\mathrm{R}}$ isolates contained more ARGs and possessed a wider diversity of the resistant determinants. From the ninety-eight $\mathrm{Cip}^{\mathrm{R}}$ isolates from all the aquatic sources showed at least 21 isolates that were resistant to all twelve antibiotics tested. The only experimental difference between $\mathrm{Cip}^{R}$ and $\mathrm{Cip}^{S}$ populations was the initial selection on ciprofloxacin which probably attributed to the increased MAR and ARI scores. The ARI score can be used to predict if a sampling location at a given time is at low-risk or high-risk location for the overall abundance of resistance determinants. This epidemiological ability helps distinguish if possible contaminants are affecting microbial communities and are not due to clonal causes. ${ }^{64}$ All sampling sites and populations within this study had ARI scores above 0.2 . This proposed threshold holds ambiguity when testing isolates against 3 or fewer antibiotics producing false-positive results in risk assessments. ${ }^{121}$

Krumperman further elaborates on possible scenarios where indices ranging from 0.2 to 0.25 need to be held with heavy scrutiny in making claims of high-risk environments. Our study with a panel of twelve antibiotics, large sample size and isolate characterization eliminates the bias within this measurement. Differences between $\mathrm{Cip}^{\mathrm{S}} \mathrm{ARI}$ scores hold very little variation with Lake Devo, Toronto Storm Drain and Humber WWTP sites showing elevated scores slightly above this threshold in Table 4. This could be indicative of the high human activity/input that these areas receive. In comparison with $\mathrm{Cip}^{\mathrm{S}}, \mathrm{Cip}^{\mathrm{R}}$ isolates ARI scores differ greatly by at least 2 times higher showing substantial acquisition of ARGs in $\mathrm{Cip}^{\mathrm{R}}$ isolates. The ciprofloxacin selection pressure may directly contribute to the increasing resistance of bacteria. 
The antibiotic resistance profiles of all isolates presented with trends of resistance cooccurrences between several antibiotics. Highly abundant resistances such as ampicillin and gentamicin were observed in both populations (Table 3 ) demonstrating the ubiquity of these resistance mechanisms in nature towards penicillin and aminoglycoside class antibiotics. Several studies show that PMQR genes are often found on transposons and insertion sequences that contain numerous amounts of different antibiotics resistances. ARGs such as sul1, blaTEM, blaOXA, blaIMP, blaDHA and aac- $\left(6^{\prime}\right)-1 b$ are often harboured alongside $q n r$ genes..$^{50}$ Antibiotic association with aminoglycosides like kanamycin, streptomycin and gentamicin can be attributed to the shared resistance mechanisms of the aminoglycoside acetyltransferase. ${ }^{102}$ The ciprofloxacin-resistant (cr) variant of this enzyme can confer resistance to both classes of antibiotics, which may already hold a strong resistance relationship in the environmental resistome. These resistance relationships can render multiple classes of antibiotics ineffective with the single selection of ciprofloxacin. This further implicates the dangers of limited resources in treating patients as very few viable antibiotic options would remain in the clinical setting. Our analysis using Weka software revealed possible resistance relationships in the populations. All association rules generated were at least at the $95 \%$ confidence level to predict strong possibilities between resistance determinants. Several outputs in the Apriori algorithm showed many relationships with gentamicin and other aminoglycosides which confirmed previous associations seen in the literature. ${ }^{146}$ These isolates could harbour the $a a c-\left(6^{\prime}\right)-l b$-cr genes along with qnr genes which can then display with the gentamicin resistance phenotype. Unique resistance relationships observed only in the $\mathrm{Cip}^{\mathrm{R}}$ isolates displayed associations with sulfamethoxazole-trimethoprim and chloramphenicol resistance determinants. Commonly observed ARGs and efflux extrusion by OqxAB pumps have been characterized to be present in ciprofloxacin resistance. ${ }^{50}$ Screening for these genes via PCR or sequencing can directly link isolates to resistant determinants further proving that a multitude of ARGs are associated with ciprofloxacin resistance. In addition, larger clusters of resistance relationships were 
evident in the Weka analysis demonstrating that several ARGs can be present in the same genetic environment as ciprofloxacin resistance. Thus, it can be concluded that the distribution and diversity of ARGs among the $\mathrm{Cip}^{\mathrm{R}}$ isolates are abundantly present and can be carried through mobile genetic elements. This can significantly impact the gene reservoirs in aquatic sources providing various opportunities of multiple transferrable genes to be passed on in the microbial communities.

\subsection{Isolate Identification}

Culture-based techniques and pure culture isolation allow effective characterization of isolates to help understand the taxonomic composition of bacterial populations in aquatic sources. Although these approaches have limitations in environmental bacteria where it is estimated that less than $1 \%$ of the microbial community can be grown under laboratory conditions, they are useful for directly relating functional ARGs to specific ARBs. On the other hand, metagenomic analysis can be used to detect antibiotic resistance in a whole community but is unable to link the ARG with the corresponding host. This study determined the bacterial identity of 184 isolates, through amplification and sequencing of the highly conserved V3 and V4 variable regions of the 16S rRNA gene. This allows the identification of bacterial genera as closely related bacterial species contain high sequence similarity which can not be differentiated without sequencing the entire 16S rRNA gene. ${ }^{147,148}$ Table 5 displays all 184 isolate identities sampled in all aquatic sources covering an overall total of six phyla, eleven classes and 51 different genera characterized. Abundantly observed, over $50 \%$ of isolates identified in the phylum Proteobacteria with many of these isolates considered to be potential human pathogens and exclusively Gram-negative. This group of bacteria are clinically important in causing outbreaks of hospital-acquired infections. ${ }^{61,149}$ Several Cip ${ }^{R}$ isolates identified as Escherichia and Stenotrophomonas, which contained the most antibiotic resistance phenotypes among isolates. These MDR bacteria can pose several threats to the clinical setting. Observing possible pathogenic bacteria in the natural environment directly supports the likelihood of ARG transmission between clinical and environmental isolates. ${ }^{115}$ The CDC and 
IDSA list several deadly microorganisms such as the ESKAPE pathogens (Enterococcus faecium, Staphylococcus aureus, Klebsiella pneumoniae, Acinetobacter baumannii, Pseudomonas aeruginosa and Enterobacter spp.) that resist treatment to many antibiotics proving management of these bacteria to be difficult. ${ }^{36,150,151}$ Observance of Proteobacteria isolates in the Cip ${ }^{R}$ population is reflectively seen in the literature. ${ }^{142}$

In particular, Brevundimonas was shown to be most abundant in the Cip ${ }^{\mathrm{R}}$ population of about $18.75 \%$ (Table 5). Brevundimonas is an emerging opportunistic pathogen in the clinical setting that already shows fluoroquinolone resistance. ${ }^{152}$ Enumeration of this bacterium has been used to validate reverse-osmosis filtration devices for drinking water and pharmaceutical grade filters. ${ }^{153}$ However, Brevundimonas have shown capabilities in penetrating past these filters due to its small cell size. ${ }^{154}$ Initially isolated in various soils, activated sludge and wide range of aquatic environments have now shown cases of bacteremia, septicemia, pneumonia and urinary tract infections in many patients with a few known outbreaks. ${ }^{155}$ Multitude of resistances has been observed in Brevundimonas towards fluoroquinolones, $\beta$-lactams and tetracyclines posing a larger threat as a nosocomial pathogen.

Overall, the $\mathrm{Cip}^{\mathrm{S}}$ population displayed a larger genera diversity compared to $\mathrm{Cip}^{\mathrm{R}}$ population. Common ecological metrics such as the Shannon diversity index and Sorenson Co-efficient aid to track and understand shifts in populations in assessing species/genera diversity. ${ }^{127}$ With the difference of ciprofloxacin selection pressure between $\mathrm{Cip}^{S}$ and $\mathrm{Cip}^{\mathrm{R}}$ populations may demonstrate a change of genera diversity and richness that is observed in Table 6 . The Shannon diversity index and genera richness are a type of alpha diversity indices that mathematically measures species/genera diversity within a given community. The Shannon diversity is an information index based on the principle that all species/genera in a sample are randomly sampled. This also assumes that individuals are randomly sampled from an infinitely large community and that all species/genera are represented in the sample. ${ }^{127}$ Without the use of metagenomics for community comparison of uncultured bacteria and strict use of culturing methods, 
total microbial taxonomic representation of the aquatic sources cannot be done. Due to the nature of the work and random sampling, acquirement of all culturable genera in a community brings further complications and is not cost-effective in demonstrating relative diversity changes between $\mathrm{Cip}^{\mathrm{S}}$ and $\mathrm{Cip}^{\mathrm{R}}$ populations. Calculations of diversity within each aquatic source cannot be performed for similar reasons and low sampling counts. In addition, true genera richness and relative abundance of a community cannot be found even with metagenomic analysis as DNA extraction efficiencies, sequencing biases and technological limitations prevent total detectability of rare taxa. ${ }^{13,156}$ Nonetheless, based on the sampling parameters, the current data demonstrates a good representation in answering ecological differences in the cultured populations. Shannon diversity index values usually lie between 1.5 to 3.5 with higher values displaying a more diverse community. ${ }^{127}$ Comparing $\mathrm{Cip}^{\mathrm{S}}$ and $\mathrm{Cip}^{\mathrm{R}}$ populations, index values for $\mathrm{Cip}^{\mathrm{s}}$ show a more diverse population with 40 different genera observed (Table 6). The selection of ciprofloxacin resistance phenotype in the $\mathrm{Cip}^{\mathrm{R}}$ population may attribute to a lower genera diversity and richness. This may suggest certain genera are more likely to carry ciprofloxacin resistance than other ARGs. This can be seen in Table 5 where isolates identified as Microbacterium and Sphingobacterium were found to always be ciprofloxacin resistant. The Sorenson co-efficient is a beta diversity in comparing similarities between populations through species/genera overlap. ${ }^{127}$ Co-efficient values fall between 0 to 1 , where 0 represents no genera similarities between two populations and 1 indicating identical genera presence in both communities. Comparing the $\mathrm{Cip}^{S}$ and $\mathrm{Cip}^{R}$ populations showed a value of 0.3 demonstrating significant differences between populations with only nine genera overlap. Five bacteria observed in the shared genera overlap in Figure 9 are potential pathogens. Bacteria such as Escherichia, Acinetobacter and Klebsiella cultured in the environment could demonstrate possible routes of ARG dissemination towards clinical counterparts which are also part of the ESKAPE pathogen group. ${ }^{60}$ Further evidence and sampling will be needed to demonstrate this distinct taxonomic difference. 


\subsection{Qnr Prevalence}

Plasmid-mediated antibiotic resistant mechanisms have led to limited of use of several classes of clinically relevant antibiotics. The mobilization of resistance genes can effectively increase the resistance profile and become widespread in multiple bacterial species. This has been seen for quinolone resistance since PMQR genes have become prevalent in clinical and environmental settings. ${ }^{133,146,157-164}$ One of PMQR genes that have emerged rapidly in these settings are qnr genes incurring fitness advantages in the presence of fluoroquinolones. It has been shown through biochemical assays that Qnr proteins can reduce the amount of enzyme-DNA targets for ciprofloxacin inhibition. ${ }^{99}$ Screening for $q n r$ genes in isolates can directly link genes responsible for ciprofloxacin resistance. We used a multiplex PCR approach for three qnr gene variants, $q n r A$, $q n r B$ and $q n r S$, to determine the prevalence of these genes in our isolates (Figure 10). Although a low prevalence of qnr genes of less than $10 \%$ in studied isolates has been reported in the literature, we observed high prevalence of qnr genes in this study with $33.2 \%$ of the 202 isolates displaying the presence of at least one of these genes. ${ }^{126,133,142}$ This high prevalence may in part be due to the selection of ciprofloxacin isolates on agar plates containing $10 \mu \mathrm{g} / \mathrm{mL}$ of ciprofloxacin and the screening for multiple qnr genes. The current data shows that the qnr-positive isolates encompass 28 different genera in all sampled locations, including some qnr-positive isolates from the Cip ${ }^{s}$ population. The premise of culturing and identifying Cip ${ }^{s}$ isolates can aid in documenting potential recipients of ARGs via horizontal gene transfer events. ${ }^{106}$ Understanding this concept could further elaborate on the ubiquity of ARGs and observe potential gene reservoirs for highly disseminated genes. Qnr genes have been shown to be on conjugative plasmids increasing the likelihood of passing genes into other hosts. ${ }^{50}$ Presence of $q$ nr genes in both $\mathrm{Cip}^{\mathrm{S}}(14.4 \%)$ and $\mathrm{Cip}^{\mathrm{R}}(18.8 \%)$ isolates demonstrate the widespread prevalence of these PMQR genes inhabiting in these aquatic sources. No statistical significance was observed for the gnr presence and absence and was not dependent on ciprofloxacin selection indicating that qnr genes could likely be abundant and underestimated in the 
literature. The isolation of $q n r$-positive $\mathrm{Cip}^{\mathrm{s}}$ isolates suggests that screening solely for $q n \mathrm{r}$ genes in isolates cannot be used as a diagnostic selection marker of ciprofloxacin resistance.

All qnr variants in the various isolates were identified and genes were present in many different gene combinations. Figure 11 shows that qnrS shows the highest prevalence within the qnr-positive isolates. QnrS alleles have commonly been shown in several studies to be in aquatic environments hosted mostly in Aeromonas spp. ${ }^{76,133,142}$ Primarily a fish pathogen, Aeromonas is also a human pathogen that can be responsible for gastroenteritis. ${ }^{165}$ QnrS has been shown to be embedded in $\operatorname{Tn} 3$ transposons and insertion sequence ISECI 2 that encode for blaTEM and blaLAP $\beta$-lactam resistance and zinc metalloprotease..$^{50,76}$ Unlike $q n r S, q n r A$ and $q n r B$ has been described in a multitude of plasmids with heavy associations to ISCR1 commonly accompanied with many antimicrobial resistance genes. ${ }^{166}$ Overall, Brevundimonas, Pseudomonas, Aeromonas, and Stenotrophomonas isolates show the highest frequency of qnr genes presenting as a potential source of qnr determinants. Predictive analysis of $q n r$ transmission has already been reported in Stenotrophomonas as a potential qnr source. ${ }^{167}$ Interestingly, no reports of qnrA-like genes have been documented outside Enterobacteria species. ${ }^{76}$ One isolate characterized as Microbacterium (J10) showed the first instance of qnrA-like presence which holds for future verification and allelic identification. Several isolates have shown a high abundance of multiple qnr genes present in the multiplex PCR correlating mostly with qnrA combinations (Figure 11). Furthermore, additive effects of multiple Qnr proteins towards quinolone MIC still remains unclear. Additional experiments may elaborate on the function of multiple qnr genes in an isolate if simultaneous expression confers a greater competitive inhibition in binding towards DNA gyrase. Single and double knockouts of multiple qnr variants can correspond to wild-type resistance phenotype proposing less time for ciprofloxacin to interact with DNA gyrase.

Distribution of all qnr genes was observed in all five sampled aquatic sources at significantly different prevalence. Several studies show the source of qnr genes may have originated from marine 
and freshwater species such as Shewanella, Aeromonas and Vibrio spp. ${ }^{50,94,133}$ Observing counts of qnrpositive Aeromonas isolates in both $\mathrm{Cip}^{\mathrm{S}}$ and $\mathrm{Cip}^{\mathrm{R}}$ populations can evidently depict potential $q \mathrm{qn}$ reservoirs in these aquatic environments. The analysis shows certain environments like Buckhorn Lake and Humber WWTP can influence the prevalence of qnr genes but cannot be ascertained to a particular factor (Figure 12). The current data outlines the importance of water research in understanding the potentiation of ARG flow in natural ecosystems. The relationship between aquatic locations and qnr presence holds true in the literature illustrating possible epidemiological routes on possible qnr gene dissemination from environmental species. ${ }^{76}$

\subsection{Qnr Gene Contribution to Quinolone MIC}

Susceptibility testing to determine the MIC of the isolates towards nalidixic acid and ciprofloxacin showed that there was no difference in degree of susceptibility of the isolates regardless of the $q n r$ gene(s) they contained. Earlier assumptions assumed that the presence of any qnr genes could increase the resistance levels of either quinolone. ${ }^{39}$ Moreover, quinolone resistance levels were expected to be low due to the synthetic nature of the antibiotic. MIC testing on $90 \mathrm{Cip}^{\mathrm{R}}$ isolates starting at $8 \mu \mathrm{g} / \mathrm{mL}$ for ciprofloxacin and $4 \mu \mathrm{g} / \mathrm{mL}$ for nalidixic acid were performed as shown in Figure 13 .

Overall trends show that several Cip ${ }^{R}$ isolates were heavily resistant to both quinolones with MICs greater than $256 \mu \mathrm{g} / \mathrm{mL}$. Peak human serum concentration of ciprofloxacin reaches about $2.7 \mu \mathrm{g} / \mathrm{mL}$ when given a dosage of $500 \mathrm{mg}$ of ciprofloxacin. ${ }^{168}$ This is a concentration well above the clinical MIC level of most susceptible microorganisms in empirical therapy. Since many of the Cip ${ }^{R}$ isolates tested displayed resistance 94 times above this serum concentration indicates that ciprofloxacin would be ineffective against these environmental bacteria.

High nalidixic acid levels can be credited to the efficacy of this antibiotic and intrinsic mechanisms of quinolone resistance conferring high resistance. Due to the difference in chemical 
structure of this first-generation antibiotic (Figure 3) presumes lower efficacy, binding and pharmacokinetics than subsequent fluoroquinolones and as such bacteria can be more tolerant to nalidixic acid through easier resistance mechanisms such as efflux (Appendix 1). ${ }^{24,35,37}$ Acquirement of a single chromosomal mutation or PMQR gene can thoroughly reduce the therapeutic effectiveness of nalidixic acid. With ciprofloxacin MIC levels, a wider distribution of phenotype can be observed at multiple levels of resistance (Figure 13). With improved effectiveness from nalidixic acid, Cip ${ }^{R}$ bacteria can acquire consequential resistance mechanisms towards ciprofloxacin displayed as a range of resistance phenotypes. ${ }^{32,45}$ The presence of multiple $q n r$ genes can affect the overall MIC by a fraction but can increase the MPC which also can increase the mutation-selection window. Acquisition of multiple chromosomal mutations can drastically increase quinolone resistance levels. ${ }^{50}$

Qnr genes confer very little quinolone resistance to the MIC compared to chromosomal mutations in Type 2 topoisomerases. Tables 7 and 8 demonstrate no influence between qnr gene presence or absence at the tested concentrations. Lack of differences can be a result of other quinolone resistance mechanisms could be at play such as PMQR genes like $a a c\left(6^{\prime}\right)-1 b$-cr and/or chromosomal mutations present in isolates. ${ }^{102}$ To observe these subtle effects of qnr presence on MIC, micro-dilutions of quinolones could be performed using MIC test paper strips that encompass MIC ranges well below CLSI and EUCAST standards. This can be supplemented with time-kill assays in examining the bactericidal activities of quinolone drugs. ${ }^{169,170}$ These tests can be performed in Cip $^{\mathrm{s}}$ isolates as well where quinolone activity would thoroughly kill these bacteria.

\subsection{Qnr Sequencing}

The verification of qnr genes via sequencing of the PCR products was carried out for qnr-positive isolates. We were interested in determining if there was a sequence difference between qnr-positive $\mathrm{Cip}^{S}$ and $\mathrm{Cip}^{\mathrm{R}}$ isolates and hence a functional difference. Using the $\mathrm{nBLAST}$ and $\mathrm{xBLAST}$ databases, our 
qnr PCR products from $\mathrm{Cip}^{\mathrm{R}}$ isolates were found to have a high similarity to other qnr variants stated in Results 3.6. Qnr PCR products from the Cip ${ }^{\mathrm{s}}$ isolates, however, often could not be BLASTed due to poor sequencing reads. Methods of optimizing each qnr primer set, nested PCR and gel extraction were used to obtain better yield however, with little to no success. Obtaining poor qnr amplicons from Cip ${ }^{\mathrm{s}}$ isolates could be attributed to the detection of alternate genes or the presence of qnr-like genes on the bacterial chromosome. Chromosomal qnr genes are categorized when at least 70\% identical nucleotides or derived amino acids match with an existing $q n r$ family. ${ }^{50}$ These $q n r$-like genes have variable domain lengths on either side when translated into pentapeptide proteins. Several Gram-positive and Gramnegative bacteria contain these qnr-like genes imposing similar effects as plasmid derived qnr genes. ${ }^{171,172}$ Initially this was found in Shewanella through whole-genome restriction with ribosomal endonuclease, I-Ceul, followed by double southern hybridization of rRNA and qnrA DNA probes. ${ }^{173}$ This showed a signal at the same molecular weight position of the chromosome indicating the presence in genomic DNA. Further proof in sequencing these qnr-like genes showed no signatures of insertions from mobilizable elements. Due to the unequal length on these Qnr-like proteins could be a result of the inability to sequence from the Cip ${ }^{s}$ isolates but still have qnr genes. Whole-genome sequencing and proteomic software in folding Qnr proteins can decipher the full qnr amplicons whether present on the plasmid or chromosome. 


\subsection{Conclusion}


In summary, the overall study underlies the importance of ARG prevalence in culturable bacteria with screening the environment for potential reservoirs for possible dissemination. We demonstrate the prevalence of ciprofloxacin-resistant bacteria and PMQR genes in various aquatic sources. Through PCR detection methods, the presence of different qnr variants in all sampled locations strongly suggest the potential gene reservoirs of qnr genes. Quinolones to this day are often used in empirical therapy and remain an important therapeutic tool in treating several infections and keep intensive care practices available. Mediums that are involved in ARG transmission like aquatic environments need to be assessed for risks of ARG hotspots in protecting the public health. These areas can allow mix and exchange of genetic material to MDR pathogens. ARGs can cross taxonomical and geographical barriers with ease, possibly explaining their wide dispersal in the environment and the clinic. The significance of understanding ARG presence and characterization in all environments can prevent the loss of effectiveness of quinolone class antibiotics.

Using five different aquatic sources, ciprofloxacin resistance was found to be quite prevalent in the culturable bacterial population. Isolation of a huge variety of microbes from many genera speaks about the ubiquity of ARB and ARGs in the environment and the anthropogenic activities that could affect the incidence of antibiotic resistance. With the addition of $\mathrm{Cip}^{\mathrm{s}}$ isolates derived from each of the sampled location in this study aided in drawing possible conclusions and comparisons with the Cip ${ }^{R}$ population. Observations of antibiotic co-resistance data shows that with ciprofloxacin many different resistances can commonly be carried together on mobile genetic elements. To observe the prevalence and frequency of qnr genes as a possible indicator of ciprofloxacin resistance, further consideration needs to be done to verify qnr presence. Screening of all environmental isolates for qnr variants, qnrA, $q n r B$ and $q n r S$, revealed similar $q n r$ gene frequencies for both $\mathrm{Cip}^{S}$ and $\mathrm{Cip}^{\mathrm{R}}$ populations illustrating the widespread dissemination of these genes. Elucidating the possible resistance mechanisms that are found abundantly in the natural environment that confer quinolone resistance can establish better drug 
development and synthetic strategies for novel antibiotics. With the high abundance of qnr genes found in culturable isolates can significantly decrease the lifespan of quinolone usage and efficacy.

\subsection{Future Directions}

Many questions still remain for this work in understanding the prevalence of qnr genes.

Although the literature documents some epidemiological studies on how qnr dissemination occurs in clinical isolates, ARG movement of different qnr genes in the environment have not been clearly outlined. Tracking qnr genes in different aquatic sources can further elaborate on gene reservoirs if the exchange of specific qnr genes between microbes can occur in certain locations such as within the WWTP.

Future work for this study includes sequencing qnr-positive $\mathrm{Cip}^{\mathrm{s}}$ isolates and understanding the functional purpose of these qnr genes. Qnr proteins confer a small resistance increase in fluoroquinolone MIC values compared to the chromosomal mutations in type 2 topoisomerases. This may not be able to be measured accurately through agar plating methods. Experiments that can detect small changes in qnr gene expression with high specificity are necessary to elucidate these MIC changes. Possible experiments can include pulse-field gel electrophoresis in tandem with northern blotting to showcase if overexpression or downregulation of qnr genes can be seen in isolates when compared to normal levels. Additionally, a quantitative reverse transcription PCR (RT-qPCR) approach can demonstrate both the presence and functionality of qnr-positive $\mathrm{Cip}^{\mathrm{s}}$ isolates. RNA extraction and conversion into cDNA could elaborate on the possible expression and relative abundance of qnr genes that increase fluoroquinolone resistance well below the outlined resistance level. The current work can also be supplemented with metagenomic sequence data on bacterial composition from each of the sampled area and observe overall PMQR abundance. This data can increase the correlation with the cultured work performed to see if quinolone resistance genes are abundant in the uncultivable bacterial 
population. Lastly, detection of the other two PMQR mechanisms, quinolone inactivation enzyme $A A C\left(6^{\prime}\right)-\mathrm{Ib}-\mathrm{cr}$ and efflux pumps OqxAB and QepA, can be screened in understanding the dissemination of quinolone resistance. Synergistic roles between each of these PMQR genes have not been well understood due to their rarity and low abundance in the natural environment. 


\section{Appendices}


Appendix 1: Structure-activity relationship of quinolone substituents

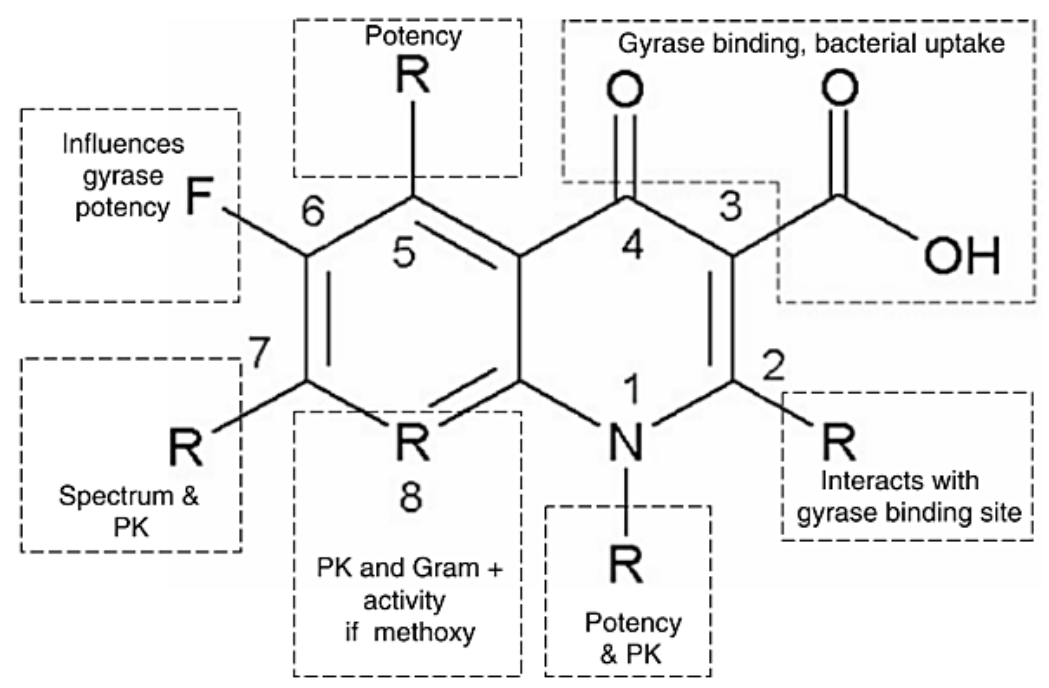

Membrane penetration is dependant by the lipophilicity of the specific quinolone. Ciprofloxacin presents as a strongly hydrophilic compound whereas nalidixic acid is strongly hydrophobic. Other chemical substituent effects are outlined in the figure. ${ }^{1}$ 
Appendix 2: Map of sampling locations within the Greater Toronto Area

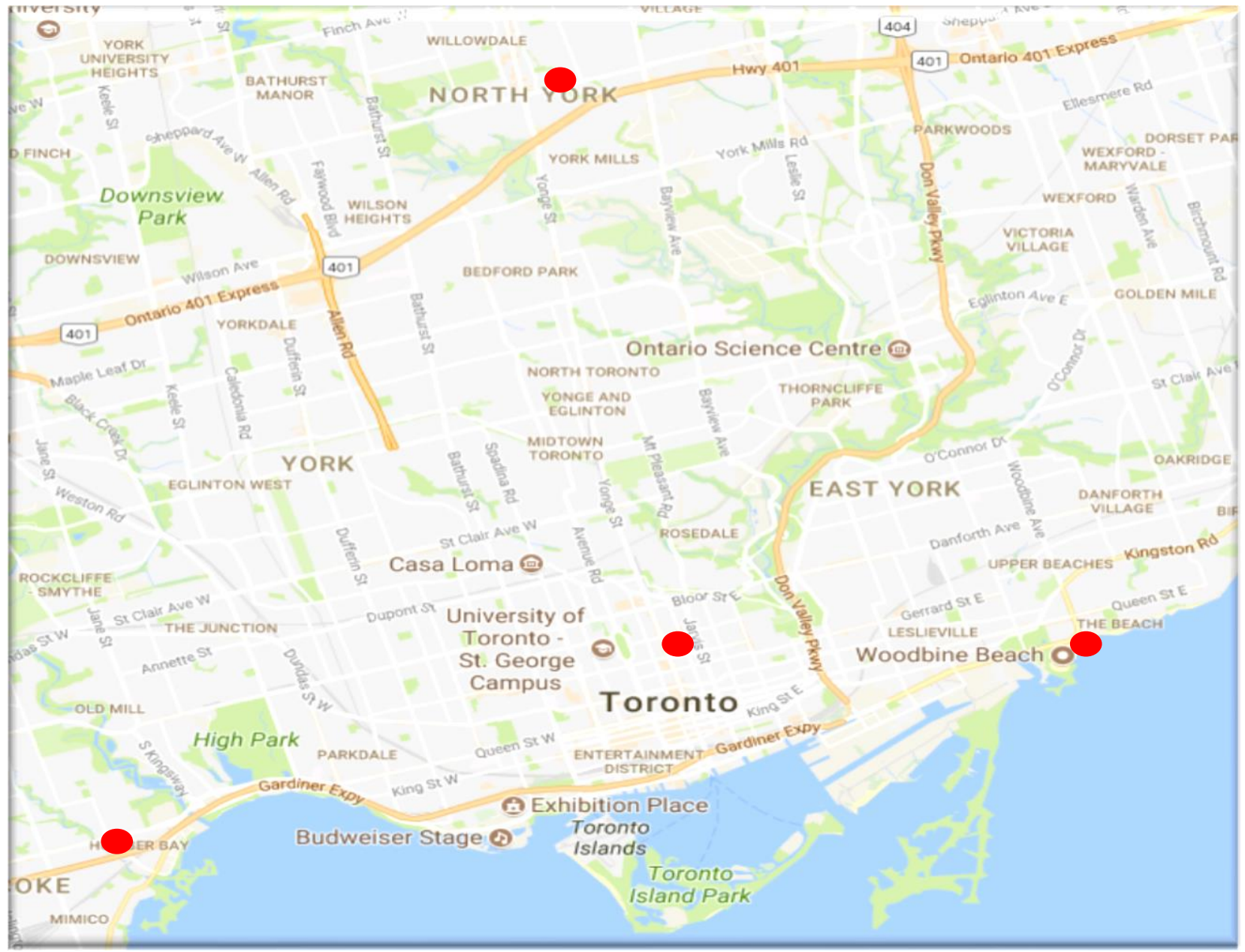

Note that Buckhorn Lake sampling location is not indicated in the above figure. 


\section{Appendix 3: Weka parameters and outputs of antibiotic resistance relationships in all isolates}

Scheme: $\quad$ weka.associations.Apriori -N 20 -T 0 -C 0.95 -D 0.05 -U 1.0 -M 0.35 -S -1.0 -c -1

Relation: all

Instances: 199

Attributes: 11

Ciprofloxacin

Ampicillin

Tetracycline

Chloramphenicol

Gentamicin

Kanamycin

Streptomycin

Sulfamethoxazole-Trimethoprim

Erythromycin

Vancomycin

Spectinomycin

$===$ Associator model (full training set) $===$

Apriori

Minimum support: 0.35 (70 instances)

Minimum metric <confidence>: 0.95

Number of cycles performed: 13

Generated sets of large itemsets:

Size of set of large itemsets $L(1): 8$

Size of set of large itemsets L(2): 21

Size of set of large itemsets L(3): 16

Size of set of large itemsets L(4): 2

Best rules found:

1. Kanamycin=t Streptomycin=t $95==>$ Gentamicin=t 94 <conf:(0.99)> lift:(1.22)

2. Ciprofloxacin=t Kanamycin=t $84==>$ Gentamicin=t 83 <conf:(0.99)> lift:(1.22)

3. Kanamycin=t Streptomycin=t Erythromycin=t $80==>$ Gentamicin=t $79<$ conf:(0.99)> lift:(1.22) 
Appendix 4: Weka parameters and outputs of antibiotic resistance relationships in Cip ${ }^{\mathrm{s}}$ isolates

Scheme: $\quad$ weka.associations.Apriori -N 20 -T 0 -C 0.95 -D 0.05 -U 1.0 -M 0.35 -S -1.0 -c -1

Relation: sensiCiproTF

Instances: 101

Attributes: 10

Ampicillin

Tetracycline

Chloramphenicol

Gentamicin

Kanamycin

Streptomycin

Sulfamethoxazole-Trimethoprim

Erythromycin

Vancomycin

Spectinomycin

$===$ Associator model (full training set) $===$

Apriori

Minimum support: 0.35 (35 instances)

Minimum metric <confidence>: 0.95

Number of cycles performed: 13

Generated sets of large itemsets:

Size of set of large itemsets L(1): 6

Size of set of large itemsets L(2): 7

Size of set of large itemsets L(3): 3

Best rules found:

1. Kanamycin=t $50==>$ Gentamicin=t 49 <conf:(0.98)> lift:(1.29)

2. Kanamycin=t Streptomycin=t $41==>$ Gentamicin=t 41 <conf:(1)> lift:(1.31)

3. Kanamycin=t Erythromycin=t $39==>$ Gentamicin=t 39 <conf:(1)> lift:(1.31) 
Appendix 5: Weka parameters and outputs of antibiotic resistance relationships in Cip ${ }^{R}$ isolates

Scheme: $\quad$ weka.associations.Apriori -N 20 -T 0 -C 0.95 -D 0.05 -U 1.0 -M 0.35 -S -1.0 -c -1

Relation: resistCiproTF

Instances: 98

Attributes: 10

Ampicillin

Tetracycline

Chloramphenicol

Gentamicin

Kanamycin

Streptomycin

Sulfamethoxazole-Trimethoprim

Erythromycin

Vancomycin

Spectinomycin

$===$ Associator model (full training set) $===$

Apriori

Minimum support: 0.45 (44 instances)

Minimum metric <confidence>: 0.95

Number of cycles performed: 11

Generated sets of large itemsets:

Size of set of large itemsets $L(1): 8$

Size of set of large itemsets L(2): 21

Size of set of large itemsets L(3): 21

Size of set of large itemsets L(4): 5

Best rules found:

1. Chloramphenicol=t Sulfamethoxazole-Trimethoprim=t $45==>$ Ampicillin=t $44 \quad<$ conf:(0.98)> lift:(1.31)

2. Ampicillin=t Streptomycin=t $52==>$ Gentamicin=t 51 <conf:(0.98)> lift:(1.14)

3. Ampicillin=t Sulfamethoxazole-Trimethoprim=t $52==>$ Erythromycin=t $51 \quad<$ conf:(0.98)> lift:(1.28) 
Appendix 6: Bacterial phylum distribution of all isolates

\begin{tabular}{|c|c|c|c|}
\hline Phylum & Cip $^{\mathbf{S}}$ & Cip $^{\mathbf{R}}$ & Total $^{-1}$ \\
\hline Actinobacteria & 5 & 11 & 16 \\
\hline Bacteroidetes & 27 & 25 & 52 \\
\hline Deinococcus-Thermus & 2 & 0 & 2 \\
\hline Firmicutes & 19 & 0 & 19 \\
\hline Proteobacteria & 51 & 43 & 94 \\
\hline Verrucomicrobia & 0 & 1 & 1 \\
\hline Total & $\mathbf{1 0 4}$ & $\mathbf{8 0}$ & $\mathbf{1 8 4}$ \\
\hline
\end{tabular}

Appendix 7: Isolate distribution by Gram-staining identification

\begin{tabular}{|c|c|c|c|c|c|}
\hline \multirow{2}{*}{ Locations } & \multicolumn{2}{|c|}{ Gram-Negative } & \multicolumn{2}{c|}{ Gram-Positive } & \multirow{2}{*}{ Total } \\
\cline { 2 - 5 } & Cip $^{\mathbf{S}}$ & Cip $^{\mathbf{R}}$ & Cip $^{\mathbf{S}}$ & Cip $^{\mathbf{R}}$ & \\
\hline BL & 9 & 13 & 10 & 3 & 35 \\
\hline TS & 12 & 10 & 6 & 1 & 29 \\
\hline LO & 23 & 12 & 4 & 6 & 45 \\
\hline HW & 20 & 20 & 5 & 0 & 45 \\
\hline LD & 15 & 13 & 0 & 1 & 29 \\
\hline Total & $\mathbf{7 9}$ & $\mathbf{6 8}$ & $\mathbf{2 5}$ & $\mathbf{1 1}$ & $\mathbf{1 8 3}$ \\
\hline
\end{tabular}


Appendix 8: Qnr gene prevalence in all isolates

\begin{tabular}{|c|c|c|c|c|}
\hline \multirow{2}{*}{ Culture Identification $^{a \neq}$} & \multirow{2}{*}{ Isolate ID ${ }^{c, d}$} & QnrA* $^{*}$ & QnrB* & QnrS* \\
\hline & & \multicolumn{3}{|c|}{ Buckhorn } \\
\hline Pseudomonas amygdali & BHW1 & $(+)$ & $(+)$ & $(-)$ \\
\hline Pseudomonas amygdali & BHW2 & $(+)$ & $(+)$ & $(-)$ \\
\hline Pseudomonas koreensis & BHW4 & $(+)$ & $(+)$ & $(-)$ \\
\hline Pseudomonas koreensis & BHW6 & $(+)$ & $(+)$ & $(-)$ \\
\hline Pseudomonas koreensis & BHW7 & $(+)$ & $(+)$ & $(-)$ \\
\hline Pseudomonas koreensis & BHW8 & $(-)$ & $(-)$ & $(+)$ \\
\hline Pseudomonas koreensis & BHW10 & $(+)$ & $(-)$ & $(+)$ \\
\hline Yersinia ruckeri & BHS8 & $(-)$ & $(+)$ & $(-)$ \\
\hline Exiguobacterium sp. & BHS10 & $(-)$ & $(-)$ & $(+)$ \\
\hline Brevundimonas sp. & BHWC1 & $(+)$ & $(-)$ & $(+)$ \\
\hline Sphingobacterium & BHWC2 & $(-)$ & $(-)$ & $(+)$ \\
\hline Brevundimonas sp. & BHWC3 & $(+)$ & $(-)$ & $(+)$ \\
\hline Brevundimonas sp. & BHWC5 & $(+)$ & $(-)$ & $(-)$ \\
\hline Microbacterium sp. & BHWC6 & $(-)$ & $(-)$ & $(+)$ \\
\hline Brevundimonas sp. & BHWC7 & $(+)$ & $(-)$ & $(+)$ \\
\hline Brevundimonas sp. & BHWC8 & $(+)$ & $(-)$ & $(+)$ \\
\hline Brevundimonas sp. & BHWC9 & $(+)$ & $(-)$ & $(+)$ \\
\hline Brevundimonas sp. & BHWC10 & $(+)$ & $(-)$ & $(+)$ \\
\hline Stenotrophomonas sp. & $\mathrm{BHSC2}$ & $(-)$ & $(+)$ & $(-)$ \\
\hline Stenotrophomonas sp. & $\mathrm{BHSC} 3$ & $(+)$ & $(+)$ & $(-)$ \\
\hline Stenotrophomonas sp. & $\mathrm{BHSC} 4$ & $(+)$ & $(+)$ & $(-)$ \\
\hline Candidatus accumulibacter phosphatis & BHSC5 & $(-)$ & $(-)$ & $(+)$ \\
\hline \multirow[t]{2}{*}{ Pedobacter sp. } & $\mathrm{BHSC7}$ & $(+)$ & $(+)$ & $(-)$ \\
\hline & & \multicolumn{3}{|c|}{ Toronto Storm Water } \\
\hline Raoultella planticola & S1 & $(+)$ & $(-)$ & $(+)$ \\
\hline \multirow[t]{5}{*}{ Shewanella baltica } & S3 & $(-)$ & $(+)$ & $(+)$ \\
\hline & $\mathrm{C7}$ & $(-)$ & $(+)$ & $(+)$ \\
\hline & B5 & $(-)$ & $(-)$ & $(+)$ \\
\hline & B6 & $(-)$ & $(-)$ & $(+)$ \\
\hline & B8 & $(-)$ & $(-)$ & $(+)$ \\
\hline Stenotrophomonas maltophilia & K3 & $(-)$ & $(-)$ & $(+)$ \\
\hline \multicolumn{5}{|c|}{ Lake Devo } \\
\hline Massilia sp. & $\mathrm{R} 7$ & $(-)$ & $(+)$ & $(-)$ \\
\hline Flavobacterium sp. & $\mathrm{R} 14$ & $(-)$ & $(-)$ & $(+)$ \\
\hline Novosphingobium aromaticivorans & U7 & $(-)$ & $(-)$ & $(+)$ \\
\hline Caulobacter segnis & U8 & $(-)$ & $(-)$ & $(+)$ \\
\hline Novosphingobium aromaticivorans & U9 & $(-)$ & $(+)$ & $(+)$ \\
\hline Caulobacter sp. & U11 & $(+)$ & $(-)$ & $(-)$ \\
\hline Aeromonas sp. & U12 & $(+)$ & $(-)$ & $(-)$ \\
\hline & & \multicolumn{3}{|c|}{ Humber WWTP } \\
\hline Citrobacter amalonaticus & E2 & $(+)$ & $(-)$ & $(-)$ \\
\hline Aeromonas sp. & E3 & $(-)$ & $(+)$ & $(-)$ \\
\hline Aeromonas aquatica & E5 & $(+)$ & $(+)$ & $(-)$ \\
\hline Chryseobacterium sp. & E8 & $(-)$ & $(+)$ & $(+)$ \\
\hline Klebsiella oxytoca & E13 & $(-)$ & $(+)$ & $(+)$ \\
\hline Aeromonas sp. & E25 & $(-)$ & $(-)$ & $(+)$ \\
\hline Deinococcus actinosclerus & E26 & $(-)$ & $(-)$ & $(+)$ \\
\hline Aeromonas sp. & $\mathrm{F} 1$ & $(+)$ & $(-)$ & $(+)$ \\
\hline Aeromonas salmonicida & F5 & $(+)$ & $(-)$ & $(-)$ \\
\hline Klebsiella pneumoniae & F6 & $(-)$ & $(+)$ & $(-)$ \\
\hline Escherichia coli & F8 & $(-)$ & $(-)$ & $(+)$ \\
\hline
\end{tabular}




\begin{tabular}{|c|c|c|c|c|}
\hline Acinetobacter haemolyticus & F9 & $(+)$ & $(-)$ & $(-)$ \\
\hline \multirow[t]{7}{*}{ Bosea sp. } & F10 & $(-)$ & $(+)$ & $(-)$ \\
\hline & F12 & $(+)$ & $(+)$ & $(+)$ \\
\hline & F13 & $(+)$ & $(-)$ & $(+)$ \\
\hline & $\mathrm{F} 20$ & $(-)$ & $(+)$ & $(+)$ \\
\hline & $\mathrm{F} 22$ & $(-)$ & $(-)$ & $(+)$ \\
\hline & F24 & $(-)$ & $(-)$ & $(+)$ \\
\hline & & \multicolumn{3}{|c|}{ Lake Ontario } \\
\hline Leptothrix cholodnii & $\mathrm{G} 2$ & $(-)$ & $(-)$ & $(+)$ \\
\hline Pseudomonas putida & G3 & $(-)$ & $(-)$ & $(+)$ \\
\hline Rhodobacter capsulate & G5 & $(-)$ & $(+)$ & $(-)$ \\
\hline Pantoea vagans & G12 & $(+)$ & $(-)$ & $(+)$ \\
\hline Rheinheimera & G15 & $(-)$ & $(+)$ & $(-)$ \\
\hline Aeromonas sp. & 11 & $(-)$ & $(+)$ & $(-)$ \\
\hline Aeromonas sp. & 13 & $(-)$ & $(+)$ & $(-)$ \\
\hline Yersinia ruckeri & 111 & $(+)$ & $(+)$ & $(+)$ \\
\hline Brevundimonas naejangsanensis & $\mathrm{H} 6$ & $(+)$ & $(+)$ & $(-)$ \\
\hline Sphingobacterium & J4 & $(-)$ & $(+)$ & $(-)$ \\
\hline Arthrobacter sp. & J8 & $(-)$ & $(-)$ & $(+)$ \\
\hline Microbacterium chocolatum & $\mathrm{J} 10$ & $(+)$ & $(-)$ & $(-)$ \\
\hline None $^{b}$ & & $(-)$ & $(-)$ & $(-)$ \\
\hline Grand total & & 30 & 29 & 39 \\
\hline
\end{tabular}

a 67 qnr-positive isolates $\left(\mathrm{Cip}^{\mathrm{S}}=29, \mathrm{Cip}^{\mathrm{R}}=38\right)$

b 135 qnr-negative isolates $\left(\mathrm{Cip}^{S}=76, \mathrm{Cip}^{R}=59\right)$

${ }^{c}$ Green designates $\mathrm{Cip}^{\mathrm{S}}$ isolates (first group in a location)

${ }^{d}$ Red is Cip ${ }^{R}$ isolates (second group in a location

${ }^{*}(+)$ indicates presence for the $q n r$ gene in yellow; (-) indicates absence of $q n r$ gene in blue

${ }^{\ddagger}$ Blank culture identification display unknown bacteria identity 


\section{References}


1. Dougherty, T. J. \& Pucci, M. J. Antibiotic Discovery and Development. (Springer, 2012).

2. Skold, O. Antibiotics and Antibiotic resistance. (John Wiley \& Sons, Ltd, 2011).

3. Adedeji, W. A. The treasure called antibiotics. Ann. Ibadan Postgrad. Med. 14, 56-57 (2016).

4. Loudon, I. Deaths in childbed from the eighteenth century to 1935. Med. Hist. 30, 1-41 (1986).

5. Erdem, H. et al. War and infection in the pre-antibiotic era: The Third Ottoman Army in 1915. Scand. J. Infect. Dis. 43, 690-695 (2011).

6. O'Neill, J. Antimicrobial Resistance : Tackling a crisis for the health and wealth of nations. The Review on Antimicrobial Resistance (2014).

7. Conley, Z. C., Bodine, T. J., Chou, A. \& Zechiedrich, L. Wicked: The untold story of ciprofloxacin. PLoS Pathog. 14, 1-13 (2018).

8. Tang, K. L. et al. Restricting the use of antibiotics in food-producing animals and its associations with antibiotic resistance in food-producing animals and human beings: a systematic review and meta-analysis. Lancet Planet. Heal. 1, e316-e327 (2017).

9. Larsson, D. G. J. et al. Critical knowledge gaps and research needs related to the environmental dimensions of antibiotic resistance. Environment International 117, 132-138 (2018).

10. Brown, E. D. \& Wright, G. D. Antibacterial drug discovery in the resistance era. Nature 529, 336343 (2016).

11. Bbosa, G. S., Mwebaza, N., Odda, J., Kyegombe, D. B. \& Ntale, M. Antibiotics/antibacterial drug use, their marketing and promotion during the post-antibiotic golden age and their role in emergence of bacterial resistance. Health (Irvine. Calif). 06, 410-425 (2014).

12. Wright, G. D. Something old, something new: revisiting natural products in antibiotic drug discovery. Can. J. Microbiol. 60, 147-154 (2014).

13. Boolchandani, M., D'Souza, A. W. \& Dantas, G. Sequencing-based methods and resources to study antimicrobial resistance. Nat. Rev. Genet. 20, 356-370 (2019).

14. Kohanski, M. A., Dwyer, D. J. \& Collins, J. J. How antibiotics kill bacteria: from targets to networks. Nat. Rev. Microbiol. 8, 423-435 (2010).

15. Arias, C. A. \& Murray, B. E. Antibiotic-Resistant Bugs in the 21st Century - A Clinical SuperChallenge. N. Engl. J. Med. 360, 439-443 (2009).

16. Tan, S. \& Tatsumura, Y. Alexander Fleming (1881-1955): Discoverer of penicillin. Singapore Med. J. 56, 366-367 (2015).

17. Franco, B. E., Altagracia Martínez, M., Sánchez Rodríguez, M. A. \& Wertheimer, A. I. The determinants of the antibiotic resistance process. Infect. Drug Resist. 2, 1-11 (2009).

18. Lewis, K. Platforms for antibiotic discovery. Nat. Rev. Drug Discov. 12, 371-387 (2013).

19. Allen, H. K. et al. Call of the wild: antibiotic resistance genes in natural environments. Nat. Rev. Microbiol. 8, 251-259 (2010).

20. Heeb, S. et al. Quinolones: from antibiotics to autoinducers. FEMS Microbiol. Rev. 35, 247-74 
(2011).

21. Fujii, Y. Overview of Research on Allelochemicals. Proceedings, MARCO Symp. 2009 3-6 (2009).

22. Lyddiard, D., Jones, G. L. \& Greatrex, B. W. Keeping it simple: lessons from the golden era of antibiotic discovery. FEMS Microbiol. Lett. 363, 84 (2016).

23. Yılmaz \& Özcengiz, G. Antibiotics: Pharmacokinetics, toxicity, resistance and multidrug efflux pumps. Biochemical Pharmacology 133, (2017).

24. Andriole, V. T. The Quinolones: Past, Present, and Future. Clin. Infect. Dis. 41, S113-S119 (2005).

25. Brauner, A., Fridman, O., Gefen, O. \& Balaban, N. Q. Distinguishing between resistance, tolerance and persistence to antibiotic treatment. Nat. Rev. Microbiol. 14, 320-330 (2016).

26. Wright, G. D. Opportunities for natural products in $21^{\text {st }}$ century antibiotic discovery. Nat. Prod. Rep. 34, 694-701 (2017).

27. Fischbach, M. A. \& Walsh, C. T. Antibiotics for emerging pathogens. Science 325, 1089-93 (2009).

28. Ventola, C. L. The antibiotic resistance crisis: part 1: causes and threats. P\&T 40, 277-83 (2015).

29. DiMasi, J. A., Grabowski, H. G. \& Hansen, R. W. Innovation in the pharmaceutical industry: New estimates of R\&D costs. J. Health Econ. 47, 20-33 (2016).

30. Galán, J. C., González-Candelas, F., Rolain, J. M. \& Cantón, R. Antibiotics as selectors and accelerators of diversity in the mechanisms of resistance: From the resistome to genetic plasticity in the $\beta$-lactamases world. Frontiers in Microbiology (2013).

31. Idowu, T., Schweizer, F., Idowu, T. \& Schweizer, F. Ubiquitous Nature of Fluoroquinolones: The Oscillation between Antibacterial and Anticancer Activities. Antibiotics 6, 26 (2017).

32. Fàbrega, A., Madurga, S., Giralt, E. \& Vila, J. Mechanism of action of and resistance to quinolones. Microb. biotechnol. 2, 40-61 (2008).

33. Lesher, G. Y., Froelich, E. J., Gruett, M. D., Hays Bailey, J. \& Pauline Brundage, R. A New Class of Chemotherapeutic Agents. 0, 1063-1065 (1962).

34. Ball, P. Quinolone generations: natural history or natural selection? J. Antimicrob. Chemother. 46, 17-24 (2000).

35. Ronald, A. \& Low, D. Fluoroquinolone Antibiotics. (Springer Basel AG, 2003).

36. Centers for Disease Control and Prevention. Antibiotic resistance threats in the United States, 2013. (2013).

37. Andersson, M. I. \& MacGowan, A. Development of the quinolones. J. Antimicrob. Chemother. 51, 1-11 (2003).

38. Hooper, D. C., Wolfson, J. S., Ng, E. Y. \& Swartz, M. N. Mechanisms of action of and resistance to ciprofloxacin. Am. J. Med. 82, 12-20 (1987).

39. Redgrave, L. S., Sutton, S. B., Webber, M. A. \& Piddock, L. J. V. Fluoroquinolone resistance: Mechanisms, impact on bacteria, and role in evolutionary success. Trends in Microbiology 22, 438-445 (2014). 
40. Lambert, P. A. Cellular impermeability and uptake of biocides and antibiotics in Gram-positive bacteria and mycobacteria. J. Appl. Microbiol. 92 Suppl, 46S-54S (2002).

41. Delcour, A. H. Outer membrane permeability and antibiotic resistance. Biochim. Biophys. Acta 1794, 808-16 (2009).

42. Drlica, K. \& Zhao, X. DNA Gyrase, Topoisomerase IV, and the 4-Quinolones. Microbiol. Mol. Biol. Rev. 61, 377-392 (1997).

43. Peter, B. et al. Genomic transcriptional response to loss of chromosomal supercoiling in Escherichia coli. Genome Biol. 5, R87 (2004).

44. Baranello, L., Levens, D., Gupta, A. \& Kouzine, F. The importance of being supercoiled: How DNA mechanics regulate dynamic processes. Biochim. Biophys. Acta - Gene Regul. Mech. 1819, 632638 (2012).

45. Rehman, A., Patrick, W. M. \& Lamont, I. L. Mechanisms of ciprofloxacin resistance in Pseudomonas aeruginosa: new approaches to an old problem.

46. Andriole, V. T. The Quinlones. (Academic Press, 2000).

47. Rodríguez-Rojas, A., Rodríguez-Beltrán, J., Couce, A. \& Blázquez, J. Antibiotics and antibiotic resistance: A bitter fight against evolution. International Journal of Medical Microbiology 303, (2013).

48. Wohlkonig, A. et al. Structural basis of quinolone inhibition of type IIA topoisomerases and target-mediated resistance. Nat. Struct. Mol. Biol. 17, 1152-1153 (2010).

49. Cirz, R. T. \& Romesberg, F. E. Induction and inhibition of ciprofloxacin resistance-conferring mutations in hypermutator bacteria. Antimicrob. Agents Chemother. 50, 220-5 (2006).

50. Strahilevitz, J., Jacoby, G. A., Hooper, D. C. \& Robicsek, A. Plasmid-mediated quinolone resistance: a multifaceted threat. Clin. Microbiol. Rev. 22, 664-89 (2009).

51. Morita, Y., Tomida, J. \& Kawamura, Y. Responses of Pseudomonas aeruginosa to antimicrobials. Front. Microbiol. 4, 422 (2014).

52. WHO. WHO Model List of Essential Medicines. (2017).

53. Vetting, M. W. et al. Pentapeptide repeat proteins. Biochemistry 45, 1-10 (2006).

54. Gubaev, A., Weidlich, D. \& Klostermeier, D. DNA gyrase with a single catalytic tyrosine can catalyze DNA supercoiling by a nicking-closing mechanism. Nucleic Acids Res. 44, 10354-10366 (2016).

55. Goossens, H., Ferech, M., Coenen, S. \& Stephens, P. Comparison of Outpatient Systemic Antibacterial Use in 2004 in the United States and 27 European Countries. Clin. Infect. Dis. 44, 1091-1095 (2007).

56. Roca, l. et al. The global threat of antimicrobial resistance: science for intervention. New microbes new Infect. 6, 22-9 (2015).

57. WHO | Antimicrobial resistance. WHO (2016).

58. Bengtsson-Palme, J., Kristiansson, E. \& Larsson, D. G. J. Environmental factors influencing the 
development and spread of antibiotic resistance. FEMS Microbiol. Rev. 42, (2018).

59. Gordon, N. C. \& Wareham, D. W. Multidrug-resistant Acinetobacter baumannii: mechanisms of virulence and resistance. Int. J. Antimicrob. Agents 35, 219-226 (2010).

60. Tommasi, R., Brown, D. G., Walkup, G. K., Manchester, J. I. \& Miller, A. A. ESKAPEing the labyrinth of antibacterial discovery. Nat. Rev. Drug Discov. 14, (2015).

61. Spellberg, B. et al. Combating antimicrobial resistance: Policy recommendations to save lives. Clin. Infect. Dis. 52, S397-S428 (2011).

62. Blair, J. M. A., Webber, M. A., Baylay, A. J., Ogbolu, D. O. \& Piddock, L. J. V. Molecular mechanisms of antibiotic resistance. Nat. Rev. Microbiol. 13, 42-51 (2015).

63. Sultan, I. et al. Antibiotics, resistome and resistance mechanisms: A bacterial perspective. Frontiers in Microbiology 9, 2066 (2018).

64. Mohanta, T. \& Goel, S. Prevalence of antibiotic-resistant bacteria in three different aquatic environments over three seasons. Environ. Monit. Assess. 186, 5089-5100 (2014).

65. Zhang, L., Li, X.-Z. \& Poole, K. SmeDEF Multidrug Efflux Pump Contributes to Intrinsic Multidrug Resistance in Stenotrophomonas maltophilia. 45, 3497-3503 (2001).

66. Su, H. C. et al. Persistence of antibiotic resistance genes and bacterial community changes in drinking water treatment system: From drinking water source to tap water. Sci. Total Environ. 616-617, (2018).

67. Hawkey, P. M. \& Jones, A. M. The changing epidemiology of resistance. J. Antimicrob. Chemother. 64, i3-10 (2009).

68. Gillings, M. R., Paulsen, I. T. \& Tetu, S. G. Genomics and the evolution of antibiotic resistance. Ann. N. Y. Acad. Sci. 1388, (2017).

69. Lekunberri, I., Balcázar, J. L. \& Borrego, C. M. Metagenomic exploration reveals a marked change in the river resistome and mobilome after treated wastewater discharges. Environ. Pollut. 234, 538-542 (2018).

70. Guo, J., Li, J., Chen, H., Bond, P. L. \& Yuan, Z. Metagenomic analysis reveals wastewater treatment plants as hotspots of antibiotic resistance genes and mobile genetic elements. Water Res. 123, (2017).

71. Wang, Q., Wang, P. \& Yang, Q. Occurrence and diversity of antibiotic resistance in untreated hospital wastewater. Sci. Total Environ. 621, 990-999 (2018).

72. Finley, R. L. et al. The scourge of antibiotic resistance: The important role of the environment. Clin. Infect. Dis. 57, 704-710 (2013).

73. Jacoby, G. A. Mechanisms of Resistance to Quinolones. Clin. Infect. Dis. 41, S120-S126 (2005).

74. Torrence, M. E. \& Isaacson, R. E. Microbial Food Safety in Animal Agriculture: Current Topics. Microbial Food Safety in Animal Agriculture (Blackwell Publising Company, 2003).

75. Jacoby, G. et al. gnr Gene nomenclature. Antimicrob. Agents Chemother. 52, 2297-9 (2008).

76. Poirel, L., Cattoir, V. \& Nordmann, P. Plasmid-mediated quinolone resistance; interactions 
between human, animal, and environmental ecologies. Front. Microbiol. 3, 1-7 (2012).

77. Li, X.-Z. Quinolone resistance in bacteria: emphasis on plasmid-mediated mechanisms. Int. J. Antimicrob. Agents 25, 453-463 (2005).

78. Blanco, P. et al. Bacterial Multidrug Efflux Pumps: Much More Than Antibiotic Resistance Determinants. Microorganisms 4, (2016).

79. Degnen, G. E. \& Cox, E. C. Conditional mutator gene in Escherichia coli: isolation, mapping, and effector studies. J. Bacteriol. 117, 477-487 (1974).

80. Ambler, J. E. \& Pinney, R. J. Positive $r$ plasmid mutator effect on chromosomal mutation to nalidixic acid resistance in nalidixic acid-exposed cultures of Escherichia coli. J. Antimicrob. Chemother. 35, 603-609 (1995).

81. Eliopoulos, G. M. \& Blazquez, J. Hypermutation as a Factor Contributing to the Acquisition of Antimicrobial Resistance. Clin. Infect. Dis. 37, 1201-1209 (2003).

82. Chen, C. R., Malik, M., Snyder, M. \& Drlica, K. DNA gyrase and topoisomerase IV on the bacterial chromosome: Quinolone-induced DNA cleavage. J. Mol. Biol. 258, 627-637 (1996).

83. Zhao, X. \& Drlica, K. Restricting the Selection of Antibiotic-Resistant Mutants: A General Strategy Derived from Fluoroquinolone Studies. Clin. Infect. Dis. 33, S147-S156 (2001).

84. Drlica, K. The mutant selection window and antimicrobial resistance. J. Antimicrob. Chemother. 52, 11-17 (2003).

85. Lindgren, P. K. \& Sa Karlsson, A Hughes, D. Mutation Rate and Evolution of Fluoroquinolone Resistance in Escherichia coli Isolates from Patients with Urinary Tract Infections. Antimicrob. Agents Chemother. 47, 3222-3232 (2003).

86. Olofsson, S. K., Marcusson, L. L., Lindgren, P. K., Hughes, D. \& Cars, O. Selection of ciprofloxacin resistance in Escherichia coli in an in vitro kinetic model: Relation between drug exposure and mutant prevention concentration. J. Antimicrob. Chemother. 57, 1116-1121 (2006).

87. Courvalin, P., Poyart-Salmeron, C. \& Derlot, E. Plasmid-Borne Resistance to 4-Quinolones a Real or Apparent Absence? Antimicrob. Agents Chemother. 241-248 (1990).

88. Munshi, M. H. et al. Plasmid-mediated resistance to nalidixic acid in Shigella dysenteriae type 1. Lancet (London, England) 2, 419-21 (1987).

89. Martínez-Martínez, L., Pascual, A. \& Jacoby, G. A. Quinolone resistance from a transferable plasmid. Lancet 351, 797-799 (1998).

90. Bateman, A., Murzin, A. G. \& Teichmann, S. A. Structure and distribution of pentapeptide repeats in bacteria. Protein Sci. 7, 1477-80 (1998).

91. McArthur, A. G. et al. The comprehensive antibiotic resistance database. Antimicrob. Agents Chemother. 57, 3348-57 (2013).

92. Robicsek, A., Jacoby, G. A. \& Hooper, D. C. The worldwide emergence of plasmid-mediated quinolone resistance. Lancet Infect. Dis. 6, 629-640 (2006).

93. Albornoz, E. et al. QnrE1, a member of a new family of plasmid-located quinolone resistance genes, originated from the chromosome of enterobacter species. Antimicrob. Agents Chemother. 
61, 1-8 (2017).

94. Saga, T. et al. Vibrio parahaemolyticus Chromosomal qnr Homologue VPA0095: Demonstration by Transformation with a Mutated Gene of Its Potential To Reduce Quinolone Susceptibility in Escherichia coli. Antimicrob. Agents Chemother. 49, 2144-2145 (2005).

95. Cattoir, V., Poirel, L. \& Nordmann, P. In-vitro mutagenesis of qnrA and qnrS genes and quinolone resistance in Escherichia coli. Clin. Microbiol. Infect. (2007).

96. Baquirin, M. H. C. \& Barlow, M. Evolution and Recombination of the Plasmidic qnr Alleles. J. Mol. Evol. 67, 103-110 (2008).

97. Xiong, X., Bromley, E. H. C., Oelschlaeger, P., Woolfson, D. N. \& Spencer, J. Structural insights into quinolone antibiotic resistance mediated by pentapeptide repeat proteins: Conserved surface loops direct the activity of a Qnr protein from a Gram-negative bacterium. Nucleic Acids Res. 39, 3917-3927 (2011).

98. Tran, J. H. \& Jacoby, G. A. Mechanism of plasmid-mediated quinolone resistance. Proc. Natl. Acad. Sci. U. S. A. 99, 5638-42 (2002).

99. Tran, J. H., Jacoby, G. A. \& Hooper, D. C. Interaction of the plasmid-encoded quinolone resistance protein Qnr with Escherichia coli DNA gyrase. Antimicrob. Agents Chemother. 49, 118-25 (2005).

100. Heddle, J. G. et al. The antibiotic microcin B17 is a DNA gyrase poison: characterisation of the mode of inhibition. J. Mol. Biol. 307, 1223-1234 (2001).

101. Park, C. H., Robicsek, A., Jacoby, G. A., Sahm, D. \& Hooper, D. C. Prevalence in the United States of $\operatorname{aac}\left(6^{\prime}\right)-1 b$-cr encoding a ciprofloxacin-modifying enzyme. Antimicrob. Agents Chemother. 50, 3953-3955 (2006).

102. Robicsek, A. et al. Fluoroquinolone-modifying enzyme: a new adaptation of a common aminoglycoside acetyltransferase. Nat. Med. 12, 83-88 (2006).

103. Vetting, M. W. et al. Mechanistic and Structural Analysis of Aminoglycoside N-Acetyltransferase $\mathrm{AAC}\left(6^{\prime}\right)-\mathrm{Ib}$ and Its Bifunctional, Fluoroquinolone-Active AAC $\left(6^{\prime}\right)-\mathrm{lb}-\mathrm{cr}$ Variant. Biochemistry 47, 9825-9835 (2008).

104. Yamane, K. et al. New Plasmid-Mediated Fluoroquinolone Efflux Pump, QepA, Found in an Escherichia coli Clinical Isolate. Antimicrob. Agents Chemother. 51, 3354-3360 (2007).

105. Yang, H. Y., Nam, Y. S. \& Lee, H. J. Prevalence of plasmid-mediated quinolone resistance genes among ciprofloxacin-nonsusceptible Escherichia coli and Klebsiella pneumoniae isolated from blood cultures in Korea. Can. J. Infect. Dis. Med. Microbiol. 25, 163-9 (2014).

106. Pashang, R., Yusuf, F., Zhao, S., Deljoomanesh, S. \& Gilbride, K. A. Widespread detection of antibiotic-resistant bacteria from natural aquatic environments in southern Ontario. Can. J. Microbiol. (2018).

107. Tehrani, A. H. \& Gilbride, K. A. A closer look at the antibiotic-resistant bacterial community found in urban wastewater treatment systems. Microbiology open 7, (2018).

108. Pärnänen, K. et al. Evaluating the mobility potential of antibiotic resistance genes in environmental resistomes without metagenomics. Sci. Rep. 6, (2016). 
109. Peterson, E. \& Kaur, P. Antibiotic resistance mechanisms in bacteria: Relationships between resistance determinants of antibiotic producers, environmental bacteria, and clinical pathogens. Front. Microbiol. 9, (2018).

110. Knapp, C. W., Dolfing, J., Ehlert, P. a I. \& Graham, D. W. Evidence of increasing antibiotic resistance gene abundances in archived soils since 1940. Environ. Sci. Technol. 44, 1-8 (2010).

111. Laxminarayan, R. et al. Antibiotic resistance-the need for global solutions. The Lancet Infectious Diseases 13, (2013).

112. Lupo, A., Coyne, S. \& Berendonk, T. U. Origin and evolution of antibiotic resistance: the common mechanisms of emergence and spread in water bodies. Front. Microbiol. 3, 18 (2012).

113. Czekalski, N., Sigdel, R., Birtel, J., Matthews, B. \& Bürgmann, H. Does human activity impact the natural antibiotic resistance background? Abundance of antibiotic resistance genes in 21 Swiss lakes. Environ. Int. 81, (2015).

114. Bürgmann, H. et al. Water and sanitation: An essential battlefront in the war on antimicrobial resistance. FEMS Microbiol. Ecol. 94, 101 (2018).

115. Peter, S. et al. Tracking of antibiotic resistance transfer and rapid plasmid evolution in a hospital setting by Nanopore sequencing. bioRxiv 22 (2019).

116. City of Toronto. Humber Wasterwater Treatment Plant 2016 Annual Report. (2016).

117. Liss, M. A. et al. Prevalence and significance of fluoroquinolone resistant Escherichia coli in patients undergoing transrectal ultrasound guided prostate needle biopsy. J. Urol. 185, 1283-8 (2011).

118. Liss, M. A., Nakamura, K. K. \& Peterson, E. M. Comparison of broth enhancement to direct plating for screening of rectal cultures for ciprofloxacin-resistant Escherichia coli. J. Clin. Microbiol. 51, 249-52 (2013).

119. Liss, M. A., Peeples, A. N. \& Peterson, E. M. Detection of fluoroquinolone-resistant organisms from rectal swabs by use of selective media prior to a transrectal prostate biopsy. J. Clin. Microbiol. 49, 1116-8 (2011).

120. Titilawo, Y., Sibanda, T., Obi, L. \& Okoh, A. Multiple antibiotic resistance indexing of Escherichia coli to identify high-risk sources of faecal contamination of water. Environ. Sci. Pollut. Res. 22, 10969-10980 (2015).

121. Krumperman, P. H. Multiple antibiotic resistance indexing of Escherichia coli to identify high-risk sources of fecal contamination of foods. Appl. Environ. Microbiol. 46, 165-170 (1983).

122. Frank, E., Hall, M. A. \& Witten, I. H. The WEKA Workbench Data Mining: Practical Machine Learning Tools and Techniques. Morgan Kaufmann, Fourth Edition (2016).

123. Agrawal, R. \& Srikant, R. Fast Algorithms for Mining Association Rules in Large Databases. in Proc. of the 20th International Conference on Very Large Data Bases (VLDB'94) (1994).

124. Muyzer, G., De Waal, E. C. \& Uitterlinden, A. G. Profiling of complex microbial populations by denaturing gradient gel electrophoresis analysis of polymerase chain reaction-amplified genes coding for $16 S$ rRNA. Appl. Environ. Microbiol. 59, 695-700 (1993). 
125. Lee, S. H., Malone, C. \& Kemp, P. F. Use of multiple 16S rRNA-targeted fluorescent probes to increase signal strength and measure cellular RNA from natural planktonic bacteria. Mar. Ecol. Prog. Ser. 101, 193-202 (1993).

126. Cattoir, V., Poirel, L., Rotimi, V., Soussy, C. J. \& Nordmann, P. Multiplex PCR for detection of plasmid-mediated quinolone resistance $q n r$ genes in ESBL-producing enterobacterial isolates. $J$. Antimicrob. Chemother. 60, 394-397 (2007).

127. Magurran, A. E. Measuring Biology Diversity. (Blackwell Publising Company, 2004).

128. Morris, E. K. et al. Choosing and using diversity indices: insights for ecological applications from the German Biodiversity Exploratories. Ecol. Evol. 4, 3514-24 (2014).

129. EUCAST. Determination of minimum inhibitory concentrations (MICs) of antibacterial agents by agar dilution. Clin. Microbiol. Infect. 6, 509-515 (2000).

130. Andrews, J. M. Determination of minimum inhibitory concentrations. J. Antimicrob. Chemother. 48, 5-16 (2001).

131. Paramasivam, G. Detection and characterization of antibiotic resistance plasmids in Cheney biosolids. EWU Masters Thesis Collection, 214 (2013).

132. Waglechner, N. \& Wright, G. D. Antibiotic resistance: it's bad, but why isn't it worse? BMC Biol. 15, 84 (2017).

133. Cattoir, V., Poirel, L., Aubert, C., Soussy, C.-J. \& Nordmann, P. Unexpected occurrence of plasmidmediated quinolone resistance determinants in environmental Aeromonas spp. Emerg. Infect. Dis. 14, 231-7 (2008).

134. Aminov, R. I. \& Mackie, R. I. Evolution and ecology of antibiotic resistance genes. FEMS Microbiol. Lett. 271, 147-161 (2007).

135. Michael, l. et al. Urban wastewater treatment plants as hotspots for the release of antibiotics in the environment: A review. Water Res. 47, 957-995 (2013).

136. Petrie, B., Barden, R. \& Kasprzyk-Hordern, B. A review on emerging contaminants in wastewaters and the environment: Current knowledge, understudied areas and recommendations for future monitoring. Water Res. 72, 3-27 (2014).

137. Batt, A. L., Bruce, I. B. \& Aga, D. S. Evaluating the vulnerability of surface waters to antibiotic contamination from varying wastewater treatment plant discharges. Environ. Pollut. (2006).

138. Tamtam, F. et al. Occurrence and fate of antibiotics in the Seine River in various hydrological conditions. Sci. Total Environ. 393, 84-95 (2008).

139. Ferreira Da Silva, M., Vaz-Moreira, I., Gonzalez-Pajuelo, M., Nunes, O. C. \& Manaia, C. M. Antimicrobial resistance patterns in Enterobacteriaceae isolated from an urban wastewater treatment plant. FEMS Microbiol. Ecol. 60, 166-176 (2007).

140. CLSI. Clinical and Laboratory Standards Institute Performance standards for antimicrobial susceptibility testing. international Journal of Scientific \& Technology Research 3, (2015).

141. Brauner, A., Fridman, O., Gefen, O. \& Balaban, N. Q. Distinguishing between resistance, tolerance and persistence to antibiotic treatment. Nat. Rev. Microbiol. 14, (2016). 
142. Marti, E. et al. Characterization of ciprofloxacin-resistant isolates from a wastewater treatment plant and its receiving river. Water Res. 61, 67-76 (2014).

143. Manaia, C. M., Novo, A., Coelho, B. \& Nunes, O. C. Ciprofloxacin resistance in domestic wastewater treatment plants. Water. Air. Soil Pollut. 208, 335-343 (2010).

144. Gullberg, E., Cao, S., Berg, O. G., Ilbäck, C. \& Sandegren, L. Selection of Resistant Bacteria at Very Low Antibiotic Concentrations. PLoS Pathog 7, 1002158 (2011).

145. Ju, F. et al. Antibiotic resistance genes and human bacterial pathogens: Co-occurrence, removal, and enrichment in municipal sewage sludge digesters. Water Res. 91, (2016).

146. Magesh, H., Kamatchi, C., Vaidyanathan, R. \& Sumathi, G. Identification of plasmid-mediated quinolone resistance genes $q n r A 1, q n r B 1$ and $a a c\left(6^{\prime}\right)-1 b$-cr in a multiple drug-resistant isolate of Klebsiella pneumoniae from Chennai. Indian J. Med. Microbiol. 29, 262-8 (2011).

147. Chakravorty, S., Helb, D., Burday, M., Connell, N. \& Alland, D. A detailed analysis of 16 S ribosomal RNA gene segments for the diagnosis of pathogenic bacteria. J. Microbiol. Methods 69, 330-9 (2007).

148. Van De Peer, Y., Chapelle, S. \& De Wachter, R. A quantitative map of nucleotide substitution rates in bacterial rRNA. Nucleic Acids Research 24, (1996).

149. Anton Y. Peleg, M.B., B.S., M.P.H. and David C. Hooper, M. . Hospital-Acquired Infections Due to Gram-Negative Bacteria. N. Engl. J. Med. 362, 1804-1813 (2010).

150. Li, J., Cheng, W., Xu, L., Strong, P. J. \& Chen, H. Antibiotic-resistant genes and antibiotic-resistant bacteria in the effluent of urban residential areas, hospitals, and a municipal wastewater treatment plant system. Environ. Sci. Pollut. Res. 22, 4587-4596 (2015).

151. Santajit, S. \& Indrawattana, N. Mechanisms of Antimicrobial Resistance in ESKAPE Pathogens. BioMed Research International 2016, (2016).

152. Han, X. Y. \& Andrade, R. A. Brevundimonas diminuta infections and its resistance to fluoroquinolones. J. Antimicrob. Chemother. 55, 853-859 (2005).

153. Sundaram, S., Eisenhuth, J., Howard, G. \& Brandwein, H. Retention of water-borne bacteria by membrane filters. Part I: Bacterial challenge tests on 0.2 and 0.22 micron rated filters. PDA J. Pharm. Sci. Technol. 55, 65-86

154. Lee, S.-H., Lee, S.-S. \& Kim, C.-W. Changes in the cell size of Brevundimonas diminuta using different growth agitation rates. PDA J. Pharm. Sci. Technol. 56, 99-108

155. Ryan, M. P. \& Pembroke, J. T. Brevundimonas spp: Emerging global opportunistic pathogens. Virulence 9, 480-493 (2018).

156. Cydzik-Kwiatkowska, A. \& Zieliska, M. Bacterial communities in full-scale wastewater treatment systems. World J. Microbiol. Biotechnol. 32, 1-8 (2016).

157. Garoff, L., Yadav, K. \& Hughes, D. Increased expression of Qnr is sufficient to confer clinical resistance to ciprofloxacin in Escherichia coli. J. Antimicrob. Chemother. 73, 348-352 (2018).

158. García-Fernández, A., Fortini, D., Veldman, K., Mevius, D. \& Carattoli, A. Characterization of plasmids harbouring qnrS1, qnrB2 and qnrB19 genes in Salmonella. J. Antimicrob. Chemother. 
(2009).

159. Martín-Gutiérrez, G., Rodríguez-Martínez, J. M., Pascual, Á., Rodríguez-Beltrán, J. \& Blázquez, J. Plasmidic qnr Genes Confer Clinical Resistance to Ciprofloxacin under Urinary Tract Physiological Conditions. Antimicrob. Agents Chemother. 61, (2017).

160. Izadi, N., Nasab, M. N., Mood, E. H., Meshkat, Z. \& Zahra, M. The Frequency of qnr Genes in Extended-Spectrum $\beta$-lactamases and non- ESBLs Klebsiella pneumoniae Species Isolated from Patients in Mashhad, Iran. Iran. J. Pathol. 1212, 377-383 (2017).

161. Wu, B. et al. Dissemination of Escherichia coli carrying plasmid-mediated quinolone resistance (PMQR) genes from swine farms to surroundings. Sci. Total Environ. 665, 33-40 (2019).

162. Huang, T. et al. Low-Concentration Ciprofloxacin Selects Plasmid-Mediated Quinolone Resistance Encoding Genes and Affects Bacterial Taxa in Soil Containing Manure. Front. Microbiol. 7, 1730 (2016).

163. Briales, A. et al. In vitro effect of qnrA1, qnrB1, and qnrS1 genes on fluoroquinolone activity against isogenic Escherichia coli isolates with mutations in gyrA and parC. Antimicrob. Agents Chemother. 55, 1266-9 (2011).

164. Veldman, K. et al. International collaborative study on the occurrence of plasmid-mediated quinolone resistance in Salmonella enterica and Escherichia coli isolated from animals, humans, food and the environment in 13 European countries. J. Antimicrob. Chemother. (2011).

165. Han, J. E. et al. First description of ColE-type plasmid in Aeromonas spp. carrying quinolone resistance (qnrS2) gene. Lett. Appl. Microbiol. 55, 290-294 (2012).

166. Chen, Y.-T. et al. Mobilization of qnrB2 and ISCR1 in plasmids. Antimicrob. Agents Chemother. 53, 1235-7 (2009).

167. Sánchez, M. B., Hernández, A., Rodríguez-Martínez, J. M., Martínez-Martínez, L. \& Martínez, J. L. Predictive analysis of transmissible quinolone resistance indicates Stenotrophomonas maltophilia as a potential source of a novel family of Qnr determinants. BMC Microbiol. 8, 148 (2008).

168. Gonzalez, M. A. et al. Multiple-dose pharmacokinetics and safety of ciprofloxacin in normal volunteers. Antimicrob. Agents Chemother. 36, 1296-1301 (1984).

169. Mammeri, H., Poirel, L. \& Nordmann, P. Bactericidal activity of fluoroquinolones against plasmidmediated QnrA-producing Escherichia coli. Clin. Microbiol. Infect. 11, 1048-1049 (2005).

170. Rodríguez-Martínez, J. M., Pascual, A., García, I. \& Martínez-Martínez, L. Detection of the plasmid-mediated quinolone resistance determinant qnr among clinical isolates of Klebsiella pneumoniae producing AmpC-type $\beta$-lactamase. J. Antimicrob. Chemother. (2003).

171. Rodríguez-Martínez, J. M. et al. Qnr-like pentapeptide repeat proteins in Gram-positive bacteria. J. Antimicrob. Chemother. 61, 1240-1243 (2008).

172. Shimizu, K. et al. Smqnr, a new chromosome-carried quinolone resistance gene in Stenotrophomonas maltophilia. Antimicrob. Agents Chemother. 52, 3823-3825 (2008).

173. Poirel, L., Rodriguez-Martinez, J.-M., Mammeri, H., Liard, A. \& Nordmann, P. Origin of plasmidmediated quinolone resistance determinant QnrA. Antimicrob. Agents Chemother. 49, 3523-5 (2005). 